LA-14386

Approved for public release;

distribution is unlimited.

Report on the Development of the Large-Bore Powder Gun for the Nevada Test Site 
Edited by Mable Amador, Group IRM-CAS.

Los Alamos National Laboratory, an affirmative action/ equal opportunity employer, is operated by Los Alamos National Security, LLC, for the National Nuclear Security Administration of the U.S. Department of Energy under contract DE-AC52-06NA25396.

This report was prepared as an account of work sponsored by an agency of the U.S. Government. Neither Los Alamos National Security, LLC, the U.S. Government nor any agency thereof, nor any of their employees make any warranty, express or implied, or assume any legal liability or responsibility for the accuracy, completeness, or usefulness of any information, apparatus, product, or process disclosed, or represent that its use would not infringe privately owned rights. Reference herein to any specific commercial product, process, or service by trade name, trademark, manufacturer, or otherwise does not necessarily constitute or imply its endorsement, recommendation, or favoring by Los Alamos National Security, LLC, the U.S. Government, or any agency thereof. The views and opinions of authors expressed herein do not necessarily state or reflect those of Los Alamos National Security, LLC, the U.S. Government, or any agency thereof. Los Alamos National Laboratory strongly supports academic freedom and a researcher's right to publish; as an institution, however, the Laboratory does not endorse the viewpoint of a publication or guarantee its technical correctness. 
LA-14386

Issued: March 2009

Report on the Development of the

Large-Bore Powder Gun for the Nevada Test Site

B.J. Jensen

- Los Alamos 
This page left blank intentionally. 


\section{Contents}

ABSTRACT . . . . . . . . . . . . . . . . . 1

1 INTRODUCTION ......................... 1

2 GUN SYSTEM DESCRIPTION . . . . . . . . . . . . . . . . . . . . . . . . . . . . 3

2.1 LARGE-BORE LAUNCHER $\ldots \ldots \ldots \ldots \ldots \ldots \ldots$

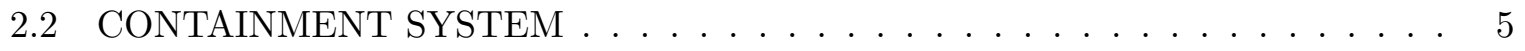

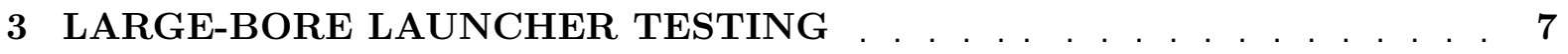

3.1 EXPERIMENTAL METHODS . . . . . . . . . . . . . . . . . . 7

3.2 EXPERIMENTAL RESULTS AND ANALYSIS . . . . . . . . . . . . . . . . 12

3.2.1 Prototype Gun Experimental Results . . . . . . . . . . . . . . . . . 15

3.2.2 Large-Bore Gun Experimental Results . . . . . . . . . . . . . . . . 15

3.2.3 Gun Performance Curve . . . . . . . . . . . . . . . . . . . . . . . 21

3.2 .4 Catch-Can Testing Results . . . . . . . . . . . . . . . . 21

3.2.5 Projectile Design Modifications . . . . . . . . . . . . . . . . . . . . 22

3.2.6 Proper Breech Assembly_Lessons Learned . . . . . . . . . . . . . . . . . 24

3.2.7 Physics Experiments . . . . . . . . . . . . . . . . . . . . . . . . 24

4 INTEGRATED SYSTEM TESTING . . . . . . . . . . . . . . . . 26

4.1 Integrated-System Test $1 \ldots \ldots \ldots \ldots \ldots \ldots$

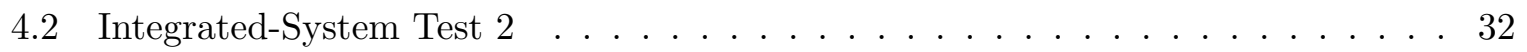

4.3 Integrated-System Test $3 \ldots \ldots \ldots \ldots \ldots \ldots$

4.4 Integrated-System Test $4 \ldots \ldots \ldots \ldots \ldots$

4.5 Integrated-System Test $5 \ldots \ldots \ldots \ldots \ldots \ldots \ldots \ldots$

4.6 Integrated-System Test $6 \ldots \ldots \ldots \ldots \ldots \ldots$

4.7 Integrated-System Test $7 \ldots \ldots \ldots \ldots \ldots \ldots$

5 DISCUSSION, SUMMARY, AND CONCLUSIONS . . . . . . . . . . . . . 46

6 ACKNOWLEDGMENTS . . . . . . . . . . . . . . . . . . . . . . . . . 51 


\section{List of Figures}

1 Photo of the NTS Powder gun located at TA-39-06 (Ancho Canyon) for the gun performance and qualification testing. . . . . . . . . . . . 3

2 Schematic of the powder breech chamber. . . . . . . . . . . . . 4

3 Photo of the large-bore prototype Powder gun located at TA-39-06 (Ancho

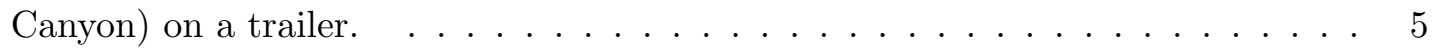

4 Schematic of the containment system for the large-bore powder gun. . . . . . . 7

5 Schematic of the standard plate impact experiment to measure projectile velocity

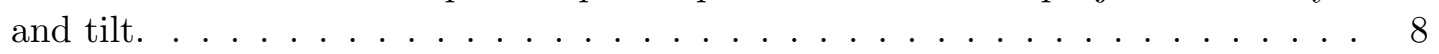

6 Drawing of the standard large-bore powder-gun projectile $\ldots \ldots \ldots \ldots$

$7 \quad$ Schematic of the propellant charge for the large-bore powder gun. . . . . . . . 10

8 Photos illustrating the construction of a powder charge for the large-bore gun breech . . . . . . . . . . . . . . . . . . . 11

9 Photos illustrating various steps in the setup of the gun breech . . . . . . . . 13

10 Photos of the large-bore powder gun located inside the gun facility at TA-39-69. 16

11 Preshot and postshot photos of the catch can for Experiment 9 . . . . . . . . 17

12 Preshot and postshot photos of the catch can for Experiment 10. . . . . . . . 18

13 Photos of the experimental configuration for Experiment 15. . . . . . . . . . . 19

14 Video frame showing water barrel explosion for the successful Experiment 23 . . 20

15 Doppler Velocimetry data for Experiment 24 and the gun performance curve . . 22

16 Schematic of a multislug plate impact experiment to measure the sound speed at pressure and Hugoniot for cerium metal. . . . . . . . . . . . . . 24

17 VISAR and Doppler Data obtained from a single multislug experiment on cerium. 25

18 VISAR data that show the results of a shock-ramp experiment in Ta and a shockrelease experiment in cerium that were performed during the LBPG integrated

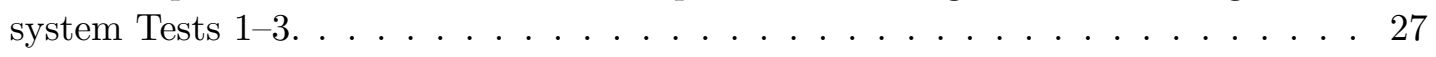

19 Photo of the containment system connected to the large-bore gun located at

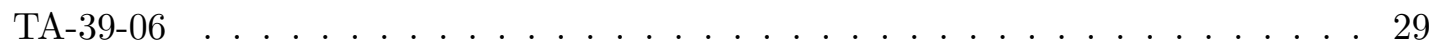

20 Photo of the target chamber and catch-can components of the containment system for LBPG integrated-system Test 1 . . . . . . . . . . . . . . . 30

21 Photos for the integrated-system Test 2 illustrating changes that were made before the experiment.

22 Photos for the integrated-system Test 3 that illustrate venting on the bottom of the EDV and at the spool-piece interface. . . . . . . . . . . . . 35

23 Photos for the integrated-system Test 3 that illustrate the EDV closure and various O-rings seals postshot . . . . . . . . . . . . . 36

24 Photos for the integrated-system Test 4 that illustrate the problems with the EDV closure and bending of the catch-can flange. . . . . . . . . . 38 
25 Photos for the integrated-system Test 4 illustrating the disassembly of the EDV

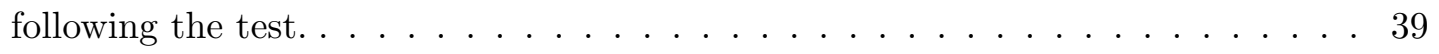

26 Video frames obtained for LBPG integrated-system Test 4 using a standard video

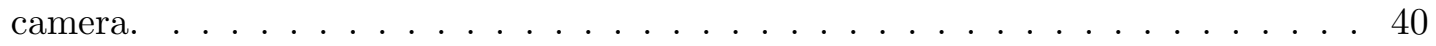

27 Video frames obtained for the integrated-system Test 4 using a high-speed Phantom video camera. . . . . . . . . . . . . . . . . . . . 4 41

28 Video frames obtained for integrated-system Test 4 using a high-speed Phantom video camera (continued from the previous figure) . . . . . . . . . . . . . . 42

29 Photos for the integrated-system Test 5 showing additional modifications and the postshot photos of the EDV. . . . . . . . . . . . . . . . 43

30 Photos for the integrated-system Test 5 showing the preshot containment setup along with various modifications. . . . . . . . . . . . . . . . . 44

31 Photos for integrated-system Test 6 showing the preshot configuration and the piston in the EDV postshot. . . . . . . . . . . . . . . . . . 47

32 Photos for the integrated-system Test 6 obtained from the fast video that shows venting from a ball valve and at the interface between the target chamber and catch can. . . . . . . . . . . . . . . . . . . . 48

\section{List of Tables}

1 Relevant Experimental Parameters . . . . . . . . . . . . . . . . . 14

2 Experimental Parameters and Results Relevant to the Catch-Can Sys-

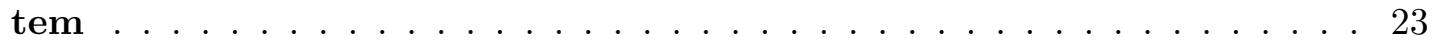

3 Relevant Experimental Parameters and Results for the Integrated System Tests . . . . . . . . . . . . . . . . . . 31 
This page left blank intentionally. 


\title{
Report on the Development of the Large-Bore Powder Gun for the Nevada Test Site
}

\author{
by
}

B. J. Jensen

\begin{abstract}
Experiments are needed to locate phase boundaries and to provide both Hugoniot data and off-Hugoniot data (such as principle isentrope, refreezing, dynamic strength, etc.) achieved through complex loading paths. The objective of the current work was to develop a large bore (3.5 inch or greater) powder gun capable of accelerating projectiles to moderately high velocities exceeding $2 \mathrm{~km} / \mathrm{s}$ for impact experiments. A total of 24 experiments were performed to measure the projectile velocity, breech strain, and projectile tilt to demonstrate the performance of the gun up to the maximum breech capacity of 16 pounds of propellant. Physics experiments using a multislug method were performed to obtain sound speed and Hugoniot for shocked cerium metal and to demonstrate the ability of the large bore gun to conduct well-defined, plate-impact experiments. In addition, six experiments were performed on the prototype containment system to examine the ability of the launcher and containment system to withstand the impact event and contain the propellant gases and impact debris postshot. The data presented here were essential for qualification of the launcher for experiments to be conducted at the U1a complex of the Nevada Test Site.
\end{abstract}

\section{INTRODUCTION}

There is a programmatic requirement that we acquire data that will be used to constrain and refine next generation, multiphase equations-of-state (EOS) models for metals. Experiments are needed to locate phase boundaries, to obtain EOS data on the relevant pure phases, and information on aging. In addition, experiments are needed that provide Hugoniot data, offHugoniot data (such as principle isentrope dynamic strength, etc.) achieved through complex loading paths (shock/release, shock/ramp, ramp, etc.), and A-B comparisons of materials. The main objective of the current work was to develop a large bore (3.5 inch or greater) powder gun capable of accelerating projectiles to moderately high velocities exceeding $2 \mathrm{~km} / \mathrm{s}$ for impact experiments at U1a (Nevada Test Site). This gun will span a performance gap between the TA-55 powder gun (40-mm bore; maximum velocity approximately $1.5 \mathrm{~km} / \mathrm{s}$ ) and the JASPER (Joint Actinide Shock Physics Experimental Research) facility two-stage gun (28-mm bore; velocity greater than $2 \mathrm{~km} / \mathrm{s}$ ), and provide a means to examine phenomena over a wide range of stresses. Advantages of the large bore gun include the following: (1) the capability to load multiple samples simultaneously, (2) large-diameter samples/impactors to significantly extend the time duration of the experiment, and (3) minimal tilt and bow. This new capability will be used to directly address the data needs described above to generate new multiphase EOS.

At the early stages of the project, the large-bore gun was designated as a disposable gun, and the experiments were envisioned to consist of multiple-disposable guns fielded simultaneously in vertical racks underground at the Nevada Test Site. The racks were to be buried in vertical shafts that were 30 to 40 feet deep with the rack itself approximately 10 to 12 feet in height. This presented a significant developmental challenge to design and qualify a 10-ft gun system 
to meet the requirements stated above. Furthermore, each experiment would be diagnostic intensive because multiple targets would be fielded with multiple samples and numerous probes for each experiment. Alternatives were considered that included installing a 20-foot reusable large-bore gun in the Armando zero room located near Cignus (a large x-ray source) followed by the discovery of an unused room (the 102.D alcove developed by Livermore National Lab) that could house a full 60 to 70 foot gun system. This last option was attractive because it would alleviate the design challenges of building a gun system that could achieve velocities greater than $2 \mathrm{~km} / \mathrm{s}$ for a large projectile, the gun could be designed as a reusable system and thus reduce the overall cost-per-experiment, and a small subset of diagnostics could be constructed and tested for a single target. Furthermore, it was expected that experiments on such a system could be performed in coordination with other tests at the U1a complex that would further reduce the costs throughout the program. Thus, the decision was made to develop reusable large-bore gun capability (3.5-inch bore) for the Nevada Test Site (NTS) U1a Complex and to locate the gun in the 102-D room. Several series of experiments were scheduled for the NTS Powder gun with the first series of eight experiments scheduled to begin in late 2008. As described in this report, delays in qualification of the containment system have delayed the first series to the fiscal year (FY) 2010 with two subsequent series planned for FY11 and FY12 (six experiments each). The first series of experiments will employ VISAR, Photonic Doppler Velocimetry (PDV), and pins as standard diagnostics and more advanced phase sensitive diagnostics, such as pyrometry and reflectivity on selected samples.

The Large-Bore Powder Gun (LBPG) system is made up of three subsystems, (1) a launcher (or gun) consisting of a breech and barrel, (2) a containment subsystem consisting of multiple components, and (3) a gas-management system. The containment subsystem physically connects to the end of the launcher and includes a fast closure device known as an Explosively Driven Valve (EDV) $[1,2,3]$, a target chamber, and a catch system that includes shear discs and crush foam to stop the projectile and gas flow. The gas-management system connects to the containment subsystem, and allows for preshot evacuation and postshot venting of the inner volumes. The main objective to develop and qualify the large-bore gun system was addressed in a phased approach. First, a prototype gun was manufactured that consisted of the large-bore breech, the support structure, and a short disposable barrel. Tests were performed (8/2006-9/2006) using low-propellant loads (approximately two pounds of propellant) to test the breech, supports, and recoil system. Following the prototype gun tests, experiments began on a prototype EDV (9/2006-5/2007) to determine the closing time of the valve (the requirement was less than two ms) and the quality of the seal (helium-leak tight required)[1]. Next, the complete large-bore gun launcher was fabricated, and plate impact experiments were performed (2/2007-8/2007) to (1) determine the gun performance by measuring projectile velocity, impact tilt, and breech strain, and (2) demonstrate the ability of the system to obtain accurate shockwave data by using the large-bore feature of the gun to obtain sound speed and Hugoniot data for cerium metal. Experiments were performed for a range of powder loads from approximately $2 \mathrm{lb}$ up to the maximum propellant load of $16 \mathrm{lb}$. In several experiments, efforts were focused on ensuring that the gun system was helium leak-tight preshot and postshot to demonstrate the gun's ability to act as primary containment. Finally, experiments were performed on the complete integrated system (10/2007-3/2008) that included the launcher subsystem and a prototype containment subsystem. The objective of this last series of tests was to examine the gun's ability to perform up to a predetermined powder load while remaining helium leak tight postshot.

A brief description of the gun system, including the large-bore launcher and the containment system, is provided in Section 2. The LBPG tests are discussed in Section 3, including 


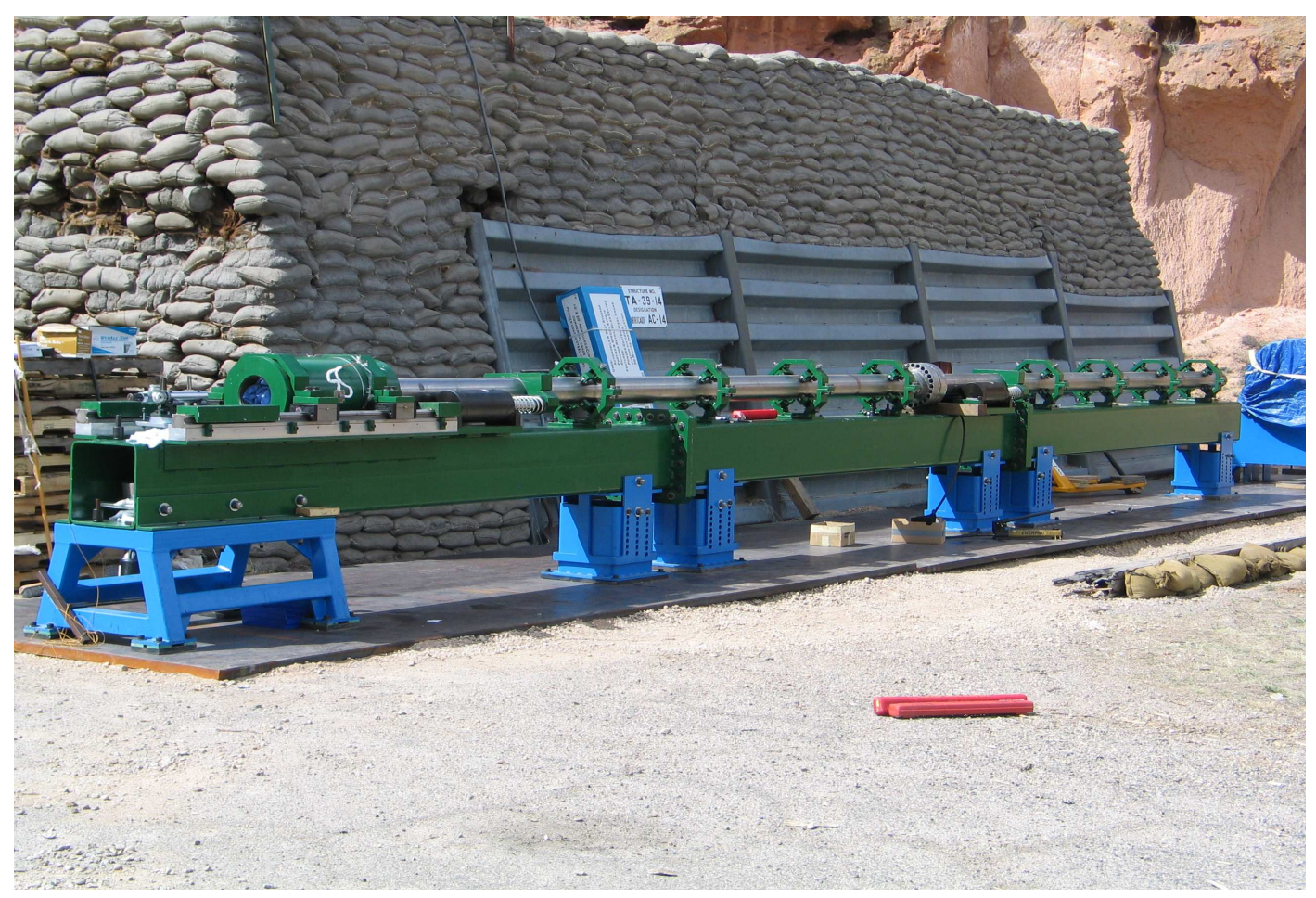

Figure 1: Photo of the NTS Powder gun located at TA-39-06 (Ancho Canyon) for the gun performance and qualification testing. The gun is shown mounted (breech to left in photo) to three steel plates of approximately 14,000 lb each and welded together.

the prototype launcher tests (Section 3.2.1), and the gun performance tests (Section 3.2.2). The complete integrated-system testing (launcher + prototype containment) are described in Section 4. A summary of the current work along with conclusions are presented in Section 5.

\section{GUN SYSTEM DESCRIPTION}

In this section, a brief description of the large-bore powder-gun system is presented. This includes a description of the launcher subsystem followed by the containment system subsystem.

\subsection{LARGE-BORE LAUNCHER}

The large-bore powder-gun system used in this work was designed by WT-7 [5] and based on the LANL two-stage gas gun (General Motors Design). The powder gun system was intended to a be a multiuse device for plate impact experiments at the U1A complex of the Nevada Test Site (NTS). The gun system (see Figure 1) consists of a large volume breech (see Figure 2) attached to a 40 -foot long barrel with a 3.5 -inch bore (two 20 -foot sections fabricated by Honematic). The two barrel sections were designed to be self-aligning to facilitate disassembly and transport and were coupled together using two coupling flanges. The flange bolts were torqued to approximately $80 \mathrm{ft}-1 \mathrm{~b}$ to compress a metal O-ring and generate a helium leak-tight seal. An orifice equipped with multiple O-rings inserted into the breech mates the breech to the barrel and provides a seal to contain the propellant gases. A breech plug and a charge 


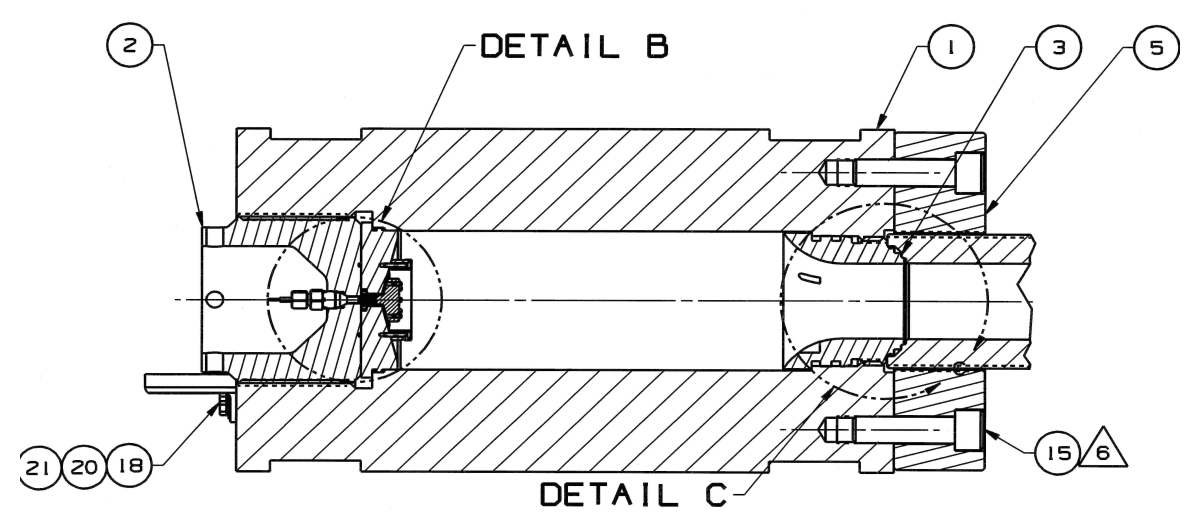

Figure 2: Schematic of the powder breech chamber(1). The breech plug is shown to the left screwed into the breech (2). The breech plug presses the charge base plate into position to form a seal on the rear of the breech. The orifice (3) screws into the right side of the breech and forms a seal with the barrel face. A flange (5) secures the barrel to the breech.

base plate seals the rear of the breech and accommodates a high-voltage feedthrough system to transmit the CDU (capacitor discharge unit) signal to initiate the SE1-PT detonator.

The barrel and breech system is supported by the gun-support structure that was designed to react the entire recoil of the breech/barrel system. Adjustable roller bearings (NUP 2203 ECP bearing) mounted to cages that were located every 3 to 4 feet along the length of the barrels support the barrels and allow for barrel alignment. These bearings are rated for 23 kilonewtons, which is approximately a factor of two larger than the forces required to remove a 0.025-inch bow from the barrel (a four foot separation is required for each set of bearings). Two THK (SR 85T bearings rated for 0.6 MN) rails support the breech and allow for approximately 36 inches of recoil or breech movement. The recoil is transmitted to the gun structure through four locomotive shock absorbers attached to the support structure and located at positions near the barrel-barrel joint and near the breech. The shock absorbers were purchased from ACE controls Inc. and were designed to make the entire load of the moving breech-barrel system react to the gun support structure. Each shock absorber was designed to stop a total weight of 1,000 lb over a distance of 7.68 inches in approximately $410 \mathrm{~ms}$. To properly use the shock absorbers, the shock plate located on the barrel that impacts the absorber must be offset by at least 8 inches so that significant velocities are reached before impact. Unlike the typical shock absorbers, these shocks do not incorporate a hardstop as a built-in feature. Thus, two steel stops are incorporated into the design of the gun structure and located on the THK rails of the breech, limiting the recoil to approximately 16 to 18 inches of total travel.

Before the fabrication of the complete launcher system, a prototype gun system was developed for an initial series of experiments intended to test the breech design, supporting structure, and the gun recoil. Provided that the initial tests were successful, the prototype design would be modified to incorporate the full 40-foot barrels. A photo of the prototype gun is shown in Figure 3 and consists of a breech based on the GM design (length extended by approximately 6 -inches to allow additional propellant), a stainless-steel disposable barrel (available off the shelf and at a low cost), and a transition section that connects the disposable barrel to the breech. The breech/barrel system sits on a support structure that includes two THK rails to allow the gun to recoil, and two shock absorbers to accommodate the recoil. The entire structure was located on a trailer to facilitate movement to and from the firing site. 


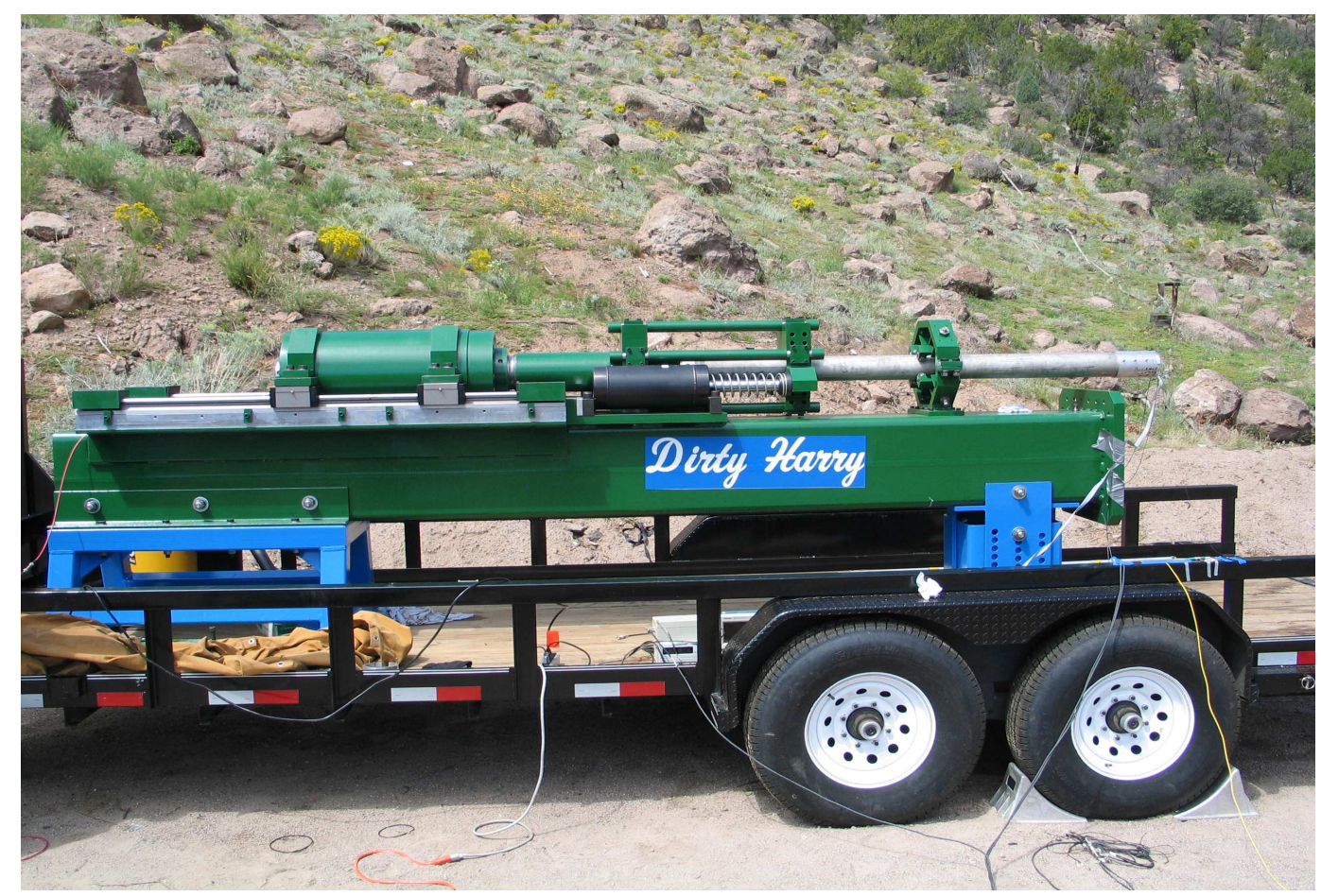

Figure 3: Photo of the large-bore prototype Powder gun located at TA-39-06 (Ancho Canyon) on a trailer.

\subsection{CONTAINMENT SYSTEM}

Because of the requirement to use the Launcher for multiple experiments, a disposable containment system was required to prevent hazardous contaminants from moving up the barrel and to protect the gun room during and after an experiment. This disposable or primary containment system (see Figure 4) consists of a fast closure mechanism, a drift tube, an experimental chamber (or target chamber), and a catch can. During the experiment, the projectile moves down the barrel, enters the containment system, impacts the target containing the physics sample, and is stopped by the shear plates located in the catch can. To prevent contamination froam moving up the system, an explosively driven valve (triggered by barrel probes before impact or impact pins) seals the containment system from the barrel. The primary containment system is designated as a Quality Level (QL) 2 system[6] and connects to the gun system (QL$3[7]$ ) through an expansion joint (slip tube) that allows both the launcher and the containment to recoil independently. The containment system rides on bearings and is brought to rest by a cylinder of honeycomb energy absorber (Plascore) attached to the backstop located at the rear of the containment.

For access to the target chamber for diagnostics or target insertion and alignment, a total of four ports are available on the target chamber. Two large (8-in. by 8-in.) side ports are available for target insertion and two smaller diagnostics ports (4-in. by 8-in.) are located on the top of the chamber. The ports are sealed using multiple flanges equipped with dualpiston seals to prevent burping of gases during the dynamic event. A diagnostics box was designed to protect the diagnostics feedthroughs[8] from the target chamber environment and incorporated multiple types of high-pressure feedthroughs (optical and electrical) to provide access for VISAR, Doppler velocimetry, reflectometry, radiance (or temperature), and electrical 
signals. The box was designed so that the feedthroughs were not directly exposed to the dynamic event by aligning the feed through assemblies parallel to the barrel axis and by minimizing access to the box from the target chamber through a thin $1 / 2$-in. slit. This diagnostics box replaced one of the top ports on the target chamber. The high-pressure feedthroughs were designed and fabricated by NSTech and consisted of a commercially fabricated feedthrough (Conax, QL-2) that was then fitted (at NSTech) with the optical fibers or electrical cables. An important part of the experiments described in Section 4 was the dynamic testing and qualification of these feedthroughs by performing experiments on the full containment system that incorporated the diagnostics box and the high-pressure feedthroughs.

To satisfy the requirement that the large-bore launcher be a reusable system, a fast-closure valve was required to seal the containment system. There are two types of closure systems that have been used in past work where containment was required: the pipe-closure method[4] and the explosively driven valve[1]. The pipe-closure method typically used multiple layers of explosives wrapped around a thin pipe (sometimes consisting of multiple layers of copper and aluminum). Typically, 6 to 10 detonators (or more) were secured to the thickest part of the explosive and detonated simultaneously. These types of closure valves can be bought commercially from at least one source, though costly and not readily available, and have been used successfully on the JASPER gun located at NTS. Disadvantages of this method include (1) relatively high-cost (research and development required) and lack of availability because only one commercial source is known that can provide a qualified device, (2) the need to use thin-walled pipe to facilitate closure, (3) the requirement for multiple detonators to initiate the closure, and (4) the requirement to have significant amounts of explosives present during early experimental operations. The advantages include a very fast closure time (100s of microseconds) and streamlined geometry (acts like a barrel extension). In contrast, EDVs use a small amount of explosive to drive a large, tapered piston made of soft aluminum into a tapered hole that is perpendicular to the barrel axis. This method was used successfully on numerous two-stage gun experiments (Ancho canyon) to seal a containment vessel located at the muzzle of the gun. Advantages of this method include (1) a low quantity of explosives required, (2) explosives are not present during normal experimental operations minimizing safety hazards, (3) fast-closing and reliable (less than $2 \mathrm{~ms}$ total system time), and (4) cost-effective and easily fabricated inhouse. In either case, these two methods proved successful on two-stage gun systems that did not have a sustained high-pressure flow following the projectile into containment because the two-stage guns allowed significant free-flight before the closure device. The EDV was chosen as the closure method used on the large-bore gun and initial prototype, and stand-alone valve testing is discussed elsewhere[1].

During the initial testing of the Large-bore Powder gun, the containment system design consisted of a bellows to connect the gun barrel to the containment system, an EDV, a drift tube, a target chamber, and a catch can. The entire containment system was surrounded by a secondary gas-containment system (extension of the barrel volume) into which the muzzle brake (or gas manifold) would vent the gas. The gas manifold was located upstream from the EDV and provided a means for gas to escape as the projectile moved through the valve and the valve began to close. This design was an attempt to approximate, as much as possible, the operation of the two stage guns (JASPER and the Ancho Canyon gun) where propellant gas expansion is allowed as the projectile enters the valve and the containment system. After gun testing had already begun, a decision was made to remove the secondary gas containment system and the muzzle brake from the design and to designate the large-bore powder gun integrated system (launcher + containment) as a primary containment system. Among other reasons, it was argued that the use of a secondary gas containment vessel would complicate 


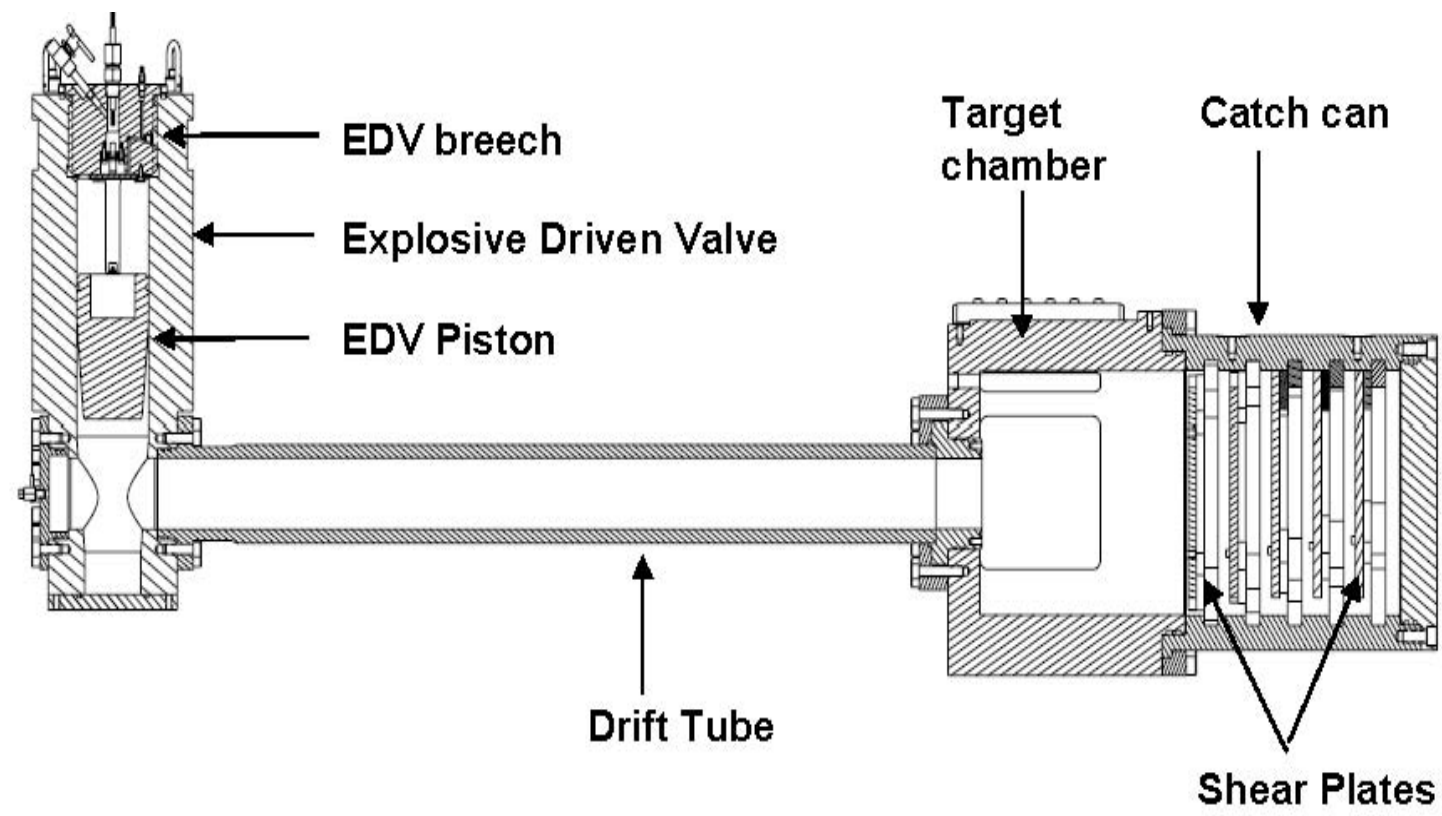

Figure 4: Schematic of the containment system for the large-bore powder gun. A slip tube (not shown) connects the containment system to the barrel and allows for recoil in both directions. Note: the projectile motion is from left-to-right from the EDV toward the target chamber.

cleanup in the event of a leak, would require additional qualification and testing of the second tank extending the delivery date of the system to the test site, and would preclude taking credit for the U1a alcove and bulkhead as secondary containment. Because the fast-closing valves, both pipe-closure and explosive pistons, were typically operated on two-stage gun systems with significant projectile free-flight before closure (allowing time for gas expansion behind the piston), there were no data available on their use when large amounts of fast-moving gas (and particles) were present. Because of scheduling and funding limitations coupled with the known advantages of the EDV system, including recently obtained performance data, it was decided to continue with the EDV closure method for the containment system with the understanding that this method required testing on the real large-bore gun system to determine the effect of the gases and system recoil on closure.

\section{LARGE-BORE LAUNCHER TESTING}

In this section, details regarding the experimental methods for the large-bore gun testing are presented (Section 3.1) followed by the experimental results (Section 3.2).

\subsection{EXPERIMENTAL METHODS}

A series of experiments were performed on the large bore gun to determine the gun performance as a function of projectile mass and propellant mass $[9,10]$. To launch the piston, a high-voltage signal $(3.5 \mathrm{kV})$ generated by the fireset system initiates the SE1-PT detonator located inside the propellant charge. The detonator is attached to a length of mild detonating fuse (MDF) that ignites the propellant. The projectile accelerates down the barrel and im- 
pacts a target attached to the end of the barrel with electrical shorting pins, PZT impact pins, and/or a Doppler probe to measure the projectile velocity and impact tilt. The entire barrel was evacuated to a vacuum level less than 100 mtorr using a standard vacuum pump.

The standard velocity target is shown in Figure 5 and is equipped with a series of impact pins to measure tilt and provide an impact signal to trigger the diagnostics such as VISAR or Doppler velocimetry[11]. The impact PZT pins were located on equal radii at 90 degree increments about the barrel axis on the target and flush with the impact surface. As the projectile impacts, each PZT pin generates a signal at times that defines the impact tilt and projectile rotation. The PZT pin signals were recorded on a digitizer along with the CDU output monitor from the fireset to determine the total system time of the gun (time from CDU to impact) and the tilt. Projectile velocity was measured using either shorting pins or Doppler velocimetry[11]. The shorting pin method used a total of ten pins located at various random heights $(1-12 \mathrm{~mm})$ all located on a constant radius equally spaced at 30 degree increments around the target. For many of the later experiments, PDV was used to continuously monitor the projectile velocity up to impact. To estimate the breech pressure, strain gauges were attached to the breech and fielded by WT-7 personnel, and engineering group.

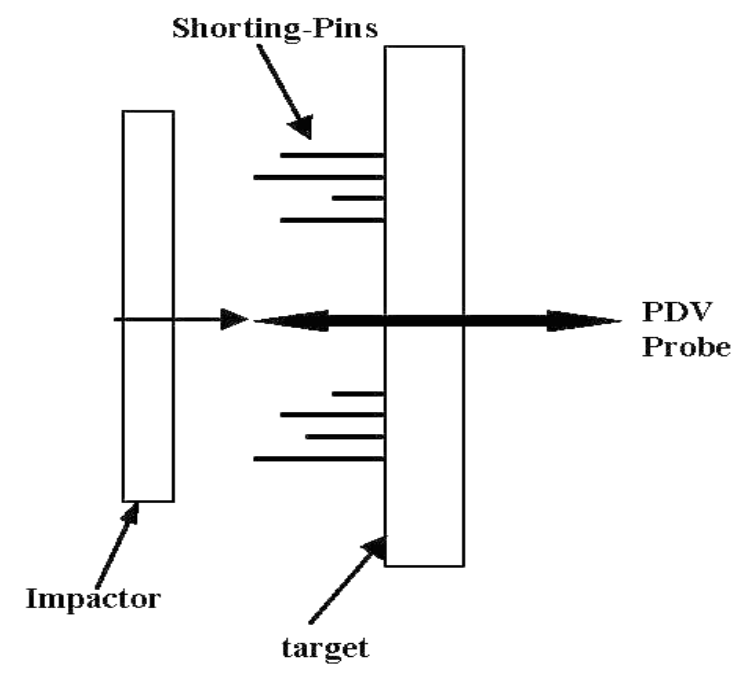

Figure 5: Schematic of the standard plate impact experiment to measure projectile velocity and tilt. Shorting pins located on the target at various heights provide impact tilt and velocity. Also shown is a PDV probe to monitor the projectile velocity continuously during acceleration up to impact.

Powder gun projectiles were initially fabricated from several different materials (6061-T6 aluminum, Lexan, or magnesium) depending on the desired projectile velocity. Aluminum was used for the earlier low-velocity tests $(0.2-0.5 \mathrm{~km} / \mathrm{s}$ range) because of the heavier mass. Lexan projectiles were used in the moderate velocity range, but were observed to fail at higher velocities. Later experiments (see Section 3.2) used magnesium projectiles that can be made lightweight (as compared to aluminum) and were shown to retain structural integrity throughout the velocity range of the gun. An example drawing of the projectile design used for the final gun performance tests is shown in Figure 6 and consists of a right-circular cylindrical projectile body with a shear disc attached to the rear end. A counter bore was machined into the front of the projectile and a foam/impactor assembly was epoxied into the counter bore. The depth of the counter bore was varied to keep the mass of the projectiles constant at approximately 


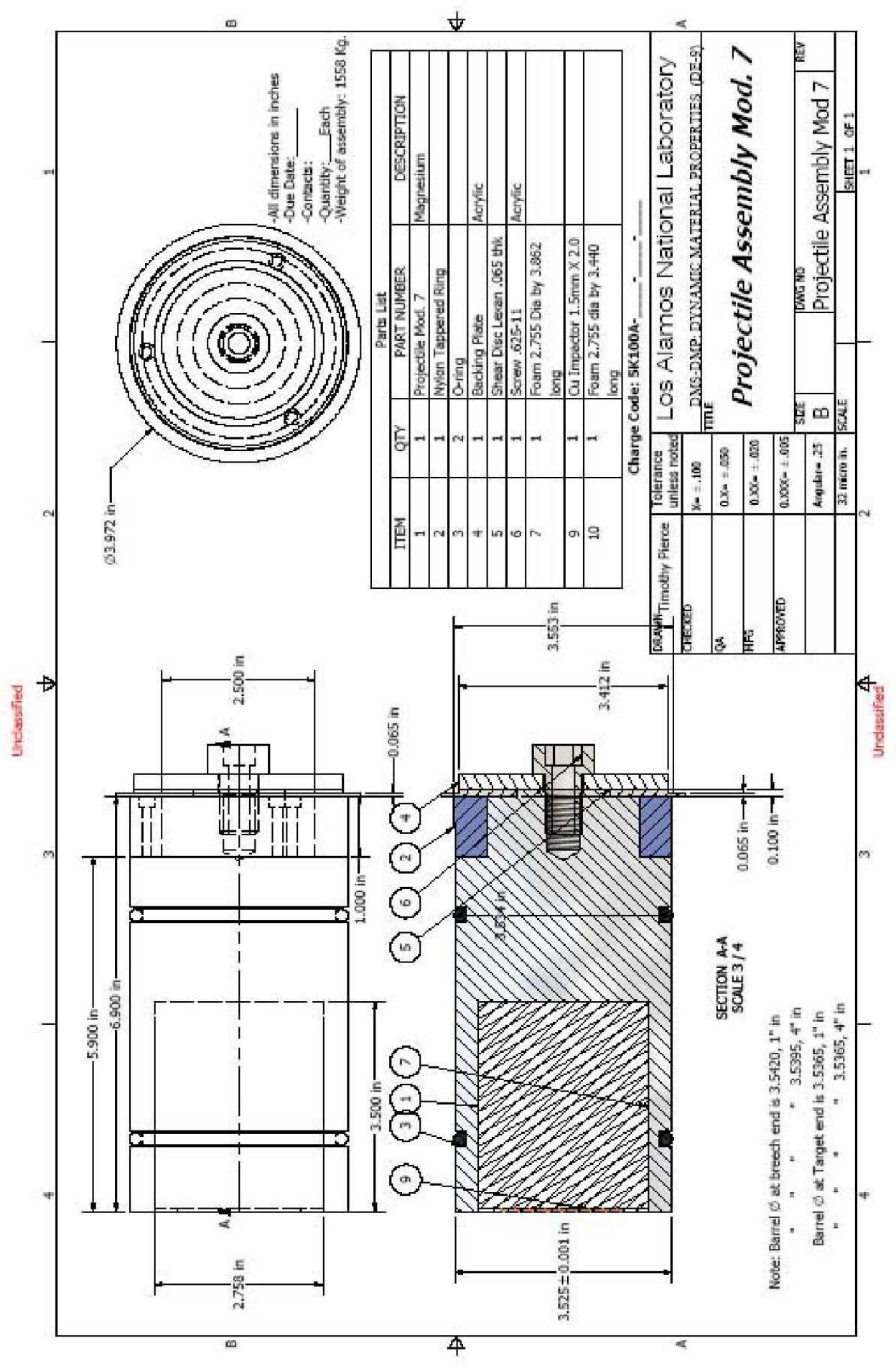

Figure 6: Drawing of the standard large-bore powder-gun projectile. The projectile consists of a cylindrical body (magnesium) with a shear disc, a nylon boot, and two O-rings to prevent gas blow-by, and a foam/impactor assembly inserted into a counterbore on the front. 


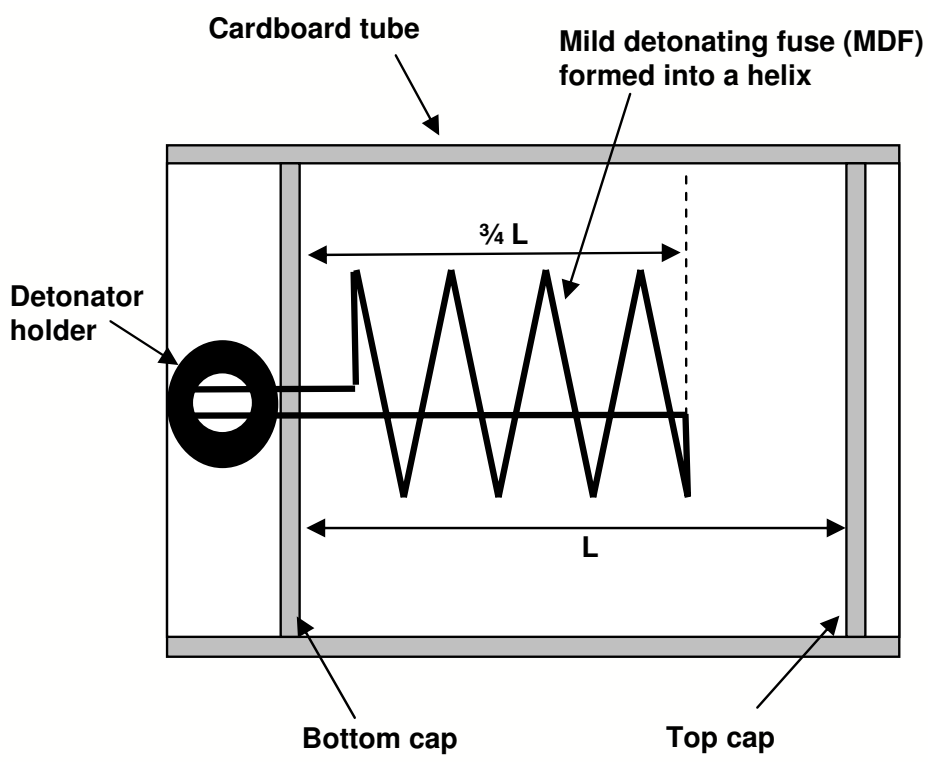

Figure 7: Schematic of the propellant charge for the large-bore powder gun. The charge consists of a cardboard tube capped at both ends with cardboard discs. The bottom cap has a 1/8-inch hole to feed the mild detonating fuse ends through for connection to the detonator holder. The MDF is wrapped into a helix that spans 3/4 of the height of the propellant.

$1.5 \pm 0.15 \mathrm{~kg}$. In the last two experiments, a nylon boot was added to the back of the projectile (oversized by approximately $0.010 \mathrm{in}$. and tapered down to the bore diameter) to prevent blow-by because of barrel wear near the breech.

The propellant charge consisted of a cardboard tube to hold the propellant, bottom and top cardboard caps, a detonator holder, an SE1-PT detonator, and a length MDF. A schematic of the charge is shown in Figure 7. The cardboard tube was pressed onto the adapter ring attached to the charge baseplate and cut to a length that fit inside the breech. Two different diameters of cardboard tube were used (1) a 4-1/4-in. tube for propellant loads less than or equal to $7 \mathrm{lb}$ and (2) a 5-3/4-in. tube for propellant loads greater than $7 \mathrm{lb}$. A cardboard cap with an $1 / 8$-in. hole drilled in the center was glued into place at one end of the charge tube to act as the bottom cap. A separate reusable cardboard tube (1.5-in. diameter) was used to shape the MDF into a helix with the height of the helix equal to $3 / 4$ of the height of the propellant. Typically, MDF lengths of 12-in. and 24-in. were used for low powder loads (less than or equal to $7 \mathrm{lb}$ ) and for higher powder loads (greater than $7 \mathrm{lb}$ ), respectively. The MDF was inserted into the charge tube, the two ends were stuck through the hole in the bottom cap, and connected to the detonator holder. The propellant was measured, poured inside the charge tube, and capped with another 1/4-in. thick piece of cardboard. The entire charge assembly (baseplate and cardboard tube) was inserted into the breech, and then the breech plug was screwed into place and secured. Figure 8 shows various steps during the charge preparation and insertion process. The MDF helix is shown in Figure 8 (c) and (d), and the detonator-charge assembly is shown in Figure 8(f).

To achieve the required high velocity, WT-7 recommended the use of M30 propellant instead of the standard M4A2 propellant that has been used successfully in the past in the two-stage gun at Los Alamos. A vendor search revealed that a sustainable supply of M30 propellant was not readily available. Discussions with other gun operators led to the M14 propellant used 


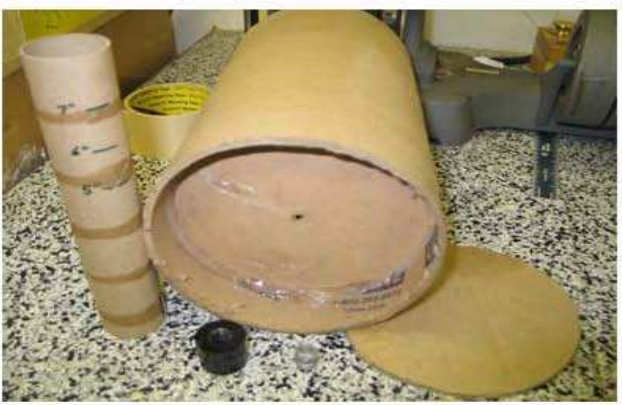

a)

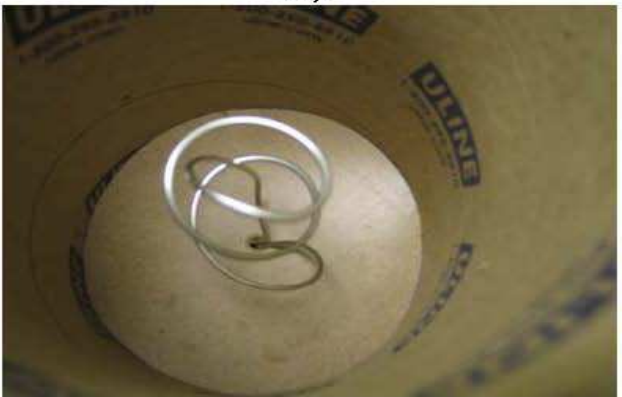

c)

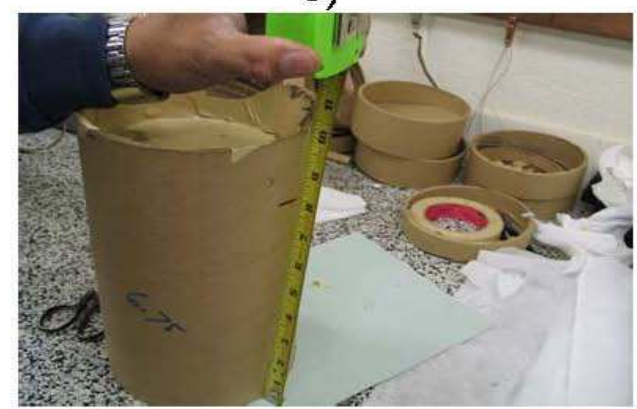

e)

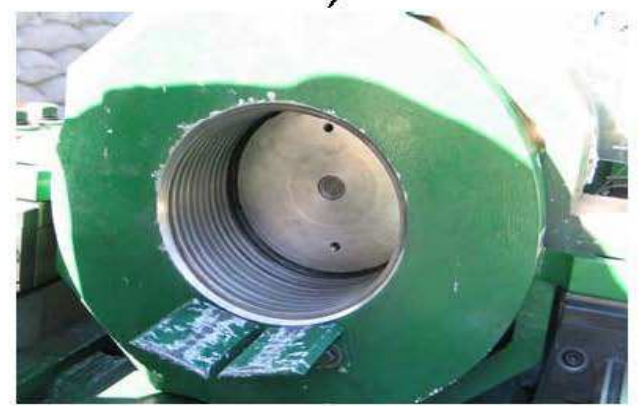

g)

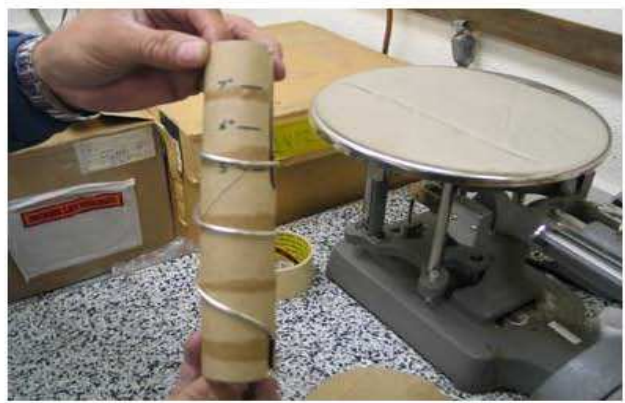

b)

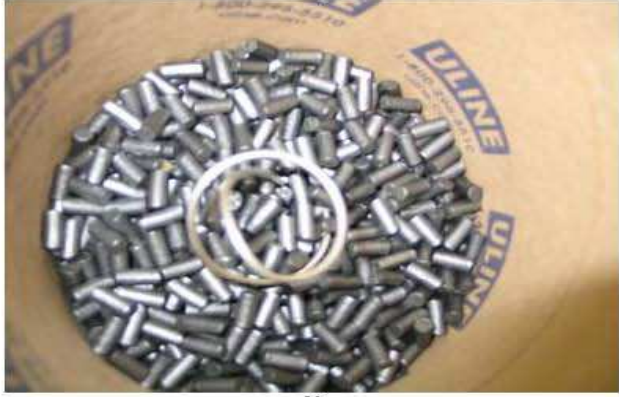

d)

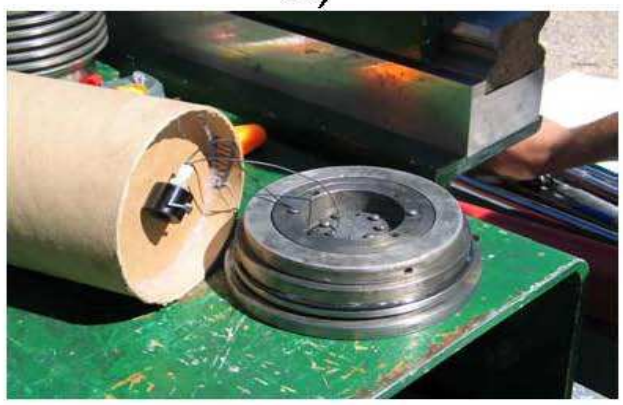

f)

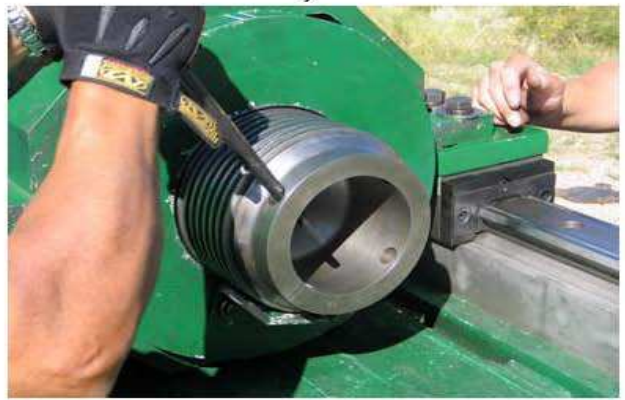

h)

Figure 8: Photos illustrating the construction of a powder charge for the large-bore gun breech. In (a) various components are shown, including the mild detonating fuse jig, the cardboard tube with a bottom cap, the black detonator holder, and the top cardboard cap. (b) The MDF is shown wrapped on the jig before insertion into the cardboard container. In (c) the MDF in the charge tube is shown, and the cardboard tube with MDF and partial load of propellant is shown in (d). The completed charge is shown in (e), and the detonator is shown connected to the charge plate in (f). The charge/baseplate assembly is inserted into the breech (g), and the breech plus is installed and secured in (h). 
in training rounds for 120-mm guns. M14 is readily available with the M1004 type consisting of 1/4-in. diameter round pellets approximately $1 / 2$-in. long with seven perforations along the length. The perforations serve to increase the surface area as the propellant burns, which further increases the production of propellant gas over time. Through consultations with WT-7, the M14 propellant was accepted as the best available choice, though it was understood that the testing was required to qualify use on the large-bore gun.

An important part of this work was to develop a gun setup procedure that would ensure a helium leak-tight system throughout the normal operating range (up to $16 \mathrm{lb}$ of propellant). The procedure for gun setup included the following tasks: (1) initial gun preparation, including cleaning, inspection, and barrel alignment, (2) breech-barrel inspection and initial assembly, (3) helium leak checks of gun volumes, (4) installation of the piston and final breech assembly, and (5) installation of the propellant charge and securing the breech plug. The most critical step included the breech-barrel assembly. Briefly, the orifice was installed within the breech with O-rings in place. The breech and barrel were assembled and disassembled multiple times to verify that the O-rings were generating a leak-tight seal with the $45^{\circ}$ taper on the barrel face. The seal was evaluated two ways. First, the breech/barrel interface was temporarily closed to allow the O-ring to compress against the sealing surface. The barrel face was then examined for O-ring grease to verify that the O-ring was being compressed. Second, fast-drying putty was used to directly measure the various distances between the orifice and the barrel face (closed with four to six bolts) to ensure that they are within specified tolerances (according to the official drawings). With proper sealing established, the breech-barrel volume was checked for leaks using a certified helium detector with the breech and breech-barrel interfaces closed. Next, the breech-barrel was again disassembled so that the projectile could be installed, followed by reassembly of the breech and final torquing to $640 \mathrm{ft}-\mathrm{lb}$. A final leak check was performed on the breech (by injecting helium through the high-voltage feedthrough port in the breech plug) to ensure that the breech-barrel interface is leak-tight with the projectile inserted. The remaining steps included insertion of the charge and charge base plate followed by securing the breech plug. The high-voltage feedthrough was installed last. Various stages of the breech assembly process are shown in Figure 9.

\subsection{EXPERIMENTAL RESULTS AND ANALYSIS}

A total of 34 experiments were conducted on the large-bore powder gun. The experiments included four prototype gun tests, gun performance tests (velocity, breech strain, structural integrity, etc.) on the complete launcher system, six integrated-system tests using the launcher and containment, and physics experiments using the large-bore and moderate velocities to study shock-induced phenomena. The relevant experimental parameters are shown in Table I where the experimental number is shown in column one. The piston material, piston mass, and quantity of propellant are shown in columns two through four, respectively. The charge/mass ratio (propellant mass divided by projectile mass) is shown in column five. The measured values for the projectile velocity and projectile tilt are shown in columns six and seven. Approximate values as reported by WT-7 for the breech pressure are shown in column eight. The barrel recoil was measured in all experiments with the average recoil equal to $15.317 \pm 0.11$ inches, which shows that the recoil is repeatable and independent of the propellant load. The breech diameter was measured following each experiment. The breech I.D. (middle breech) was measured at three locations within the breech in both horizontal and vertical directions: the front, middle, and rear (closest to barrel). The breech I.D. near the middle was measured to be $6.479 \pm 0.001$ inches. 


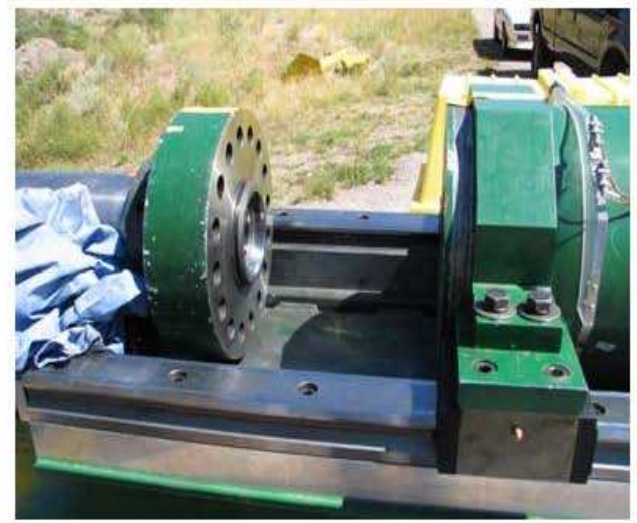

a)

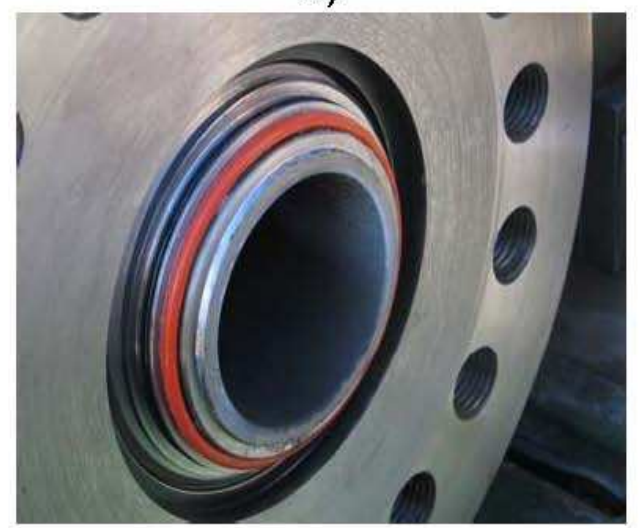

c)

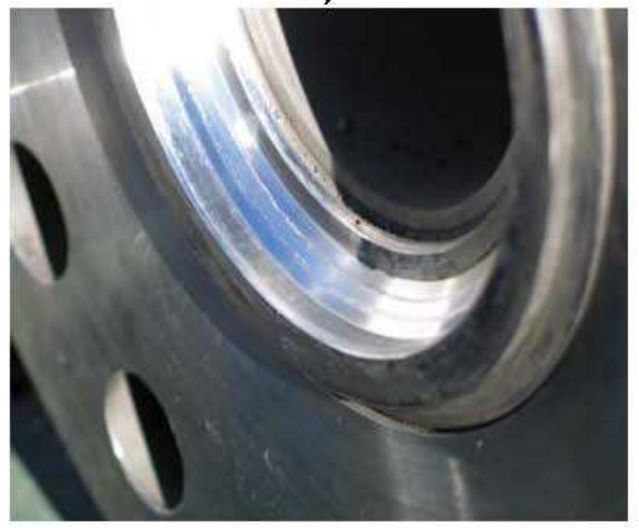

e)

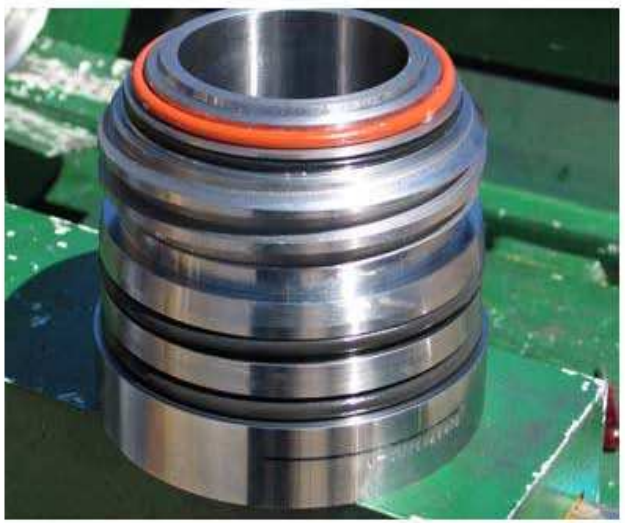

b)

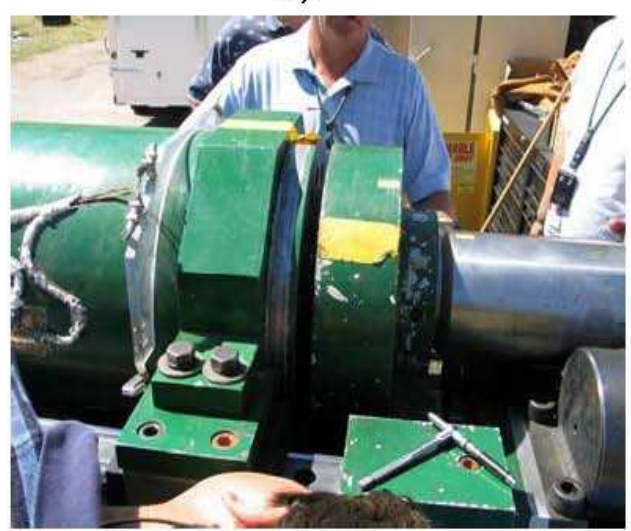

d)

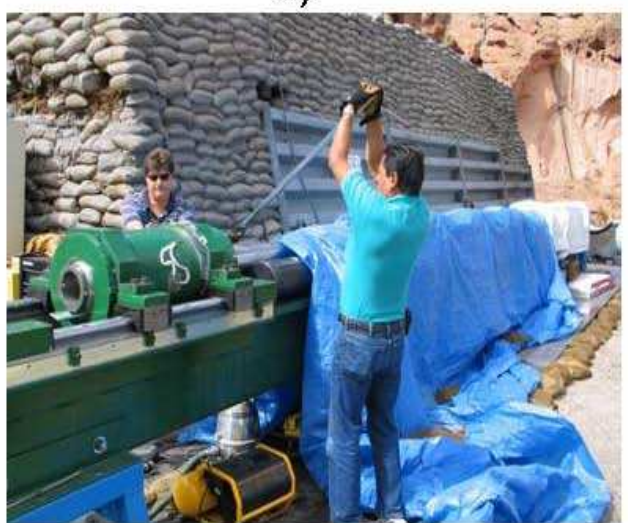

f)

Figure 9: Photos illustrating various steps in the setup of the gun breech. (a) the procedure begins with the separation of the breech flange and the breech. (b) O-rings are installed on the orifice. (c) The orifice is installed in the breech. (d) The breech flange and breech are brought together temporarily to examine the seal between the orifice and the barrel surface. The breech barrel surface is separated, and the barrel surface is examined for O-ring grease. This step is repeated using fast-drying epoxy. (f) The breech flange is torqued to the final values after projectile insertion before the shot. 
Table 1: Relevant Experimental Parameters

\begin{tabular}{|c|c|c|c|c|c|c|c|}
\hline $\begin{array}{l}\text { Test } \\
\text { Number }\end{array}$ & $\begin{array}{l}\text { Piston } \\
\text { Material }\end{array}$ & $\begin{array}{c}\text { Piston } \\
\text { Mass } \\
\text { (g) }\end{array}$ & $\begin{array}{c}\text { M14 } \\
\text { Mass } \\
(\mathrm{g})\end{array}$ & $\begin{array}{c}\text { Charge } \\
\text { mass } \\
\text { ratio }\end{array}$ & $\begin{array}{c}\text { Projectile } \\
\text { Velocity } \\
(\mathrm{km} / \mathrm{s})\end{array}$ & $\begin{array}{c}\text { Impact } \\
\text { Tilt } \\
\text { (mrad) }\end{array}$ & $\begin{array}{c}\text { Breech* } \\
\text { Pressure } \\
\text { (KPSI) }\end{array}$ \\
\hline 69nts_07_01 & Lexan & 737 & $9^{* *}$ & 0.01 & 0.107 & 0.430 & - \\
\hline 69nts_07_02 & $\mathrm{AL}$ & 1558 & 908 & 0.58 & 0.573 & 0.595 & 0.9 \\
\hline 69nts_07_03 & $\mathrm{AL}$ & 1562 & 1362 & 0.87 & 0.660 & 0.909 & 1.1 \\
\hline 69nts_07_04 & Lexan & 778 & 1362 & 1.75 & 0.739 & 1.710 & - \\
\hline 69nts_07_05 & Lexan & 775 & 2270 & 2.93 & - & - & 2.2 \\
\hline 06nts_07_06 & Lexan & 777 & 2270 & 2.92 & 0.879 & 0.562 & 3.7 \\
\hline 06nts_07_07 & Lexan & 773 & 3178 & 4.09 & - & - & 4.2 \\
\hline 06nts_07_08 & Lexan & 777 & 3178 & 4.09 & - & - & - \\
\hline 06nts_07_09 & $\mathrm{AL}$ & 1572 & 3178 & 2.02 & 1.190 & 0.100 & 6.8 \\
\hline 06nts_07_10 & $\mathrm{AL}$ & 1565 & 4086 & 2.61 & 1.483 & 0.378 & - \\
\hline 06nts_07_11 & $\mathrm{AL}$ & 1520 & 4994 & 3.29 & 2.045 & - & 16 \\
\hline 06nts_07_12 & $\mathrm{AL}$ & 1564 & 5902 & 3.77 & - & - & 27 \\
\hline 06nts_07_13 & Lexan & 1489 & 5902 & 3.96 & 2.070 & - & 30 \\
\hline 06nts_07_14 & Lexan & 1609 & 2724 & 1.69 & 1.159 & 1.450 & 7.5 \\
\hline 06nts_07_15 & Lexan & 1582 & 3178 & 2.01 & 1.284 & - & - \\
\hline 06nts_07_16 & Lexan & 1438 & 2429 & 1.69 & 0.892 & 0.528 & - \\
\hline 06nts_07_17 & Lexan & 1512 & 6810 & 4.50 & 2.260 & - & 59 \\
\hline 06nts_07_18 & Lexan & 1404 & 2724 & 1.94 & 1.158 & 1.69 & 5.3 \\
\hline 06nts_07_19 & Lexan & 1470 & 2611 & 1.78 & 1.119 & 0.88 & 4.5 \\
\hline 06nts_07_20 & Lexan & 1506 & 7264 & 4.82 & - & - & 62 \\
\hline 06nts_07_21 & Lexan & 1570 & 5039 & 3.21 & 1.788 & 2.31 & - \\
\hline 06nts_07_22 *** & $\mathrm{Mg}$ & 1590 & 3405 & 2.14 & 1.336 & 0.865 & - \\
\hline 06nts_07_23*** & $\mathrm{Mg}$ & 1596 & 5108 & 3.21 & 1.797 & 1.353 & 20 \\
\hline 06nts_07_24*** & $\mathrm{Mg}$ & 1592 & 6810 & 4.28 & 2.312 & 0.170 & 43 \\
\hline
\end{tabular}

${ }^{*}$ Pressure values obtained from WT-7 shot reports

** Shear disc on projectile broke prematurely and projectile accelerated by vacuum

** No leaks detected greater than $2 \mathrm{e}-6 \mathrm{cc} / \mathrm{s}$ helium range 


\subsubsection{Prototype Gun Experimental Results}

A total of four experiments were performed on this prototype system (see Figure 3) using 2-3 lb of IMR 4350 gun propellant to launch a lexan projectile with a mass of approximately one kg. The IMR propellant was used for these tests because a fast-burning propellant was required because of the short length of the barrel. Standard video was the main diagnostics used to observe the gun operation and recoil. The average measured projectile velocity for $2 \mathrm{lb}$ of propellant was $0.5 \mathrm{~km} / \mathrm{s}$. A video showed a flawless operation of the gun for all experiments with the shock absorbers slowing down the breech so that it came to rest before impacting the stops located behind the rails. For all experiments, only minor motion of the trailer was observed that provided additional confirmation that the shock absorbers were functioning properly.

\subsubsection{Large-Bore Gun Experimental Results}

The first five experiments on the large bore gun were conducted inside the gun facility at TA-39-69 where the two-stage and 40-mm guns are located (Ancho canyon). A temporary catch tank (see Figure 10) was assembled using an old prototype Oboe vessel, an aluminum transition section that connects the barrel to the catch can, and a support structure. This tank was expected to be used until the actual large-bore gun containment system could be designed and fabricated. Before the first experiment, a detailed test plan was developed to mitigate any possible damage to the gun facility and equipment during qualification of this new gun that consisted of an incremental increase in propellant (no more than 1 to $2 \mathrm{lb}$ per experiment) up to the maximum desired propellant charge for the gun. At each increment, the gun and experimental results would be reviewed before proceeding to the next experiment.

Experiment one (shot 69nts_07_01) used a lexan projectile $(0.7 \mathrm{~kg})$ and approximately $2 \mathrm{lb}$ of M14 propellant. The measured projectile velocity was low $(0.107 \mathrm{~km} / \mathrm{s})$ and post-shot examination revealed an incomplete powder burn (99 percent propellant recovered) and an irregularly broken shear disc. It was suspected that the mild detonating fuse was too close to the shear disc, and the shock caused by initiating the MDF cracked the shear disc and prematurely launched the projectile. Experiment two (shot 69nts_07_02) was performed using $2 \mathrm{lb}$ of M14 propellant to launch a more massive $1.5 \mathrm{~kg}$ projectile (to increase available propellant burn time). The shear disc was reinforced using a large lexan washer, and an 18-inch length of the mild detonating fuse was wound into a helix so that the fuse was completely covered by the propellant and at a greater distance from the projectile. The experiment was successful with a measured velocity of $0.573 \mathrm{~km} / \mathrm{s}$ and a measured tilt of 0.596 mrads. A minimal amount of propellant ( 5 grams) was recovered postshot, indicating a nearly complete propellant burn. Postshot examination of the catch can revealed a direct impact of the first plate that deformed (not sheared) and impacted the second. The second shear plate remained in position, but was deformed and impacted the third plates causing minimal damage to the third plate. The energy-absorbing crush foam was impacted by the catch can and suffered approximately 0.5 to 1 in. of deformation. The shear disc (0.07-in. thick) was recovered during disassembly of the breech exhibiting a clean circular break as expected. The barrel motion was recorded using the paper-and-pencil method and a total motion of $4 \mathrm{in}$. was recorded.

Experiments three (shot 69nts_07_03) and four (shot 69nts_07_04) both used three pounds of M14 propellant to launch 1.5 and $0.77 \mathrm{~kg}$ projectiles, respectively. The measured velocities were $0.660 \mathrm{~km} / \mathrm{s}$ and $0.739 \mathrm{~km} / \mathrm{s}$, respectively. These two experiments showed that the reinforced shear disc and the modifications to the mild detonating fuse geometry were sufficient to successfully launch the projectile. This experimental series continued with experiment five 


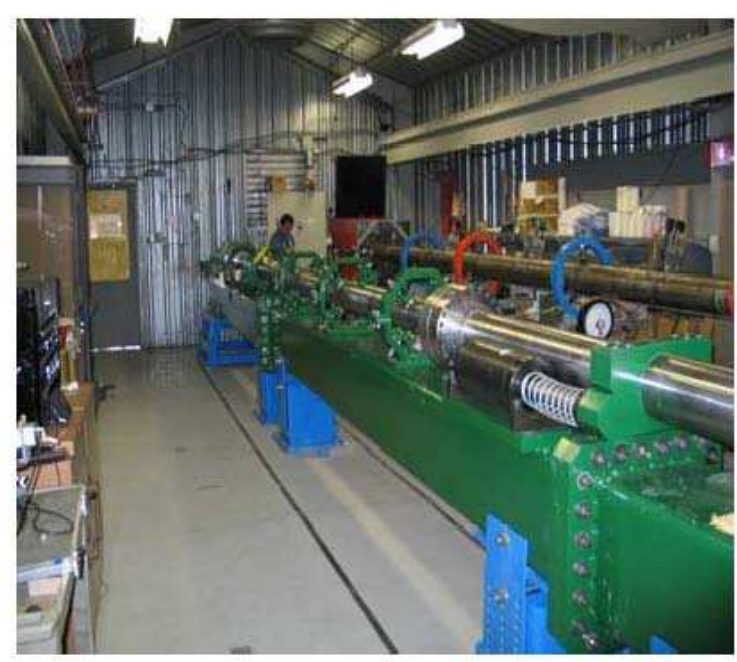

a)

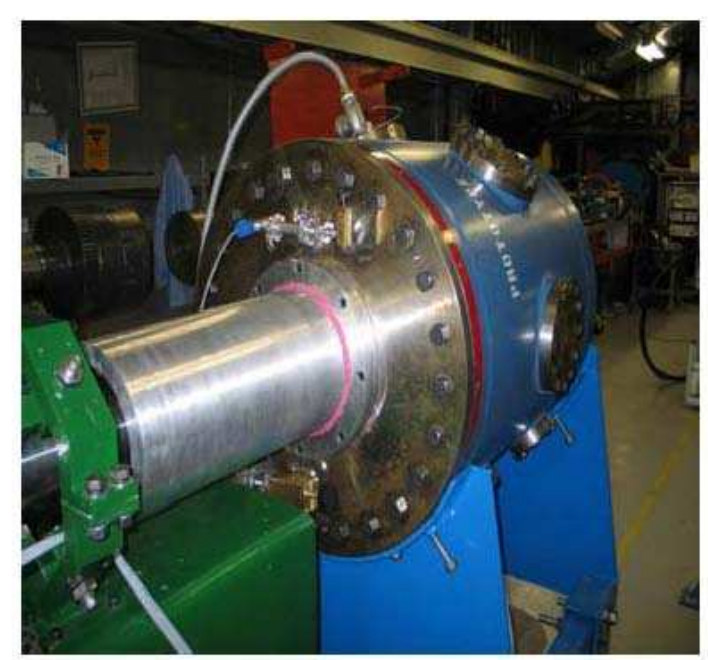

b)

Figure 10: Photos of the large-bore powder gun located inside the gun facility at TA-39-69. Early experiments (test 1-5) were conducted inside before moving the gun to an open firing site at TA-39-06 as shown in Figure 1.

(Shot_69nts_07_05) that used 5 pounds of M14 propellant to launch a $764 \mathrm{~g}$ lexan projectile. Although strain data were obtained on the breech, velocity data were not obtained, likely because of a pinched velocity cable discovered during disassembly of the catch-tank flanges. In addition, the catch-tank and barrel separated during the experiment, venting propellant gases into the gun room. Postshot inspection revealed broken bolts on both the catch-can and gun support structures. Shot video revealed that the most likely cause was misalignment of the slip-seal tube with the catch-tank transition tube (See Figure 10). Thus, as the barrel recoiled it exerted a significant vertical force on the slip tube (the catch can was not designed to account for this additional force) breaking the bolts that tied the structure to the floor. Despite the problems observed in this experiment, these results provided important information for the design of the slip for future catch/containment system designs.

The sixth experiment (Shot_06nts_07_06) was conducted at an open firing site (TA-39-06) to avoid any issues of indoor firing as propellant load is increased toward a maximum of $16 \mathrm{lb}$ (See Figure 1). The support structures of the gun were welded to three large steel plates. The previously used catch tank can was secured in front of the gun (approximately $10 \mathrm{ft}$ from the muzzle) and used to mitigate the dispersal of shrapnel and debris into the canyon. A total of 5 lb of M14 propellant to launch a $778.4 \mathrm{~g}$ lexan projectile at a target attached to a bolster plate at the gun muzzle. The shot was successful with a measured velocity of $0.879 \mathrm{~km} / \mathrm{s}$. Postshot examination of the structure revealed no major damage with the exception of two broken rollerbearings on the support cages, likely because of to over-tightening. Experiments seven through nine were all performed using $7 \mathrm{lb}$ of M14 propellant. In experiments seven and eight, the projectiles were made of lexan weighing $777 \mathrm{~g}$ and $778 \mathrm{~g}$, respectively. The gun recoil for both experiments was normal, although velocity data were not obtained, and PZT pin data exhibited an abnormal response with preimpact ringing and distorted signals. It was hypothesized that the projectile was breaking up during the initial acceleration, allowing propellant gas to blowby preshorting the velocity pins. In Experiment nine, the projectile material was changed to 

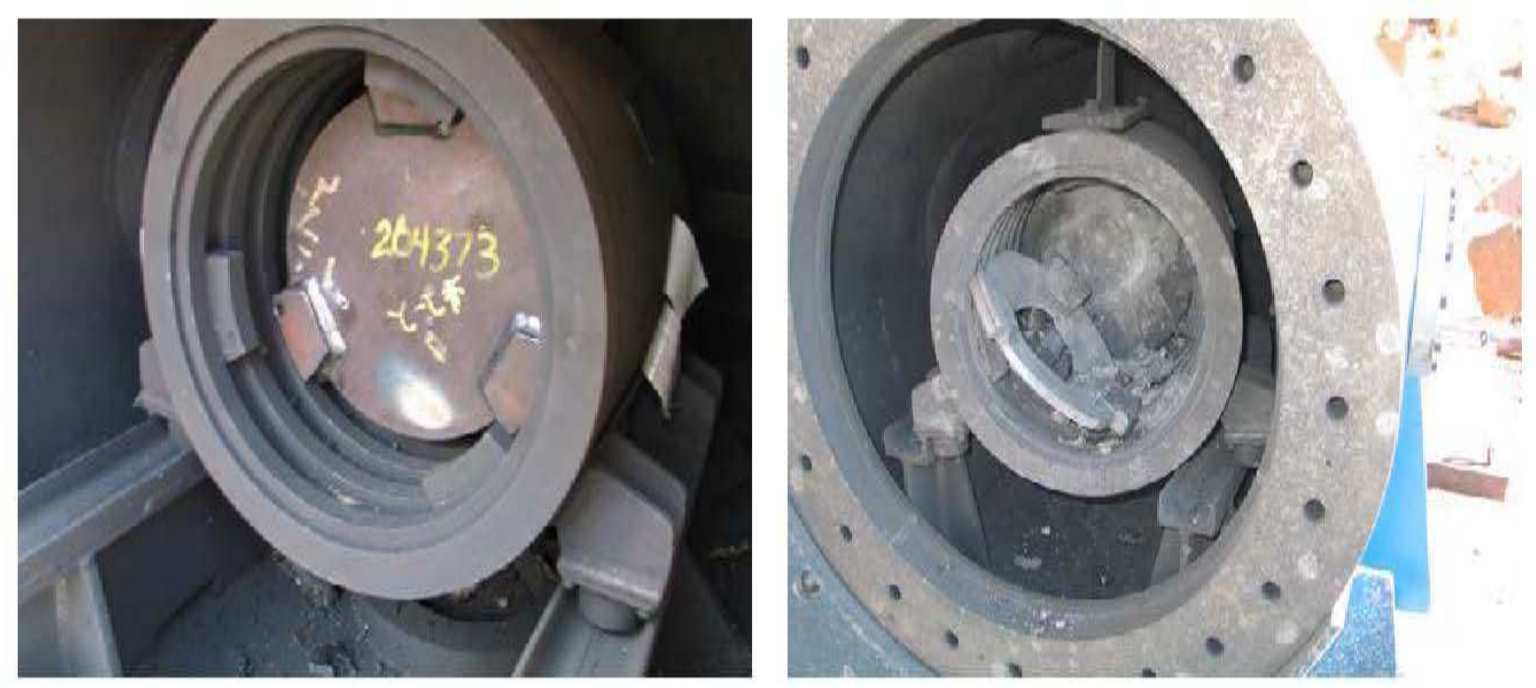

Figure 11: Preshot and posthot photos of the catch can for Experiment 9.

aluminum for added strength and durability, and the mass was increased to $1.57 \mathrm{~kg}$. The shot fired successfully; strain and velocity data $(1.2 \mathrm{~km} / \mathrm{s}$ and $0.1 \mathrm{mrads}$ tilt $)$ were obtained, and the measured projectile velocity was $1.2 \mathrm{~km} / \mathrm{s}$. For this last experiment, the catch can (loaded with two 0.5-in. steel plates in positions 2 and 5) was used to stop the projectile. The projectile punched a clean hole in the first plate and significantly deformed the second and last plate. The aluminum honeycomb material behind the catch can was uniformly compressed (approximately $1 / 2$ compression).

Experiments 10 through 12 used a total of 9, 11, and $13 \mathrm{lb}$ of M14 propellant to launch projectiles (hollow aluminum) with nominal masses of $1.5 \mathrm{~kg}$, respectively. Experiments 10 and 11 were successful with measured velocities of 1.483 and $2.05 \mathrm{~km} / \mathrm{s}$, respectively. Despite a crack in the rear of the catch can observed before test 10, the can was used with plates loaded in positions 2 and 5 . The projectile penetrated plate two, deformed plate five, and caused the crack on the catch can to propagate, resulting in can failure. The catch can was refurbished before to Experiment 11, and four plates were installed for that test. The projectile penetrated the first and second plates and impacted the third plate, but left the fourth plate completely untouched. The aluminum crush foam and compressed it by nearly 50 percent. The same catch can setup was used for Experiment 12 that used $13 \mathrm{lb}$ of propellant. The shot was fired with no damage visible to the gun or structure, but no velocity data were obtained. Four shear plates were installed in the catch can, but the first plate exhibited a "shot-gun" effect with multiple holes (not on center) in the first plate with no significant damage observed to the remaining plates. The loss-in-velocity data coupled with the shear-plate data indicate that the projectile likely broke up during acceleration. Experiment 13 was a repeat of shot 12 using $13 \mathrm{lb}$ of propellant (24 inches of MDF) and a solid lexan projectile. Lexan was used in this experiment because of it's strength coupled with low density (as compared to aluminum) that allows the mass to remain constant at approximately $1.5 \mathrm{~kg}$. The shot was successful with a measured velocity of $2.07 \mathrm{~km} / \mathrm{s}$, indicating that the projectile modifications were successful.

In addition to the gun performance tests, physics experiments were conducted to obtain shock-wave data for cerium and to demonstrate the ability to conduct well-defined plate impact experiments. Experiment 14 used $6 \mathrm{lb}$ of propellant to launch an aluminum flyer (solid lexan 

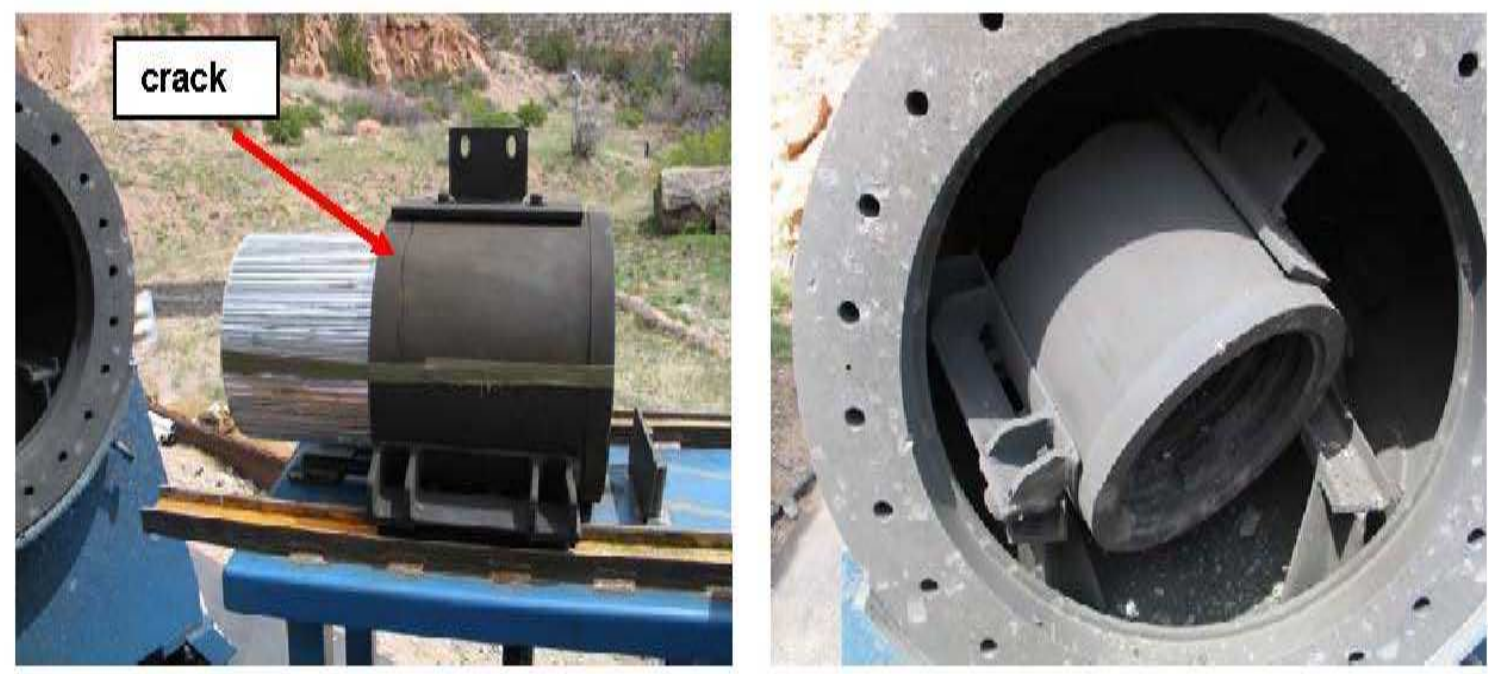

Figure 12: Preshot and postshot photos of the catch can for Experiment 10.

projectile with an aluminum/foam impactor) onto an aluminum target and served as a test experiment for the multislug cerium experiments below. Doppler velocimetry probes were used to measure the projectile velocity and the free surface particle velocity at the rear of the aluminum target. The experiment was successful with a measured projectile velocity of $1.159 \mathrm{~km} / \mathrm{s}$. In this shot, the catch tank was replaced with a 55-gallon drum of water that served to slow down the projectile and debris and to act as fire mitigation. Experiments 15, 16, 18, and 19 were all multislug cerium experiments that used a total of $7,6,6$, and $5.75 \mathrm{lb}$ of M14 propellant, respectively, to launch solid lexan projectiles with copper/foam impactors at a copper-cerium-LiF target assembly. In each experiment, there were four cerium samples ranging from $2-5 \mathrm{~mm}$ thick and backed by aluminum-plated LiF windows. All experiments were successful and provided important data on the dynamic melt boundary for cerium metal. Further details regarding the physics tests are provided in Section IV-F.

Experiment 17 used a 1.512-kg solid Lexan projectile, $15 \mathrm{lb}$ of M14 propellant, and $24 \mathrm{in}$. of MDF to launch a projectile with a 6061-T6 aluminum impactor that was epoxied to the front of the projectile. One PDV probe (collimated) located on the center provided the projectile velocity. The experiment was successful with data obtained from all impact pins and with a measured velocity of $2.26 \mathrm{~km} / \mathrm{s}$. The breech pressure was estimated to be $65 \mathrm{Kpsi}$ from the strain gauges. No structural damage was observed postshot, but there were minor amounts of gas venting observed, as propellant residue on the surfaces, through the barrel/breech interface and through the high-voltage feedthrough (on the breech plug). The breech was disassembled, and it was found that the plastic insulator on the high-voltage feedthrough and the O-ring on the orifice were consumed during the experiment. Before the next experiment, the highvoltage feedthrough (the original BNC connector) was replaced with a certified 20,000 psi Conax feedthrough that used a solid-copper center conductor to provide a backup seal in the case that the plastic insulator was consumed in future experiments. To prevent leakage through the breech-plug threads, an O-ring groove was machined into the face of the breech plug. To address the leak at the breech-barrel interface, all bolts on the breech/barrel flange were retorqued to specifications, and these steps were included in the shot checklist for each experiment. In Experiments 18 and 19 discussed in the previous paragraph, no blow-by was observed following these modifications. 


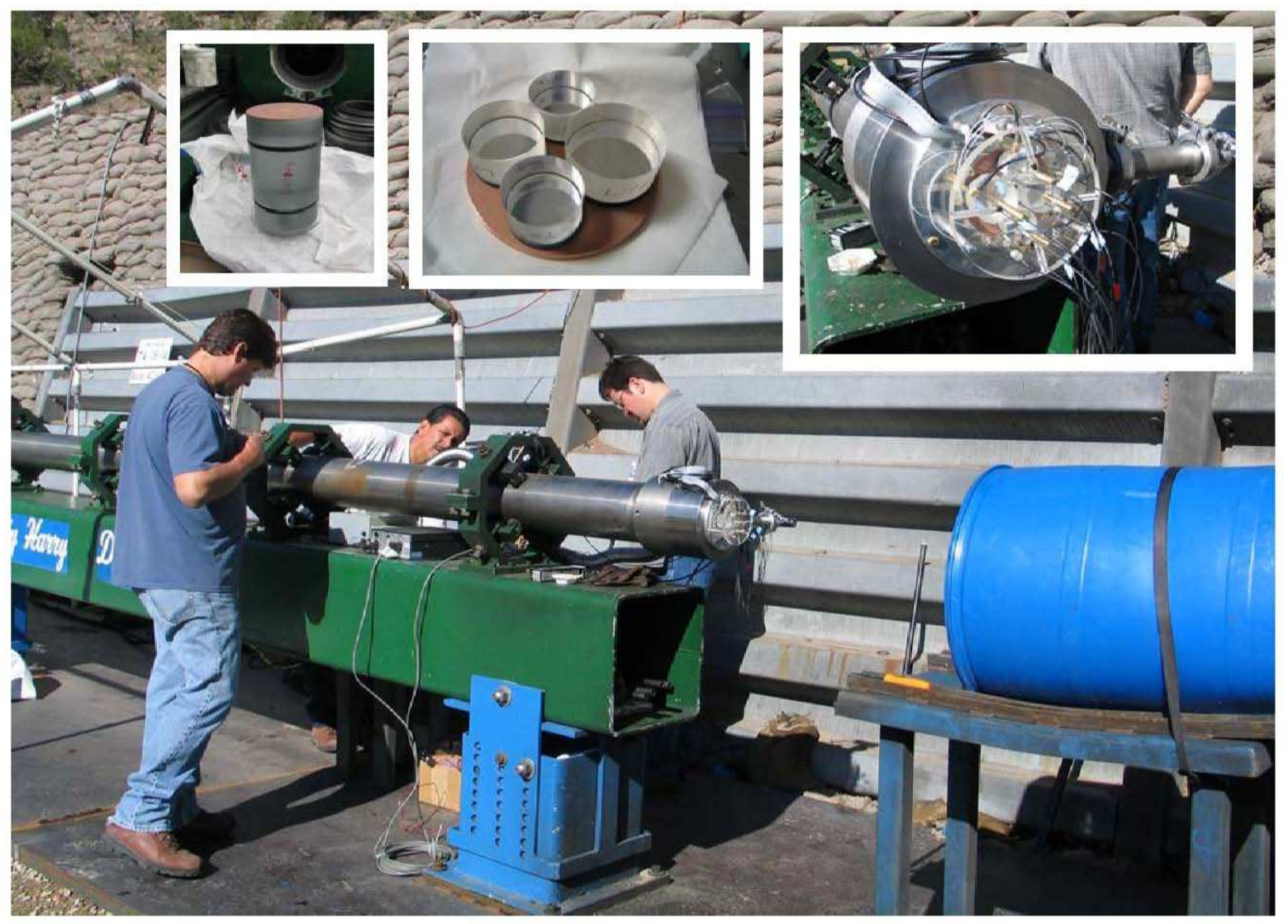

Figure 13: Photos of the experimental configuration for Experiment 15. This experiment was the first multislug cerium test performed on the large-bore gun. The gun is shown with a cerium target (total of 14 optical probes) attached to the bolster plate on the muzzle of the gun and pointing towards a 55-gallon (blue barrel) drum of water. The inset figures show (from left to right) the projectile with a copper impactor, the copper-cerium-LiF assembly, and a closeup of the target mounted on the bolster plate.

Experiment 20 was a gun performance test that used a total of $16 \mathrm{lb}$ of M14 propellant and 24-in. of MDF to launch a 1.5-kg solid Lexan projectile with an aluminum impactor. The shot fired successfully with an estimated breech pressure of $90 \mathrm{kpsi}$ based on strain gauge measurements. Video were obtained during the experiment, and a postshot examination revealed significant gas venting from the breech/barrel interface, but there was no venting observed at the breech plug or at the high-voltage feedthrough. In addition, the breech flange bolts were found to be loose and exhibited measurable elongation, but there were no other damage (such as cracks) within the breech or to the threaded bolt holes. It was suspected that the O-ring on the orifice failed, and therefore, two piston O-ring grooves were machined into the orifice to act as backup seals in future experiments.

Experiment 21 was another cerium experiment that used $11.1 \mathrm{lb}$ of M14 propellant to launch a lexan projectile $(1.570 \mathrm{~kg})$ with a cerium impactor backed by foam. The projectile impacted an aluminum front-plated $\mathrm{LiF}$ window with one PDV probe and one VISAR probe to monitor the particle velocity at the cerium-LiF interface. A second PDV probe was used to monitor the projectile velocity. The shot was successful, velocity data were obtained, and the measured 


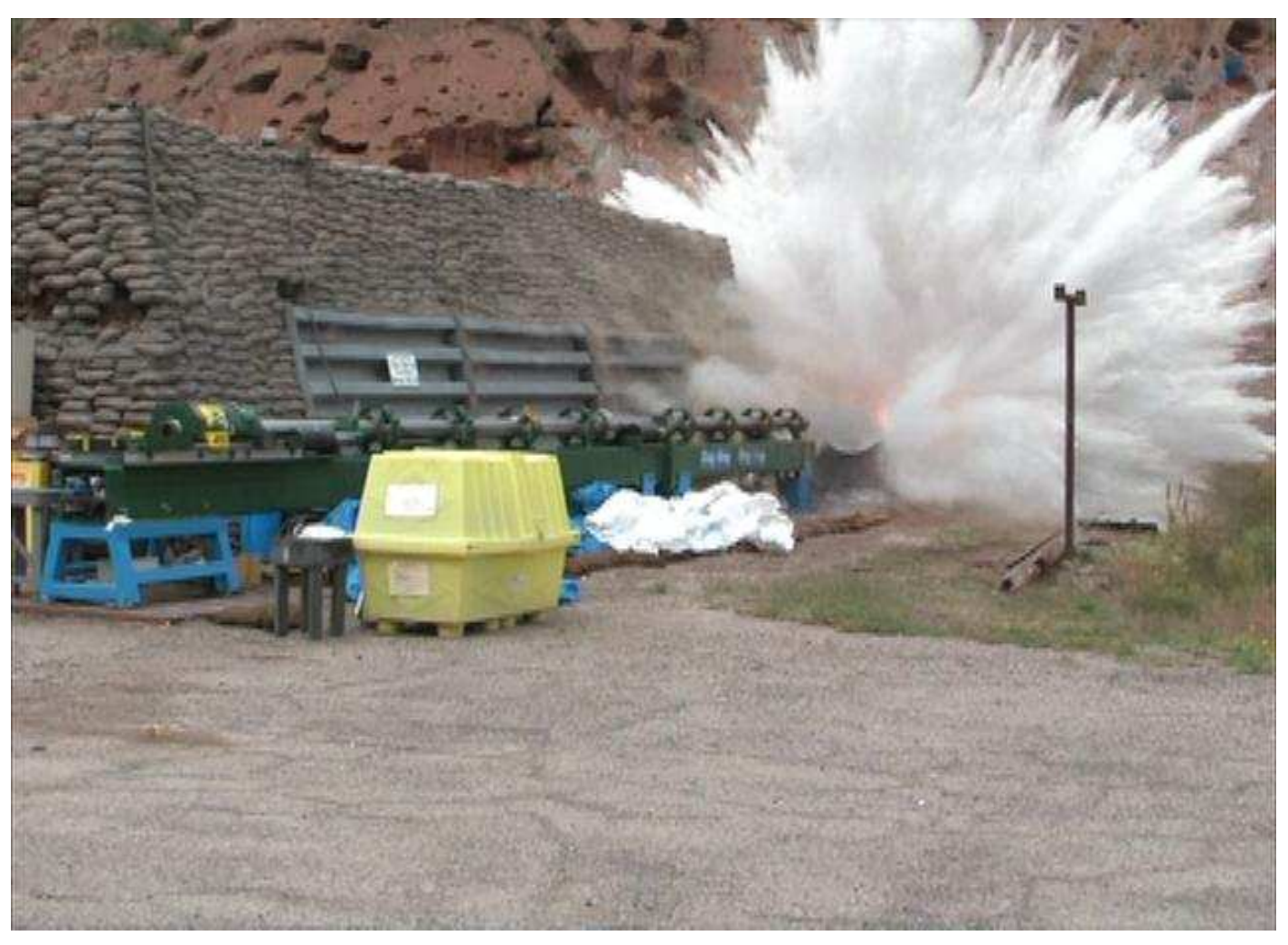

Figure 14: Video frame showing water barrel explosion for Experiment 23. This was the second test in the final gun qualification series (three tests performed at $50 \%, 75 \%$, and $100 \%$ breech capacity) that consisted of a magnesium projectile launched into the standard velocity target and a 55-gallon water drum.

projectile velocity was $1.788 \mathrm{~km} / \mathrm{s}$. Postshot examination of the gun structure revealed no structural damage, although the gun failed the postshot He leak check at the barrel-breech interface - all other interfaces were leak-tight, including the new high-voltage feedthrough. An investigation was initiated to understand the venting of the breech. The breech and barrel assembly were disassembled and reassembled numerous times, and it was discovered that the barrel had rotated during the previous tests so that the orifice could not seal properly on the barrel surface. A new procedure was developed that included disassembling the breech and using both vacuum grease and fast-drying putty to verify that the orifice mates properly to the barrel before each experiment. It is suspected that this has been the problem during all the previous tests (higher powder load) and explains why the bolts on Test 20 were deformed because $90 \mathrm{kpsi}$ across the breech diameter translates into very high pressures across the surface.

With the new procedure in place for breech assembly, three final experiments were planned for the gun performance tests using $7 \mathrm{lb}$ (50\% powder load), $11.1 \mathrm{lb}$ (75\% load), and $15 \mathrm{lb}$ (100\% load). All experiments were performed using magnesium projectiles with nominal masses of $1.5 \mathrm{~kg}$ and aluminum impactors backed by syntactic foam. The projectile impacted a standard velocity target with one PDV (collimated) on center and four impact pins positioned around the diameter (flush with the impact surface). All three experiments were successful with measured velocities of $1.336 \mathrm{~km} / \mathrm{s}, 1.797 \mathrm{~km} / \mathrm{s}$, and $2.312 \mathrm{~km} / \mathrm{s}$, respectively. Postshot examination of the gun structure in all three experiments revealed no structural damage. The gun system had passed both the preshot and postshot leak checks, indicating that the new procedures for barrel 
setup were successful and illustrating that the gun can remain helium-leak tight (1e-5 or better) throughout the normal operating range.

\subsubsection{Gun Performance Curve}

Velocity data were obtained using two methods: electrical shorting pins and/or PDV. The first method used ten shorting pins set at random heights from the impact surface of the target and when shorted generate a pulse (1-10 volts) recorded on a digitizer. The known pin heights coupled with the impact times provide the projectile velocity and impact tilt. The second method uses the Doppler method to track the projectile velocity as the projectile approaches and impacts the target. The pin method has been used extensively over the years and provides highly accurate impact-velocity measurements with a typical accuracy within 0.1 percent. The Doppler method results in values of similar accuracy during projectile flight up to impact, but does not provide tilt information. Tilt information is obtained using four PZT impact pins typically located on a 3.4-inch bolt circle equally spaced (90-degree increments) and flush with the target surface. The results are shown in column 7 (Table I) with the average tilt equal to $1.0 \pm 0.59$ mrads.

An example of the velocity obtained using the Doppler method is shown in Figure 15 for shot 06nts_07_23 and shot 06nts_07_24 that used 11.25 and 15 lb of M14 propellant to launch a magnesium projectile. The measured projectile velocity at impact was $1.797 \mathrm{~km} / \mathrm{s}$ and $2.312 \mathrm{~km} / \mathrm{s}$, respectively. For both experiments, the velocity is observed to slowly accelerate over the approximate $1 \mathrm{~ms}$ of recording time. The impact velocities were used to determine the gun performance curve for the large-bore gun system. Figure 15 also shows the impact velocities plotted versus the CM ratio (propellant charge versus projectile mass ratio) for the nominal $1.5 \mathrm{~kg}$ projectiles. The solid curve shown indicates a fit to all the data. Overall, the data form a well-defined curve that defines the gun-performance curve,

$$
V_{P}=0.134+0.62 C_{M}-0.03 C_{M}^{2},
$$

where $V_{p}$ is the projectile velocity and $\mathrm{C}_{M}$ represents the charge/mass ratio. This relation allows the prediction of final impact velocities within a few percent over the entire operating range of the gun.

\subsubsection{Catch-Can Testing Results}

A prototype catch can was used in the first eleven experiments that consisted of a hollowed steel can machined from solid 4140 hardened steel. Up to five half-inch-thick steel plates were used as shear discs and placed at approximately 1-in. intervals inside the catch can. The catch can was located inside a second steel cylinder (prototype Oboe vessel) on rails so that it could recoil during impact. An aluminum energy-absorbing cylinder was placed behind the catch can to slow down the system during impact.

In the first several experiments, all five shear plates were installed in the catch can. It was observed that the shear discs would deform, but not shear, and would stack up making removal difficult. It was suspected that the 1 -in. distance between each plate was insufficient to allow the plates to shear. Thus, as testing continued using propellant loads up to $11 \mathrm{lb}$ of gun propellant, only three steel shear plates were used. To provide some additional distance between plates 1 and 2, the plates were installed into positions 1, 4, and 5 in the catch can. This was successful, and complete shearing of plate one was observed in many of the experiments. 

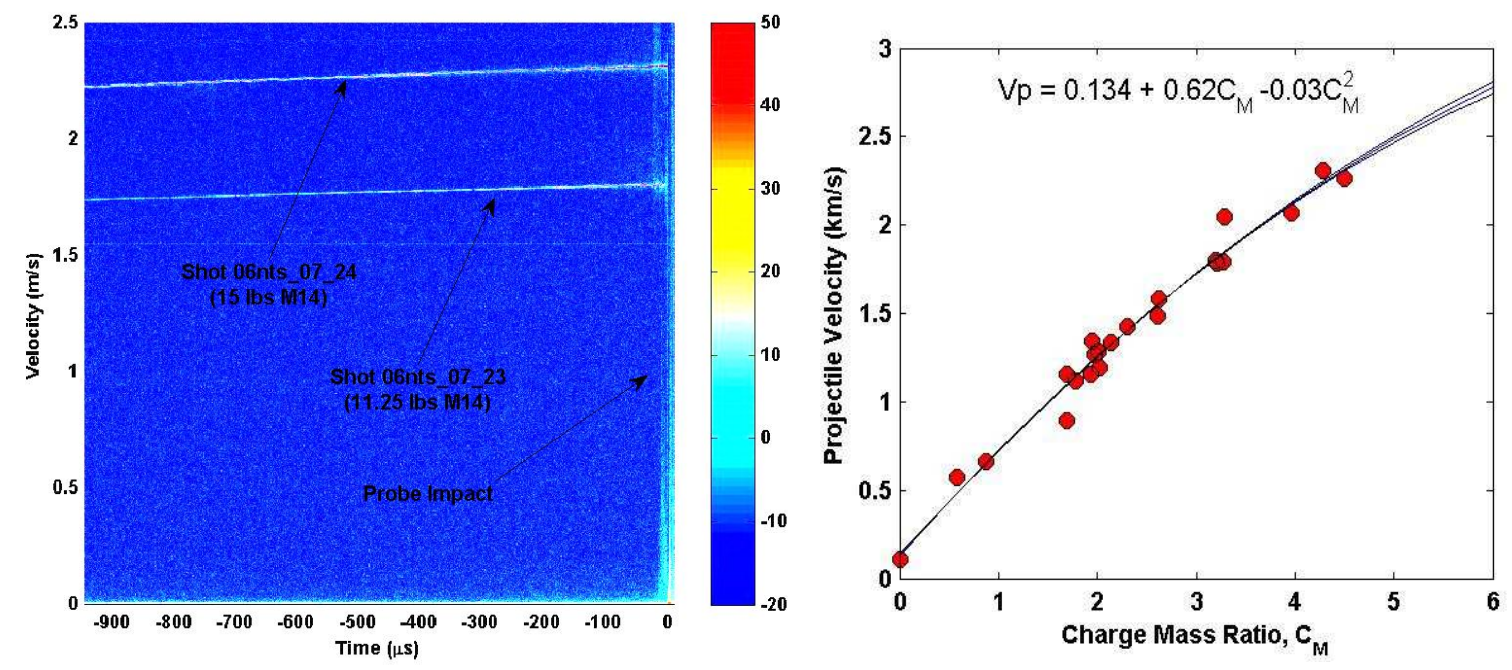

Figure 15: (Left) Doppler Velocimetry data for Experiment 24 and the gun performance curve. The data are shown as an image plot with velocity $(\mathrm{km} / \mathrm{s})$ plotted versus time $(\mu \mathrm{s})$. The colorbar indicates the intensity level of the data. The data show the projectile accelerating up to impact with a measured impact velocity of approximately 2.3 and $1.79 \mathrm{~km} / \mathrm{s}$, respectively. (Right) The performance curve for the large-bore powder gun shows the measured velocities as a function of propellant charge to projectile mass ratio.

After nine experiments, a crack formed in the back of the catch can likely because of continued use (good test of durability) coupled with the increasing projectile velocity and the use of only three shear plates in the can. In Experiment 10, the crack propagated, and the back of the can was separated from the main part of the catch can. The catch can was refurbished, and the back was secured to the can using bolts. The catch can was used for two more shots without incident. During Experiment 13, the catch tank structure was compromised, and it's use was discontinued in favor of a water barrel that provided both stopping assistance and fire mitigation useful for pyrophoric sample experiments (cerium tests).

\subsubsection{Projectile Design Modifications}

The projectile design was originally fabricated from lexan (medium range velocities) or aluminum 6061-T6 (low velocities) by counter-boring a hole in the rear of the projectile. A shear disc was then screwed into the back of the projectile. The shear disc was made from lexan and served to secure the projectile while under vacuum and to delay projectile motion until significant pressures were achieved in the breech. This original design was a result of the requirement that the projectile remain light to achieve the highest possible velocities but was abandoned because of the concern that the structural integrity of the projectile would be compromised by the large propellant force at higher velocities. This decision was based on several experiments where velocity data and tilt data were not obtained, and a shotgun effect was observed on the catch system. In addition, during fabrication of the projectiles, it was observed that the lexan would crack over time if a small hole were drilled into the material. Based on these observations, it was concluded that the projectiles likely came apart during acceleration and that both the design and materials required reconsideration. 
Table 2: Experimental Parameters and Results Relevant to the Catch-Can System

\begin{tabular}{|c|c|c|c|}
\hline $\begin{array}{l}\text { Experiment } \\
\text { Number }\end{array}$ & $\begin{array}{l}\text { M14 } \\
\text { Mass } \\
\text { g (lbs) }\end{array}$ & $\begin{array}{l}\text { Shear Plate } \\
\text { Config. }{ }^{* *}\end{array}$ & Observations \\
\hline 69nts_07_01 & $9 *(0)$ & 12345 & No damage — low velocity \\
\hline 69nts_07_02 & $908(2)$ & 12345 & $\begin{array}{l}\text { Plate } 1 \text { significantly deformed (not sheared) } \\
\text { Plates } 2 \text { and } 4 \text { impacted with minimal deformation }\end{array}$ \\
\hline 69nts_07_03 & $1362(3)$ & 12345 & $\begin{array}{l}\text { Plate } 1 \text { significantly deformed (not sheared) } \\
\text { Plate } 2 \text { and } 3 \text { showing minimal deformation } \\
\text { Plate } 4 \text { impacted - not deformed }\end{array}$ \\
\hline 69nts_07_04 & $1362(3)$ & 145 & $\begin{array}{l}\text { Plate } 1 \text { significantly deformed (not sheared) } \\
\text { Plates } 4 \text { and } 5 \text { impacted with minimal deformation }\end{array}$ \\
\hline 69nts_07_05 & $2270(5)$ & 145 & $\begin{array}{l}\text { Plate } 1 \text { significantly deformed (not sheared) } \\
\text { Plate } 4 \text { significantly deformed - impacted plate } 5 \\
\text { Plate } 5 \text { minimally deformed and stuck in can }\end{array}$ \\
\hline 06nts_07_06 & $2270(5)$ & - & Catch can not used - Oboe vessel used for debris mitigation \\
\hline 06nts_07_07 & $3178(7)$ & - & Catch can not used - Oboe vessel used for debris mitigation \\
\hline 06nts_07_08 & $3178(7)$ & - & Catch can not used - Oboe vessel used for debris mitigation \\
\hline 06nts_07_09 & $3178(7)$ & 25 & $\begin{array}{l}\text { Plate } 2 \text { completely penetrated } \\
\text { Plate } 5 \text { deformed and stuck in can } \\
\text { Crack observed at the rear, exterior part of the catch can }\end{array}$ \\
\hline 06nts_07_10 & $4086(9)$ & 25 & $\begin{array}{l}\text { Plate } 2 \text { completely penetrated } \\
\text { Plate } 5 \text { significantly deformed }\end{array}$ \\
\hline 06nts_07_11 & $4994(11)$ & 1234 & $\begin{array}{l}\text { Plate } 1 \text { completely penetrated } \\
\text { Plate } 2 \text { partially penetrated (small hole) } \\
\text { Plate } 3 \text { deformed and plate } 4 \text { untouched }\end{array}$ \\
\hline 06nts_07_12 & $5902(13)$ & 1234 & $\begin{array}{l}\text { Plate } 1 \text { penetrated multiple times } \\
\text { Shot-gun effect observed because of possible projectile failure }\end{array}$ \\
\hline 06nts_07_13 $3^{* * *}$ & $5902(13)$ & $1234-$ & $\begin{array}{l}\text { Plates } 1 \text { and } 2 \text { completely penetrated } \\
\text { Plate } 3 \text { and } 4 \text { significantly deformed } \\
\text { Catch tank structure failed }\end{array}$ \\
\hline
\end{tabular}

* The shear disc on the projectile broke prematurely - the projectile was accelerated by vacuum

** The number shown indicates the position of each shear plate used

*** An aluminum tube was used to direct the propellant gas and projectile directly into tank

The projectile design was modified in two ways. First, the projectile material was changed from aluminum or lexan to magnesium except for low velocities (less than $0.5 \mathrm{~km} / \mathrm{s}$ ). Magnesium is lightweight with a density of $1.776 \mathrm{~g} / \mathrm{cc}$ as compared to aluminum $(2.703 \mathrm{~g} / \mathrm{cc}$ ), easily machinable despite it's pyrophoric property, and results in a cleaner gun bore following the experiment than either aluminum or lexan. The lower density allows for thicker walls that add to the structural stability of the projectile. Second, the projectile was machined with a counter bore in the front of the projectile filled with syntactic foam epoxied to the impactor material. Again, a shear disc was secured to the back of the projectile using a 3/8-in. plastic bolt. In one experiment (shot 06nts_07_23), gas blow-by was observed as multiple velocities in the Doppler data. Inspection of the barrel near the breech indicated significant barrel wear and therefore a nylon boot was fabricated that tapered down $(0.010 \mathrm{in}$. + measured bore diameter at the breech) to the projectile diameter of $3.535 \mathrm{in}$. This boot was secured to the projectile by the shear disc and bolt. The final projectile design is shown in Figure 7. The gun setup procedure was modified to require a measurement of the barrel bore near the breech before fabrication of the boot for the projectile. 

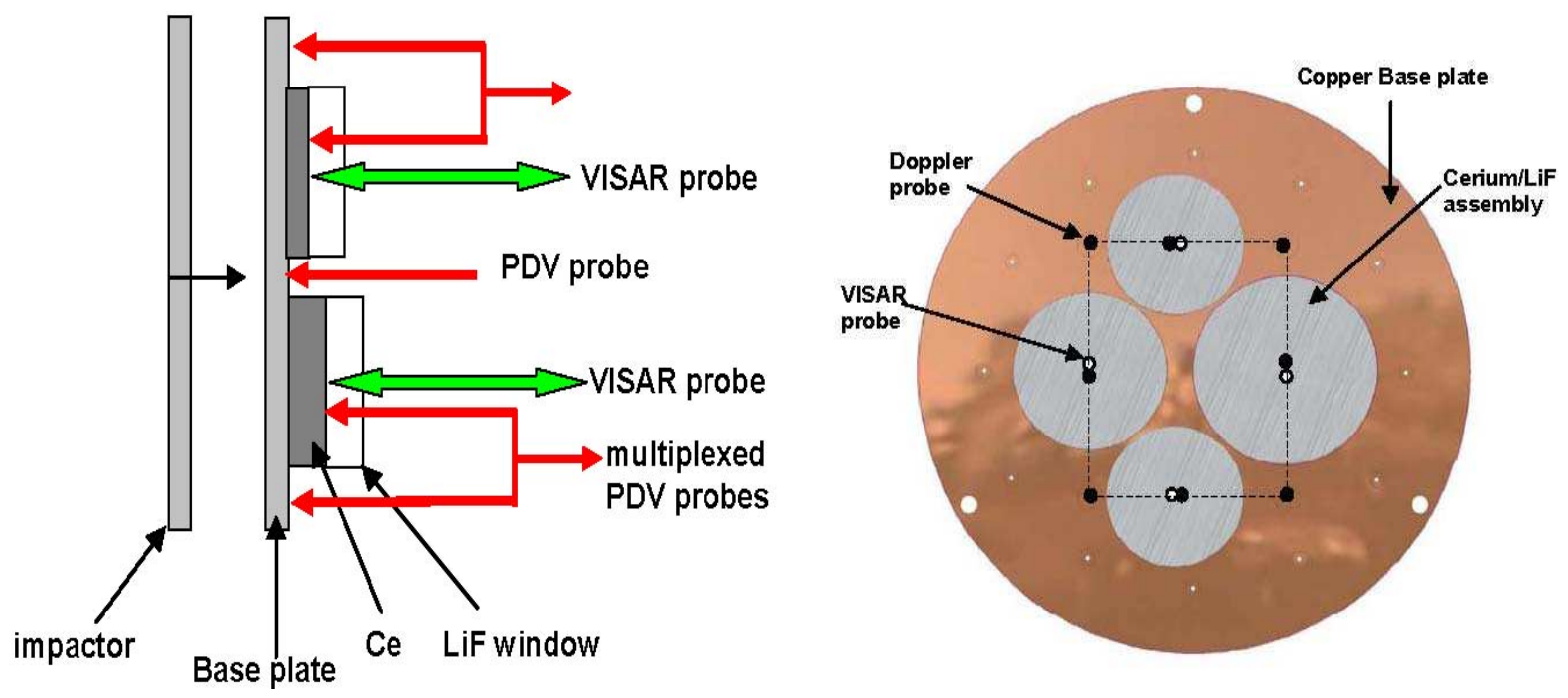

Figure 16: (Left) Schematic of a multislug plate impact experiment to measure the sound speed at pressure and Hugoniot for cerium metal. Multiple optical probes are shown that are used to monitor the shock-wave profile, obtain shock arrival times, and velocities. (Right) Top view of the multislug plate-impact experiments illustrating the placement of four cerium samples on the copper baseplate.

\subsubsection{Proper Breech Assembly_Lessons Learned}

The operation of the large bore gun was based on the procedures for the two-stage gun (located at Ancho Canyon) and developed over more than 30 years of operation. The two-stage gun breech used up to $7 \mathrm{lb}$ of M4 propellant, approximately $50 \%$ of the maximum load used in the large-bore gun. Thus, no abnormal situations were observed during operation of the large bore gun for moderate propellant loads $(7-10 \mathrm{lb})$. As testing progressed to higher powder loads, propellant "burping" was observed at the breech-barrel interface. Results from the postshot investigation revealed that the barrel had rotated during operation, likely because of the intense cycling of the gun system from subsequent shots. This rotation compromised the sealing ability of the orifice and opened a direct vent line from the breech through breech/flange interface. This finding resulted in a significant change in the procedure for setup of the large-bore gun. In this new procedure described in Section 3.1, the barrel-breech interface is opened so that the Oring seal can be evaluated before the experiment. Following this procedure modification, three additional tests were conducted (shots 06nts_07_22 to 24) using approximately 50\%, 75\%, and $100 \%$ propellant loads. Helium leak checks were conducted preshot and postshot to illustrate that the gun can maintain a helium-leak tight throughout the normal operating range.

\subsubsection{Physics Experiments}

In addition to gun performance tests, part of the qualification for the large-bore gun was to demonstrate the ability to obtain accurate shock-wave data for well-defined, plate-impact experiments. Multiple experiments were performed on cerium metal to examine the dynamic melt boundary using the overtake sound speed method[12,13]. The experimental configuration is shown in Figure 16 and consisted of a copper flyer impacting a copper/cerium/LiF target assembly. The target was equipped with four PZT pins for tilt measurement and one standoff PZT pin to serve as a diagnostics trigger. Cerium samples, varying in thickness from 1.5 

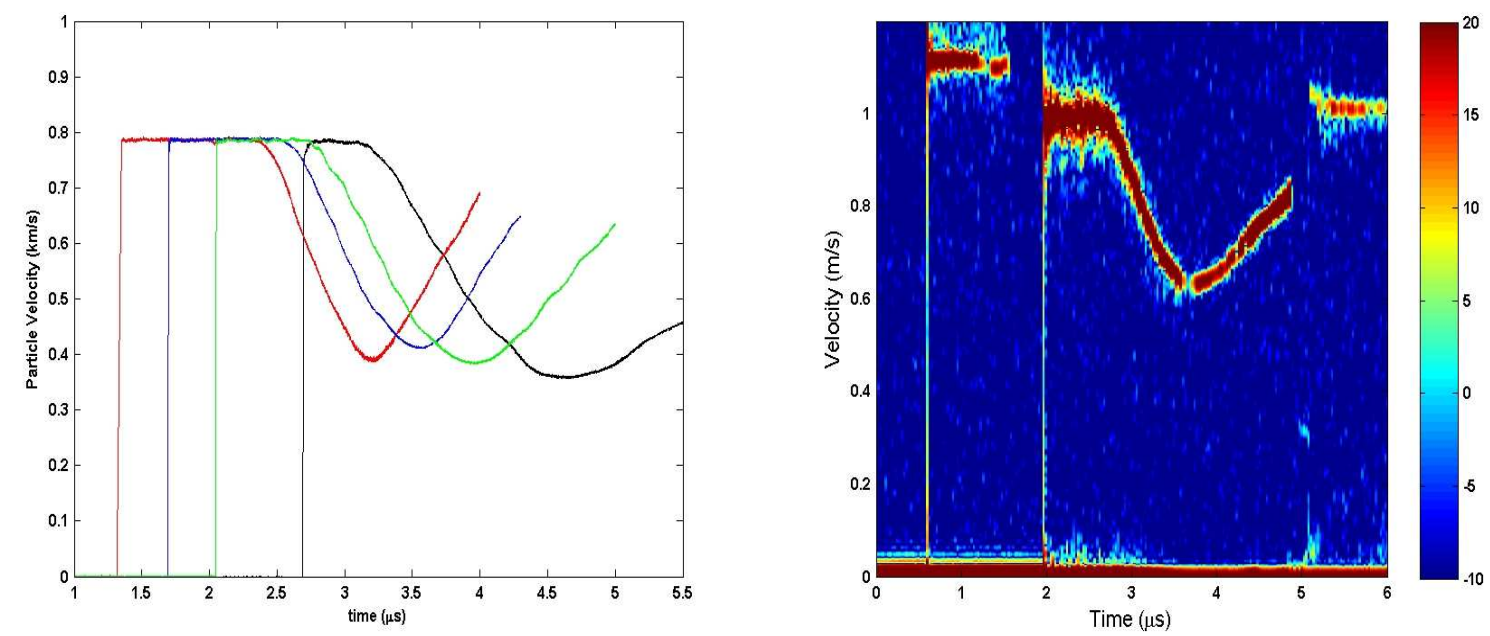

Figure 17: (Left) Four VISAR wave profiles obtained from a single multislug experiment (Experiment 06_nts06_07_19) that consisted of a copper plate impacting a copper base plate (both approximately $3.5 \mathrm{~mm}$ thick) backed by cerium samples ranging from 1.5 to 5 -mm thick and $\mathrm{LiF}$ windows. These wave profiles are used to determine the Hugoniot and sound speed at pressure. (Right) PDV data obtained from the same experiment as the VISAR data shown in Figure 14. The data show a series of three shock jumps caused by the baseplate (approximately $0.5 \mu \mathrm{s}$ ), the cerium-LiF interface (approximately $2 \mu \mathrm{s}$ ), and the free surface of the LiF window (approximately $5 \mu \mathrm{s}$ ).

to 5-mm thick, were arranged on the 3.5-in. copper baseplate (3-5 $\mathrm{mm}$ thick) and backed by aluminum-plated LiF optical windows. Four PDV probes were used to monitor the shock breakout at the rear free-surface of the copper baseplate, and four probes were used to monitor the $\mathrm{Ce} / \mathrm{LiF}$ interface. In addition, four VISAR probes (focused on center) were used to obtain accurate wave profiles at the ce/LiF interface. The data collected were used to obtain the shock velocity in all four samples, the wave profiles including the peak state velocity, and the release profiles. These data were used to determine the sound speed at pressure.

A representative example of VISAR and Doppler data are shown in Figure 17. The VISAR data show multiple wave profiles obtained from a single experiment for multiple cerium samples. The wave profile for the thin sample shows the longest peak-state plateau, whereas the thick sample shows a shorter peak state duration with the release wave catching up to the shock front. The PDV data shown in Figure 17 show three separate shock events due to shock-breakout at the rear of the copper, the wave profile at the ce/LiF interface, and the free-surface release at the back of the LiF optical window. Preliminary results have provided important information for the melt-transition stress as well as the Hugoniot and sound speed at high pressures. Most importantly, these experiments illustrate the ability to obtain accurate shock-physics data on the large-bore gun.

Three additional physics experiments (shot 06nts_07_25 through 06nts_07_27 that discussed in Section 4) were performed, including a standard shock-release experiment to obtain higherpressure cerium data (above melt) and two layered impactor experiments to generate a shockramp profile into tantalum. The cerium experiment used a copper impactor backed by foam to generate a shock-release profile into a 1.408 -mm-thick cerium sample backed by a LiF window. One VISAR and three PDV were fielded to obtain the shock velocity in cerium and the wave 
profile at the Ce-LiF interface. The shock wave profile is shown in Figure 18 and exhibits a sharp initial shock followed by a steady state with a particle velocity of $1.011 \mathrm{~km} / \mathrm{s}$, and then the release to lower pressures. The measured projectile velocity and shock velocity were 1.425 $\mathrm{km} / \mathrm{s}$ (shock transit time $=513 \mathrm{~ns}$ ) and $2.745 \mathrm{~km} / \mathrm{s}$, respectively. The particle velocity in the cerium $(1.007 \mathrm{~km} / \mathrm{s})$ was calculated using the jump conditions, the projectile velocity, the known densities for copper and cerium, and the known Hugoniot for copper $\left(\mathrm{Us}=3.94+1.489 \mathrm{u}_{p}\right)$. For the shock-ramp experiments on tantalum, a magnesium projectile was fitted with an impactor consisting of an aluminum(6061-T6)-copper-foam impactor (aluminum impact surface). The projectile impacted a target consisting of an aluminum target backed by tantalum. The target for shot 06nts_07_25 consisted of two tantalum samples (one backed by sapphire and one backed by $\mathrm{LiF}$ ) and one LiF sample. Sapphire is a better impedance match for tantalum, but likely does not remain transparent during the ramp portion of the loading above approximately $180 \mathrm{kbar}$. The LiF base-plate measurement provided a direct measure of the loading profile into the tantalum. The target was equipped with two PDV probes and 3 VISAR probes to monitor the shock-wave profile at the Ta-LiF, Ta-sapphire, and Al-LiF interfaces. A collimated PDV probe was used to monitor the projectile velocity up to impact. The second target consisted of one tantalum-LiF assembly and one Al-LiF base plate measurement. Two PDV and two VISAR probes were used to monitor the interface velocities. The tests were successful, and examples of VISAR data are shown in Figure 18. The data from the first test show a release immediately following the initial shock that was later determined to be a result of the possible separation of the layers in the flyer (gap between the aluminum and copper). The second test was a repeat and does not show the pullback in velocity, but does show a glitch after the first jump. An analysis of the cerium and tantalum data is ongoing along with additional testing to proof impactor designs and an analysis for complex loading experiments, including shock-ramp, shock-release-reshock, etc. In addition to dynamic experiments, current efforts are underway to implement a multiphase equation of state for cerium for experimental design and analysis along with complementary static experiments on the diamond anvil cell to explore the multiphase diagram.

\section{INTEGRATED SYSTEM TESTING}

Upon completion of the Large-Bore powder gun qualification testing described in Section 3, a prototype containment system had been designed and fabricated that consisted of an EDV, a drift tube, a target chamber, and a catch can. The entire system was connected to the launcher system through a slip-tube barrel extension that allowed both systems to recoil during the experiment. The containment system was secured to a table with a rail system, and the entire system was brought to rest using honeycomb aluminum crush cylinders (Plascore). This section describes the series of experiments designed to test the complete integrated system that included the large-bore launcher and the prototype containment system. Each integrated system test would consist of the following events: propellant ignition followed by acceleration of the projectile through the slip tube, the explosive valve, the drift tube, impact in the target chamber and the catch can. The explosively driven valve would be triggered either using barrel-triggers (optical and/or electrical) located upstream from the EDV or impact triggers located on the target. Following a successful contained experiment, the gas would be vented through the manifold system that included a remote valve for the containment system and HEPA filters. This significantly complex series of events was diagnosed using (1) strain gauges on the breech, drift tube, and catch can, (2) pressure sensors on the EDV breech and target chamber, (3) accelerometers on the target chamber and EDV, (4) fast-video monitoring of the 


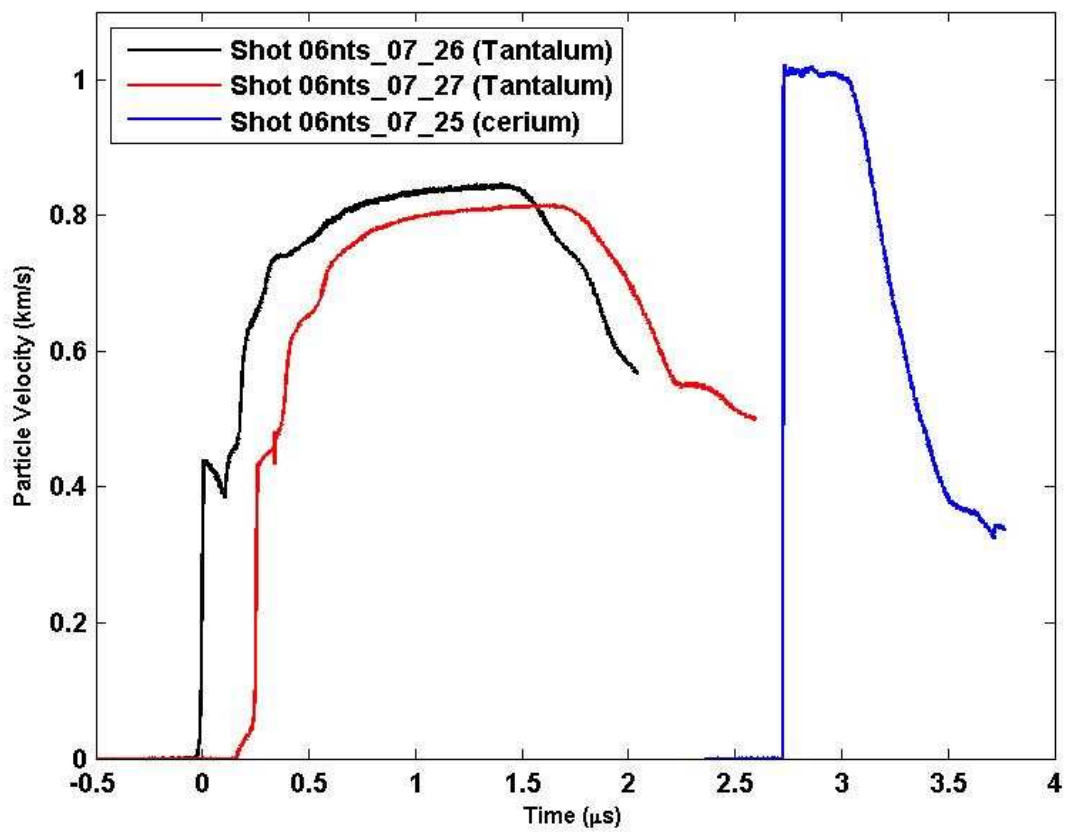

Figure 18: VISAR data that show the results of a shock-ramp experiment in Ta and a shockrelease experiment in cerium that were performed during the LBPG integrated system Tests 1-3.

entire containment system from slip-tube to crush foam, (5) PZT impact pins to monitor the impact time and measure the impact tilt, and (6) velocimetry (PDV) to monitor the projectile velocity through the system up to impact. In addition to system diagnostics, plat-impact physics experiments were conducted to proof the complex loading impactors required for the large-bore experiments and to obtain data on cerium and tantalum. These experiments required PDV and VISAR to measure shock velocities and particle velocities of the base plates, standards, and sample interfaces. Though these tests were not required for qualifying the containment system, the ability to perform well-defined plate-impact experiments was necessary for the overall success of the project.

A photo of the containment system coupled to the Large-Bore gun is shown in Figure 19. Because of the need to remove the containment system after each test coupled with the tight tolerance requirements for the projectile to make it through the system to the target chamber, a straight-forward and reliable procedure was needed that would make installation efficient. The first attempt at assembly and alignment of the containment system used an autocollimator and projectile targets to align the system both vertically and horizontally before connecting the slip-tube to the barrel. In this case, the containment-system components were first assembled using a projectile to verify that all barrel regions were concentric, the projectile was then moved back and forth while being viewed with the autocollimator, and adjustments were made to the containment structure to align the system to the barrel axis. Unfortunately, this method did not work, and another approach was needed. The final procedure consisted of assembling the containment from the muzzle to the catch can in sequence. First, the slip tube was suspended in position at the muzzle using the crane. Next, the slip tube was threaded onto the muzzle and then backed off approximately one-half turn. A tapered nylon jig (oversized by approximately 0.020-in) was pushed through the tube so that it spanned the muzzle-slip tube joint. This 
forced the barrel regions to be concentric while the slip tube was completely threaded onto the muzzle. The alignment screws were then hand-tightened to prevent motion when the jig was removed. The remaining components were then installed in a similar manner using the crane to suspend them and allowing the machined tolerances to pull the joints together as the bolts were tightened. Finally, all supports were adjusted to support each component before the removal of the crane. After the containment was assembled, the projectile was pushed up and down the system to ensure that all components were aligned within the tolerance of the projectile. Provided all O-rings and components were ready and available, this procedure could be used to assemble the containment system in approximately one day or less.

The initial test plan is described in the document $[14,15]$ titled "Qualification of the Integrated Powder Gun Test System," that consisted of five experiments, (1) low-velocity test (50\% propellant charge) without the EDV, (2) low-velocity test (50\% propellant charge) using the EDV to seal the containment, (3) medium-velocity test (75\% propellant charge) using the EDV, (4) high-velocity test (100\% propellant charge or $15 \mathrm{lb}$ ) using the EDV, and (5) a high-velocity test (100\% propellant charge) without the EDV. The first and the last tests were required because calculations had shown that the highest pressures achieved in the system occurred when the valve was left open. As discussed in the Section 4.1, difficulties were encountered during this test series that resulted in a modification of the test plan. A total of six experiments were conducted in this work with the first four following the initial test plan. The remaining two were performed under a modified test plan before the completion of this experimental series. The relevant experimental parameters and results are shown in Table 3 . The projectile mass and propellant mass are shown in columns two and three, respectively. The measured projectile velocity is shown in column four. Finally, some comments regarding the test are shown in column five.

\subsection{Integrated-System Test 1}

Experiment 1 (test 06nts_07_25) was performed using 7.9 pounds (49\% breech capacity) of M14 propellant to launch a $1.559 \mathrm{~kg}$ magnesium projectile with a copper impactor. The target consisted of a copper baseplate backed by a cerium sample and a LiF window. Doppler velocimetry was fielded to monitor the projectile velocity up to impact along with the shock arrival times (back of copper baseplate to back of cerium sample) and the particle velocity at the cerium-LiF interface. In addition to velocimetry, the standard suite of gun diagnostics were fielded, including strain gauges, pressure gauges, accelerometers, Doppler velocimetry (projectile velocity), thermocouples, fast video, etc. The main goal of this first experiment was to test the integrated system with the explosive valve in place, but not operated, using a moderate powder load in the breech to test the structural integrity of the system coupled with it's ability to contain the gases while conducting a well-defined plate impact experiment.

The test was partially successful with the projectile passing through the entire containment system without obstruction impacting the target and providing accurate shock-wave data on cerium. The measured projectile velocity was $1.425 \mathrm{~km} / \mathrm{s}$, a value within $1 \%$ of the predicted value based on the measured gun-performance curve. The gun system and containment recoiled flawlessly and the aluminum energy absorber (located at the back of the containment) coupled with the five shear plates in the catch can stopped the projectile and gases. The energyabsorbing material was observed to compress less than $10 \%$ (estimated). Despite the success, containment was not achieved because of a rupture in one of the high-pressure vent lines that was attached to the target chamber (see Figure 20). It was concluded that the line was located too close to the impact event and was adversely affected by direct exposure to the dynamic 


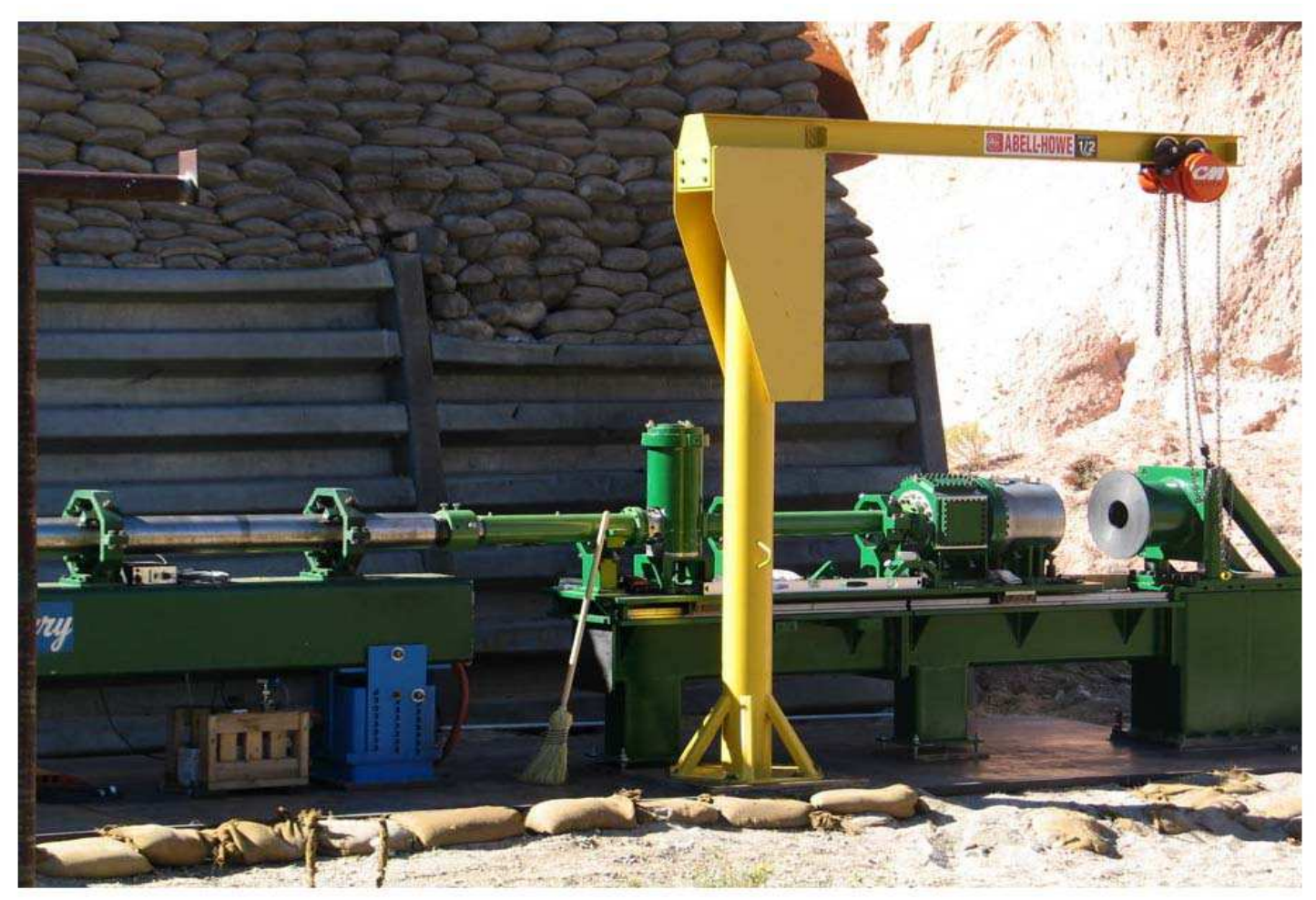

Figure 19: Photo of the containment system connected to the large-bore gun located at TA-3906. The last 20 foot section of the gun is shown to the left, and the containment system is shown to the right. A slip tube connects the two together and allows for recoil in both directions. The crane (yellow) is required to lift components before and after the test.

pressure and high temperatures. According to the vendor-part specifications, the high pressure line was not rated for high temperature. A post-shot helium leak check was performed by plugging the ruptured vent lines that revealed a helium leak-tight system. The containment system and gun were systematically disassembled beginning with the catch tank and target chamber. Each O-ring was inspected during this process, and it was observed that, on all seals, dirt and debris were found in contact with the first O-ring and that no debris passed this first seal. No damage was visible because of the projectile motion through the containment system. The projectile impacted the shear plates, deforming all five plates so that the last plate that impacted the rear catch can flange (see Fig 20(b) and (c)). Postshot inspection of the catchtank rear flange showed that the rotatable flange joining the catch tank to the target chamber had yielded (or flared) likely because of the 1-in. gap left between the back of the catch can and the energy-absorbing cylinder. This gap allowed the containment system to accelerate before impacting the energy-absorbing material, generating a significant load on the target chamber components as it decelerated. The pressure data obtained from the transducer installed in the spool piece (in front of the EDV) revealed a pressure in the 2,750 to 3,400 psi range as the projectile passed into the containment system. Refer to the WT-7 test documents for additional information related to strain gauges, accelerometers, and pressure gauges.

Although containment was not achieved, this test was an important milestone for the powder gun project. The test results illustrate that a well-defined plate impact experiment is possible even with such a complex containment system and that structural integrity of the 


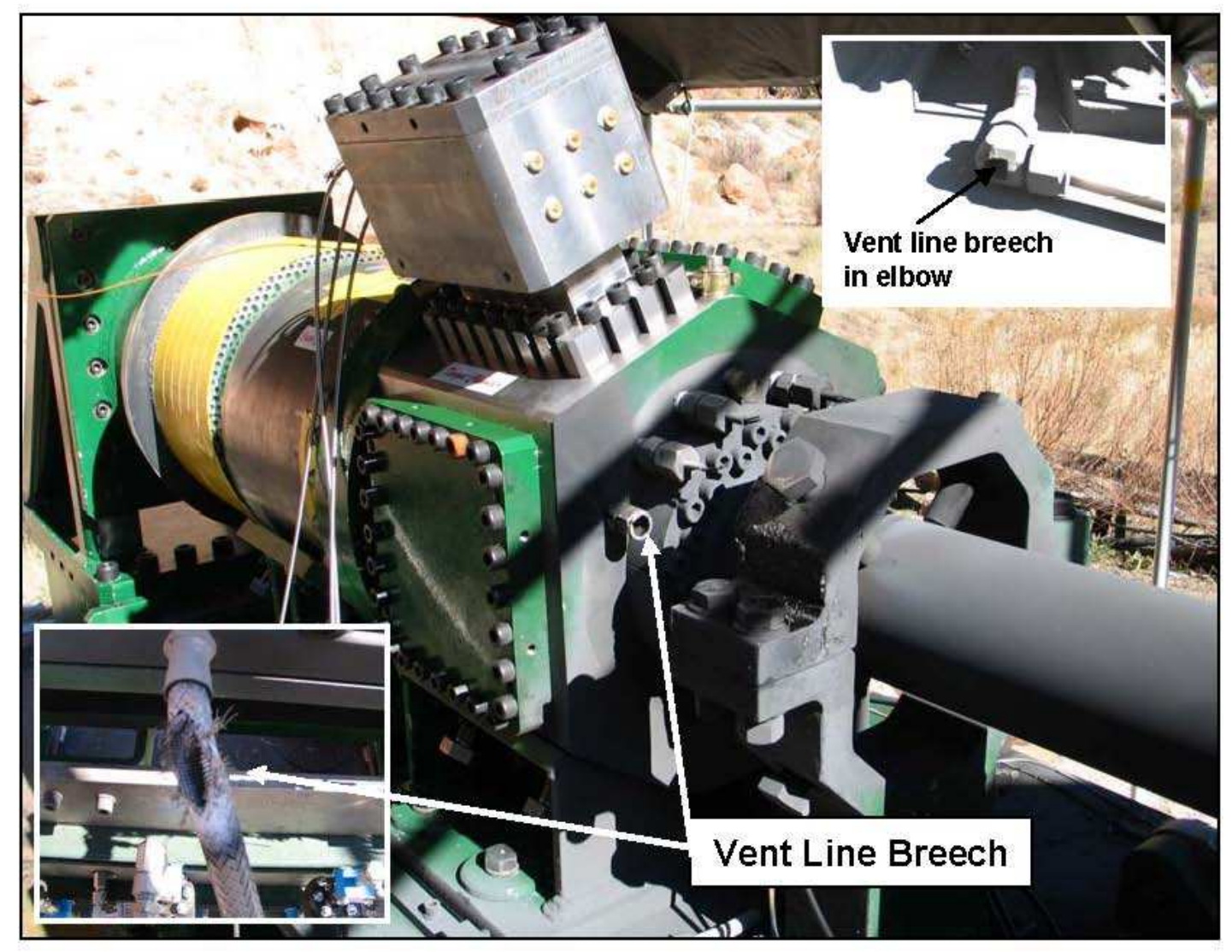

(a)

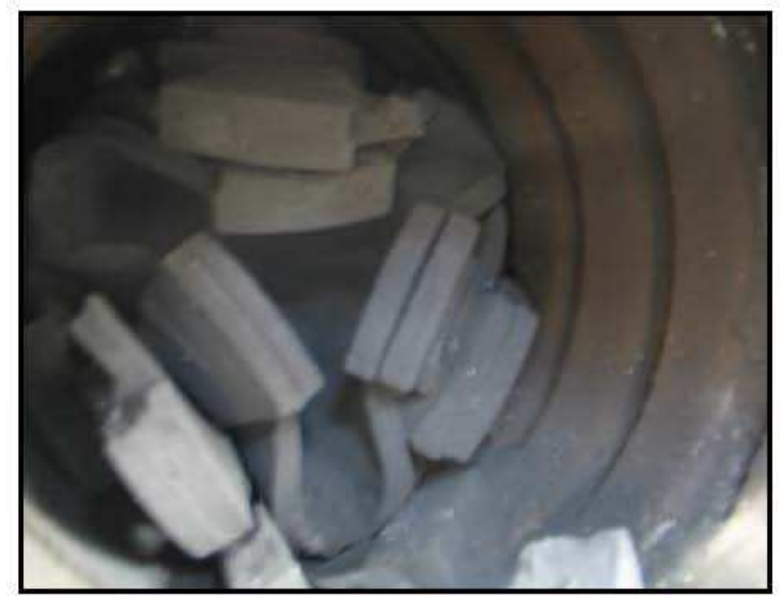

(b)

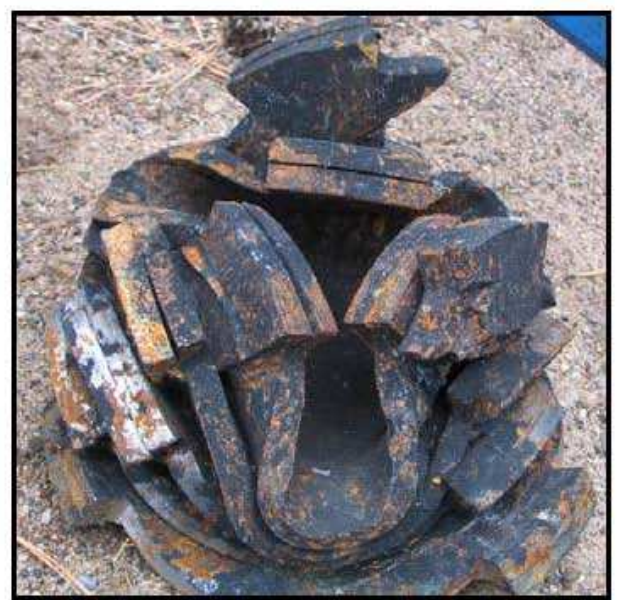

(c)

Figure 20: Photo of the target chamber and catch-can components of the containment system for LBPG integrated-system Test 1 showing the high-pressure vent line attached to the target chamber that ruptured during the test. The shear plates are shown in (b) and (c) showing significant deformation of all five shear plates. 
Table 3: Relevant Experimental Parameters and Results for the Integrated System

\begin{tabular}{|c|c|c|c|c|}
\hline $\begin{array}{l}\text { Test \# } \\
\text { (Shot \#) }\end{array}$ & $\begin{array}{l}\text { Piston } \\
\text { Mass } \\
(\mathrm{g})\end{array}$ & $\begin{array}{l}\text { M14 } \\
\text { Mass } \\
\text { g (lb) }\end{array}$ & $\begin{array}{l}\text { Projectile } \\
\text { Velocity } \\
(\mathrm{km} / \mathrm{s})\end{array}$ & Comments \\
\hline $\begin{array}{l}\text { Test 1 } \\
\text { (06nts_07_25) }\end{array}$ & 1559 & $\begin{array}{l}3586 \\
(7.9)\end{array}$ & 1.425 & $\begin{array}{l}\text { EDV not used - containment not achieved } \\
\text { because of a rupture in the high-pressure ventline } \\
\text { All } 5 \text { shear plates were deformed impacting back flange }\end{array}$ \\
\hline $\begin{array}{l}\text { Test } 2 \\
\text { (06nts_07_26) }\end{array}$ & 1570 & $\begin{array}{c}3064 \\
(6.75)\end{array}$ & 1.340 & $\begin{array}{l}\text { Repeat of Test } 1-\text { EDV not used } \\
\text { Containment of LBPG-IST system achieved } \\
\text { New shear plate used }-3 \text { out of } 5 \text { sheared }\end{array}$ \\
\hline $\begin{array}{l}\text { Test } 3 \\
\text { (06nts_07_27) }\end{array}$ & 1560 & $\begin{array}{c}3084 \\
(6.75)\end{array}$ & 1.270 & $\begin{array}{l}\text { EDV used - containment of LBPG-IST achieved } \\
\text { Containment system sealed from barrel using EDV } \\
\text { Small leak detected between drift tube and } \\
\text { EDV breech but not to the outside } \\
4 \text { of the } 5 \text { shear plates penetrated w/ } \\
\text { counterbore facing projectile }-5 \text { th plate deformed }\end{array}$ \\
\hline $\begin{array}{l}\text { Test } 4 \\
\text { (06nts_07_28) }\end{array}$ & 1558 & $\begin{array}{c}5107 \\
(11.25)\end{array}$ & 1.795 & $\begin{array}{l}\text { EDV used-containment of LBPG-IST not achieved } \\
\text { Containment system not sealed from barrel using EDV } \\
\text { Piston was not properly seated in valve } \\
\text { venting observed at EVD vent ports and spool piece } \\
5 \text { shear plates penetrated/deformed }\end{array}$ \\
\hline $\begin{array}{l}\text { Test } 5 \\
\text { (06nts_07_31) }\end{array}$ & 1560 & $\begin{array}{c}3084 \\
(6.75)\end{array}$ & 1.271 & $\begin{array}{l}\text { EDV used - containment demonstrated } \\
\text { EDV triggered by impact pins (delayed) } \\
\text { EDV results similar to Test \#3 } \\
3 \text { of } 5 \text { shear plates sheared/deformed }\end{array}$ \\
\hline $\begin{array}{l}\text { Test } 6 \\
\text { (06nts_07_35) }\end{array}$ & 1558 & $\begin{array}{l}4086 \\
(9.0)\end{array}$ & 1.581 & $\begin{array}{l}\text { EDV used - containment of LBPG-IST achieved } \\
\text { Containment system not sealed from barrel using EDV } \\
\text { Piston was properly seated in valve } \\
3 \text { of } 5 \text { shear plates penetrated }-4 \text { and } 5 \text { deformed }\end{array}$ \\
\hline
\end{tabular}

main components (drift tube, slip tube, target chamber, and catch can) can be maintained. Several modifications were made before the second test, including (1) the high pressure vent line that was moved so that it connected to the target chamber through the diagnostics feedthrough flange that was designed to withstand the dynamic pressures and high temperatures of the target chamber to protect the diagnostics feed-throughs, (2) a manual ball valve was used to isolate the vent line from the target chamber during the test, (3) the shear plates were modified by increasing the thickness from $0.5 \mathrm{in}$. to $1 \mathrm{in}$. and a counter bore (approximately 4-in. diameter by 0.5 -in. thick) was machined in the center to facilitate shearing during impact, and (4) a spacer was fabricated to eliminate any gap between the catch tank flange and the energy-absorbing material. 


\subsection{Integrated-System Test 2}

Test 2 was a repeat of Test 1 with the modifications described in the previous paragraph, using a total of $6.75 \mathrm{lb}$ ( $42 \%$ breech capacity) of M14 propellant to launch a 1.57-kg magnesium projectile into the containment system. The main goal of this test was to test the ability of the integrated system to act as a primary containment without the operation of the explosive valve. In addition to the containment test, a physics experiment was performed to use the large-bore feature of the gun to subject a multislug target (two tantalum samples and one $\mathrm{LiF}$ window) to a shock-ramp (step ramp) loading profile. The shock-ramp profile was generated using a layered impactor consisting of a copper-aluminum assembly. The two tantalum samples (backed by a $\mathrm{LiF}$ window or a sapphire window) and the $\mathrm{LiF}$ window were epoxied to an aluminum baseplate. The LiF window provided a drive measurement required for analysis of the tantalum data. Two VISAR probes were used to monitor the wave profile at the tantalumwindow interface and seven Doppler probes were used to measure the shock velocity through the tantalum and obtain additional wave-profile information. The experiment was a complete success with the gun firing normally, and containment was demonstrated by both the launcher and the containment systems. The pressure was maintained postshot for approximately 15 minutes and then vented remotely through the HEPA-filter system. All physics diagnostics data were obtained from the target, and the measured projectile velocity was $1.340 \mathrm{~km} / \mathrm{s}$. Accurate wave profile and shock velocity data were obtained, although a feature was observed in the data (particle-velocity relaxation) that was later determined to be due to delamination of the impactor assembly. The target chamber was opened, revealing two punctured shear plates with the third plate bowing more than 1-in. and impacting the fourth plate. Again, the compression of the energy absorber was minimal with an estimated compression of less than $10 \%$. The catch tank was inspected for cracks with magnetic particle inspection and revealed no cracks. The pressure transducer in the front of the EDV recorded a maximum pressure of approximately $2,500 \mathrm{psi}$, and the thermocouples on the breech and catch tank recorded temperature changes of less than $3^{\circ}$ and $70^{\circ} \mathrm{F}$, respectively. Refer to WT-7 test documents for further details on the gun diagnostics.

\subsection{Integrated-System Test 3}

Experiment 3 used $6.75 \mathrm{lb}$ of M14 propellant to launch a $1.5 \mathrm{~kg}$ magnesium projectile at a target consisting of a layered projectile (copper-aluminum) impacting an aluminum baseplate backed by a tantalum-LiF assembly. The layered flyer was used to generate a shock-ramp pressure pulse into a tantalum sample similar to the previous test. The main objective of this experiment was to perform a repeat of the previous shot (using $6.75 \mathrm{lb}$ propellant) with the addition of the use of the explosively driven valve (triggered using upstream electrical barrel probes) to close the containment system. One additional modification included using the new shear disc design as in the previous experiment, but turned around so that the projectile entered the counterbore before impacting the shear plate. In the previous experiment, the counterbore faced the rear of the catch can. The shot was successful with the projectile passing through the valve followed by valve closure. VISAR, pin, and PDV data were all obtained providing shock-ramp data on tantalum. The measured projectile velocity was $1.27 \mathrm{~km} / \mathrm{s}$ at impact and was observed to accelerate from $1 \mathrm{~km}$ to $1.27 \mathrm{~km} / \mathrm{s}$ over the $4 \mathrm{~ms}$. Following the shot, the pressure in the containment system peaked to a value of $400 \mathrm{psi}$ and then decreased to a value of 100 psi that was maintained for approximately 30 minutes. A video was obtained showing that the gun system vented through the bottom flange of the EDV and through the spool piece on the gun side of the EDV (next to the slip tube). A postshot helium-leak check revealed that 


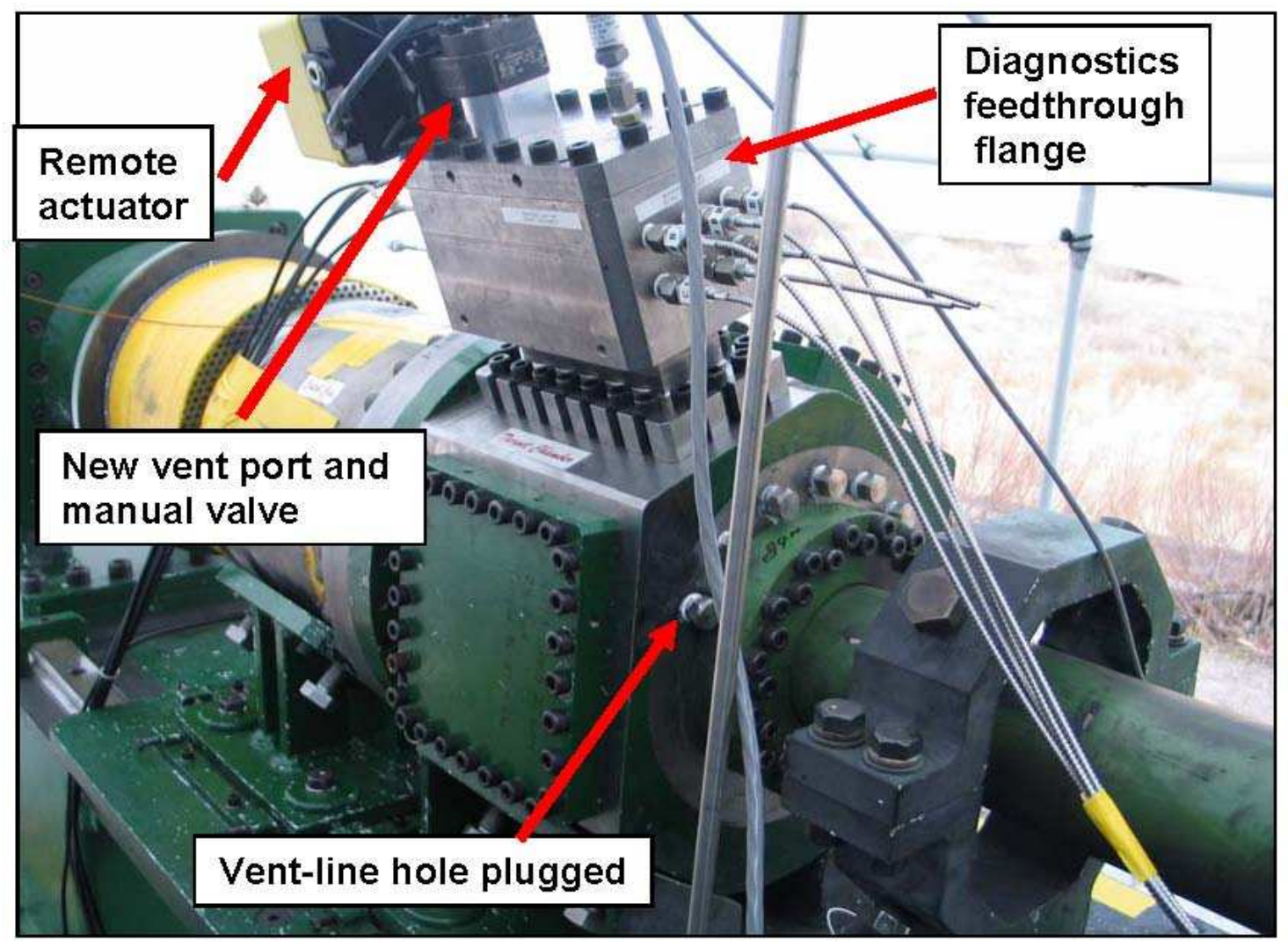

Figure 21: Photos for the integrated-system Test 2 illustrating changes that were made before the experiment. The modifications included moving the vent line to the diagnostics feedthrough flange and protecting it with a ball valve. The original vent line port is shown plugged. 
the containment system was leak tight with the exception of a small leak from the drift tube to the interior breech of the EDV. Thus, no leak was observed to the outside and containment was demonstrated. The launcher system was also found to be leak tight (gun breech and barrel). The containment system was opened, revealing four of the five shear plates sheared near the center consistent with impact of the counterbore region of the plates. One plate was thrown forward into the target chamber with the last one deformed. As in the past two experiments, the energy absorber was minimally deformed. Postshot inspection of the catch can revealed that the diameter was out-of-round by 0.03 -in., yet a detailed inspection did not reveal any cracks.

The containment system was disassembled following the shot, and each part was examined (see Figures 22 and 23). No damage was found on the target chamber, catch can, drift tube, slip tube, spool piece, or launcher system. However, the bolts holding the bottom flange of the EDV were broken. The EDV was removed from the system, and it was found that the piston was seated properly with an aluminum ear curled up on the downstream side of the containment system. However, the piston on the barrel side of the EDV did not show this. Furthermore, the piston was slightly tilted when examined from underneath (tilted away from the breech side). It was suspected that the propellant gases and/or force resulting from the system acceleration preferentially pushed the piston while it was seating in the tapered region of the valve. Regarding the EDV flange bolts, it was hypothesized that the pressure contained in the bottom of the EDV upon closure caused the face-seal on the bottom flange to vent and break the bolts. This in turn could cause enough force on the system to crack the face-seal on the spool piece. Thus, these two design flaws were fixed by adding double-piston seals to the bottom EDV flange and the spool piece.

\subsection{Integrated-System Test 4}

Experiment 4 (test 06nts_07_28) on the complete integrated system was performed using $11.25 \mathrm{lb}$ (75\% breech capacity) of M14 propellant to launch a 1.5-kg magnesium projectile with an aluminum impactor at a standard velocity/tilt target. A single collimated PDV probe was used to monitor the projectile velocity through the containment system up to impact, and five impact pins were positioned about the target: four pins were used for tilt and one for pretrigger. Four of the PZT pins were combined together and used as a backup trigger for the barrel trigger probes that initiated the EDV during flight through the containment system. A single disc of PBX 9501 was used in the EDV, and the standard energy-absorber crush cylinder was used as in the past three experiments. The shear plates were installed in the catch can using the same design as the previous two tests (1-in.-thick plates with a $1 / 2$-in. counterbore in the center) with the counterbore oriented toward the back of the catch can (away from the projectile).

The shot was performed with a measured velocity of $1.795 \mathrm{~km} / \mathrm{s}$ at impact. Venting was observed from the manual ball valve on the top of the EDV and from the vent line attached to the spool piece followed by significant venting from the bottom of the EDV. The gun recoiled the typical 15.2 in. while the containment system recoiled significantly less, resulting in minimal compression of the energy-absorber material. Analysis of the fast-video revealed the following sequence of events: (1) gun and containment both begin to recoil (time $=0),(2)$ during recoil, both the high-pressure vent line on top of the EDV coupled to a manual ball valve (vertically positioned), and the high-pressure vent line on the bottom of the EDV moved and flexed, (3) approximately $700 \mu$ s after the first motion, a breakdown was observed at the high-voltage feedthrough on the EDV, indicating that the EDV was initiated before impact as intended, 


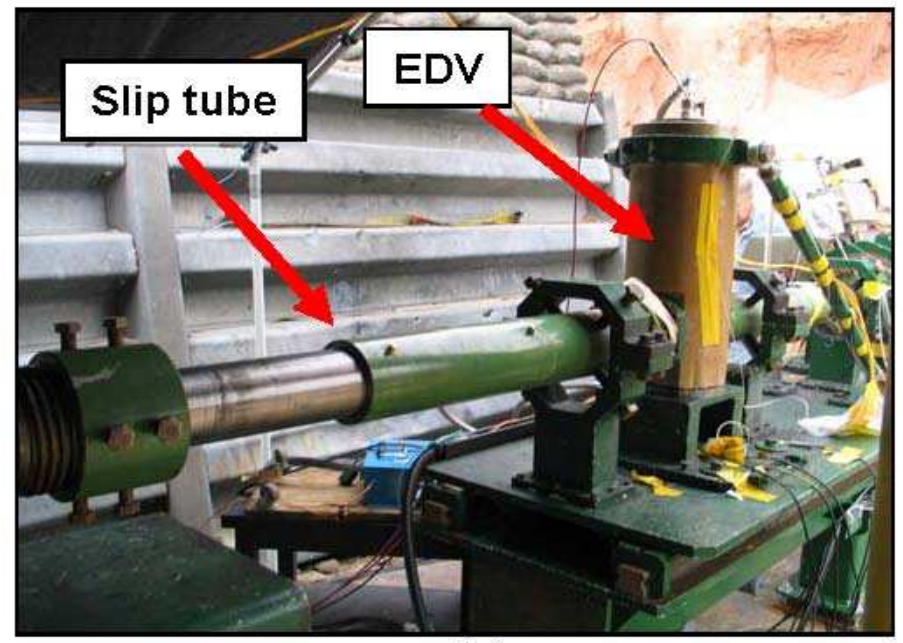

(a)

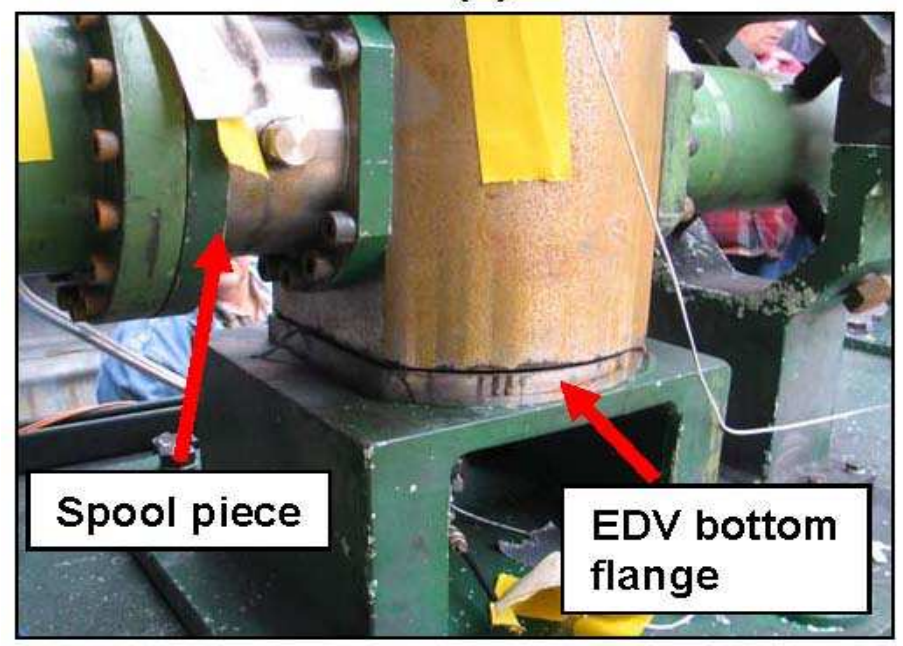

(b)

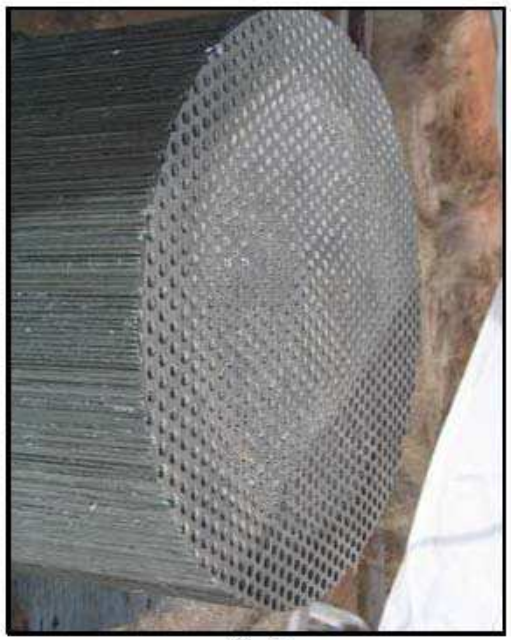

(c)

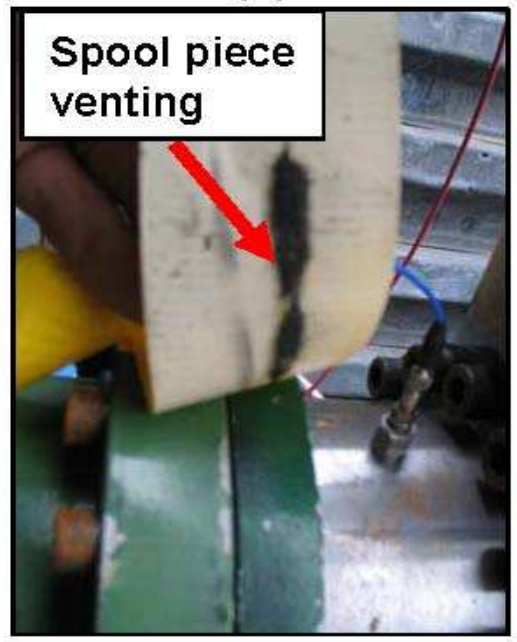

(d)

Figure 22: Photos for the integrated-system Test 3 that illustrate venting on the bottom of the EDV and at the spool piece interface. The expanded slip tube is shown in (a). The aluminum crush cylinder is shown (b) exhibiting minimal compression. Venting was observed from the face-sealed joints of the spool piece and the bottom of the EDV as shown in (c) and (d). The face seals on these joints were replaced with dual piston seals to prevent venting. 


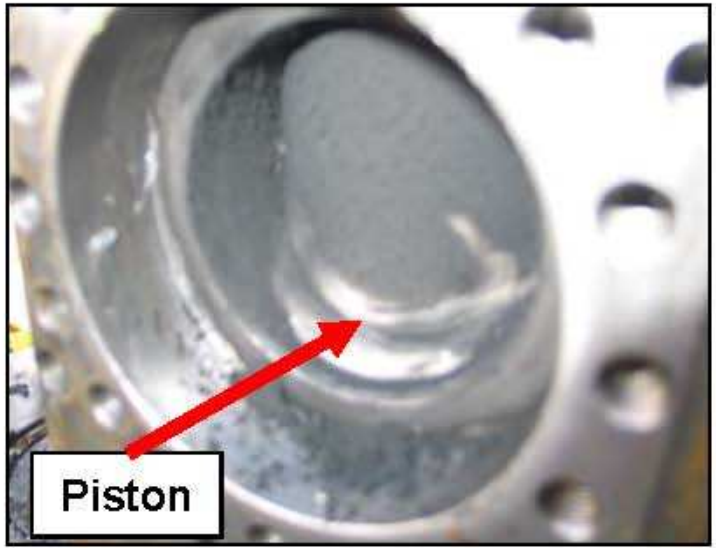

(a)

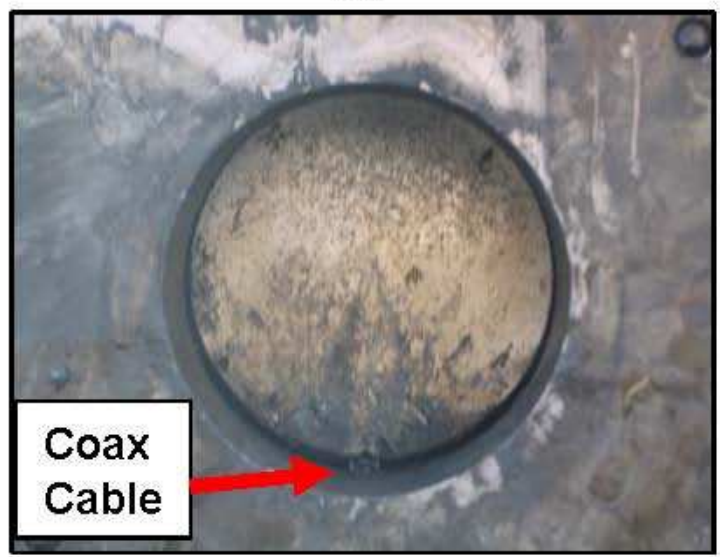

(b)

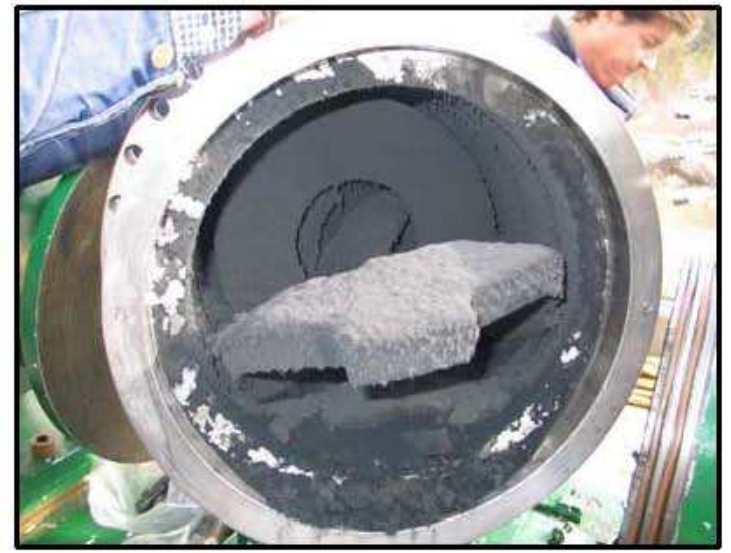

(c)

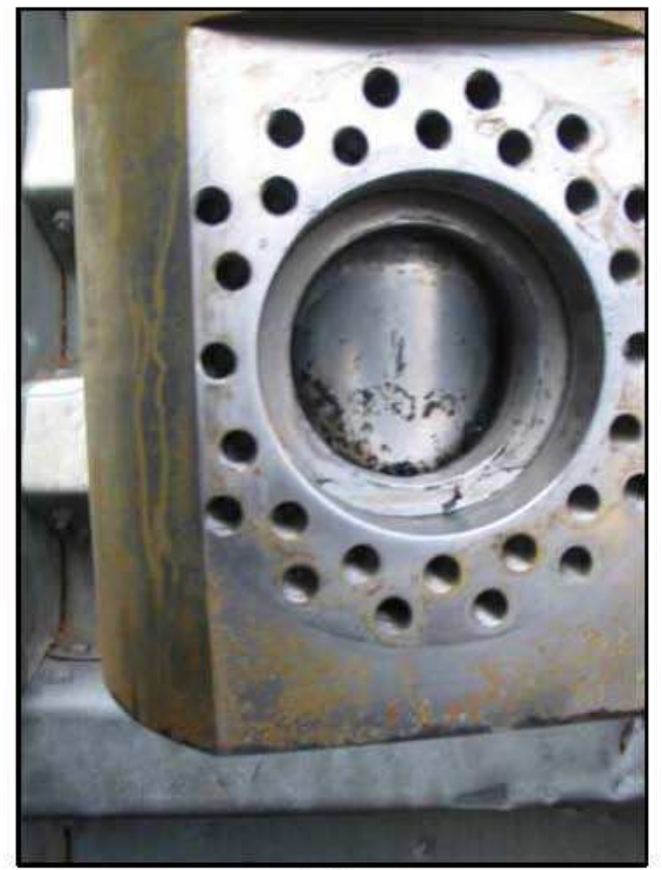

(d)

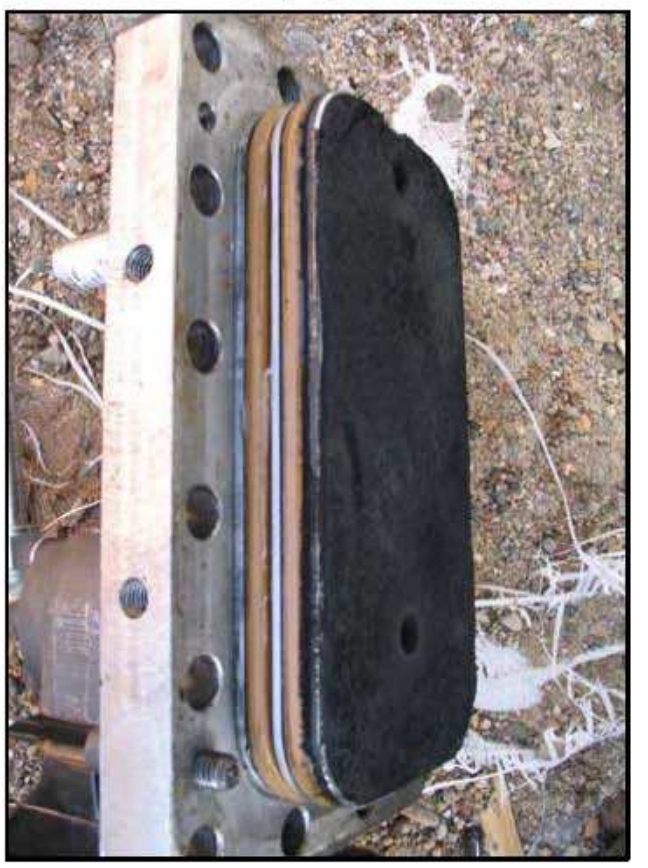

(e)

Figure 23: Photos for the integrated-system Test 3 that illustrate the EDV closure and various O-rings seals postshot. The explosive valve was disassembled during the postshot examination revealing a properly seated piston (a), (b), and (d). The piston exhibited aluminum ears curling up on the containment side (a), but not on the launcher side (d). This is also visible in (b) where a piece of coaxial cable was pulled into the gap during venting. The catch can is shown in (c) along with the shear discs where complete penetration of the five discs was observed. One of the many flanges is shown in (e) where clean O-rings were found with dirt/debris only on the inner side toward containment. 
(4) the back of the catch can impacts the crush cylinder (ejected dust was observed) observed approximately $2.3 \mathrm{~ms}$ later, (5) venting was observed from the top of the EDV at approximately $3.9 \mathrm{~ms}$, (4) bolts from the target chamber and catch-can supports were broken and were ejected from the table (visible around 6-7 ms), (5) venting from the EDV bottom flange and the high-pressure vent line attached to the spool piece begins at approximately $19 \mathrm{~ms}$. Postshot inspection of the target chamber revealed clean O-rings on the flanges, broken bolts that attach the support structure to the chamber, and with all five of the shear plates sheared and deformed. The EDV was removed from the table where the piston was found partially lodged within the barrel area, severely worn away, likely because of pressure flow (approximately $40 \%$ missing), and easily removed by hand. The bolts on the bottom of the EDV (both the flange to the EDV and the EDV to the stand) were found intact and unbroken. Examination of the bottom of the EDV revealed a broken high-pressure fitting.

\subsection{Integrated-System Test 5}

Experiment five used $6.75 \mathrm{lb}$ of M14 propellant and 24 in. of tin-clad MDF (previous MDF was lead clad) to launch a $1.5-\mathrm{kg}$ magnesium projectile with an aluminum flyer impacting the standard tilt/velocity target. This experiment deviated from the original test plan and served as a test experiment for which the main goal was to observe the effect of a delayed EDV closure (a previous test initiated closure before the piston passed through EDV) on the quality of the seal formed in the EDV. The explosively driven valve was initiated using impact PZT pins instead of the barrel probes as an attempt to allow any high-velocity gas/debris to pass the piston to mitigate any effects on closure. Additional EDV modifications included (see Figure 29) using a steel can (or hanger) to position the EDV piston within the valve body and to prevent the highpressure gases from pushing the piston upwards. The vent lines were reinforced structurally, and manual ball valves were included on the spool-piece vent line and the top and bottom of the EDV. In past experiments, minimal deformation of the energy absorber was absorbed, and therefore, in this experiment the diameter of the cylinder was reduced (based on WT7 calculations) to approximately $12 \mathrm{in.} \mathrm{to} \mathrm{increase} \mathrm{the} \mathrm{compression} \mathrm{of} \mathrm{the} \mathrm{cylinder} \mathrm{during}$ deceleration. All diagnostics feedthroughs were installed in the diagnostics flange to provide further dynamic testing of those components.

The shot was successful with the projectile passing through the valve followed by valve closure. The system was vented by opening the manual ball valves and then venting through the HEPA filter system to the outside. Before venting, a gas cylinder was attached to the vent line, and a sample of the venting gas was taken for analysis. The impact pin and PDV data were obtained providing both projectile tilt and projectile velocity for approximately $8 \mathrm{~ms}$ up to impact with an impact velocity of $1.271 \mathrm{~km} / \mathrm{s}$. A post-shot helium leak check revealed that the containment and launcher system was helium-leak tight. Analysis of the velocity data also revealed a possible perturbation in the piston velocity as the projectile passed through the containment. The velocity data were integrated back in time to estimate the projectile position at the time of the perturbation, and it was found that this occurred near the EDV. The containment system was disassembled following the shot, and each part was examined. No damage was found on the target chamber, catch can, drift tube, slip tube, spool piece, or launcher system. Three of the five shear plates were sheared/deformed with minimal damage to the last two plates. Upon removing the EDV from the system, it was found that the containment side of the piston seal looked normal with an aluminum ear on the down side of the barrel. In contrast, the barrel side of the EDV seal did not show this similar to Test \#3. Also, the piston, though seated, did not penetrate as far in the valve (toward the bottom 


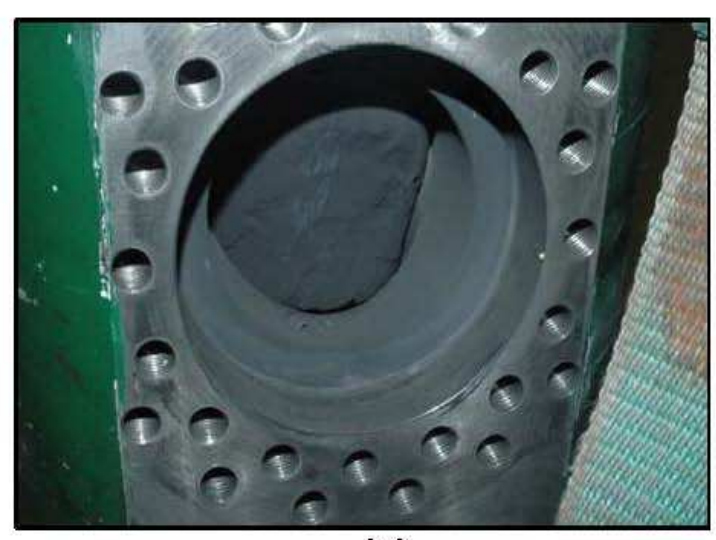

(a)

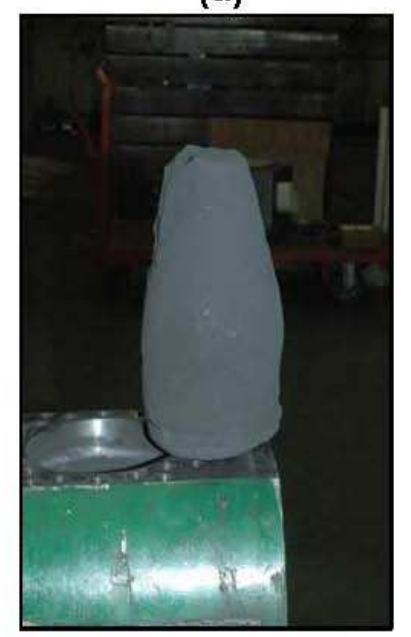

(c)

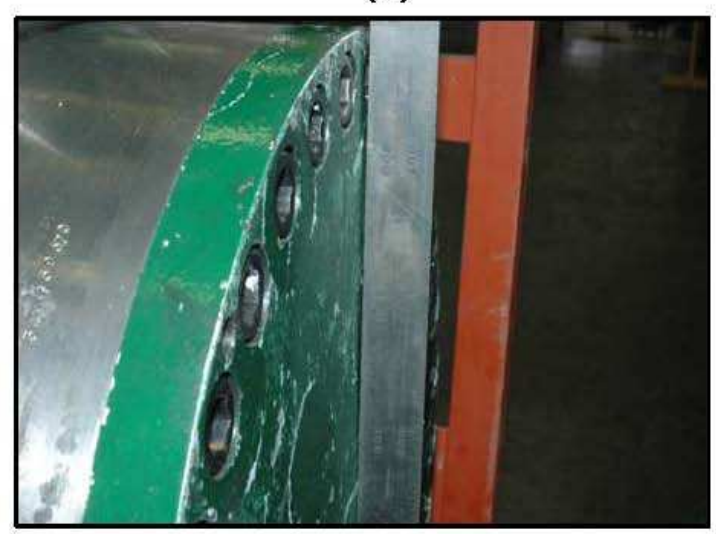

(e)

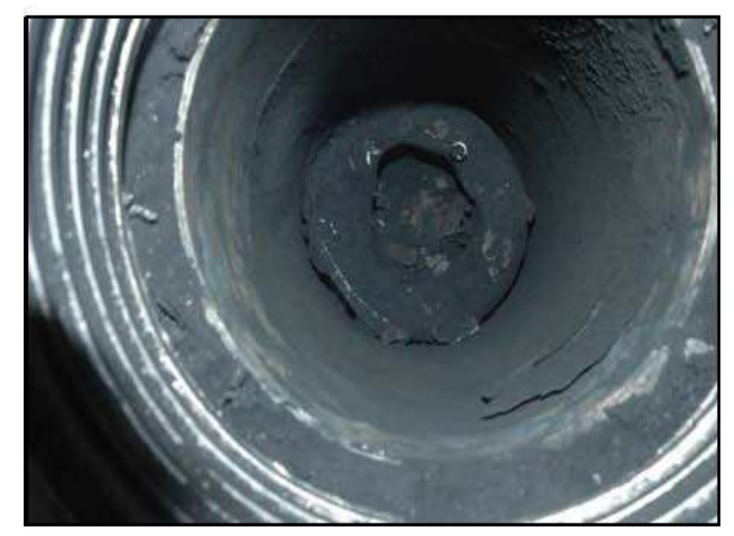

(b)

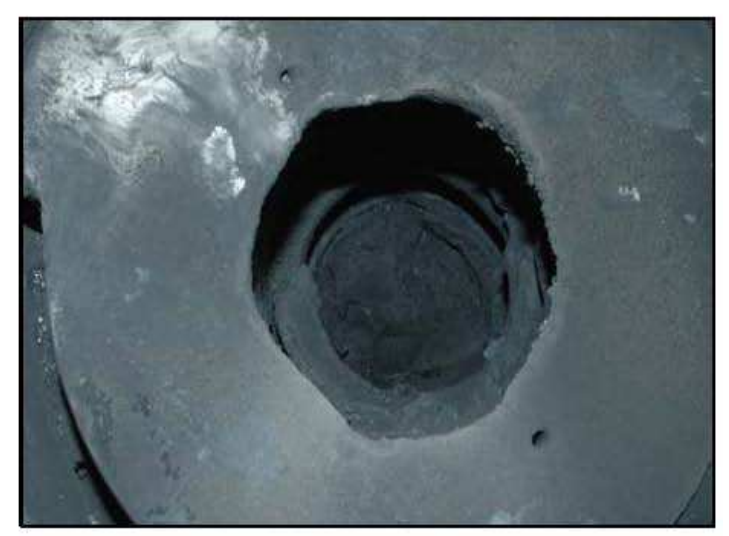

(d)

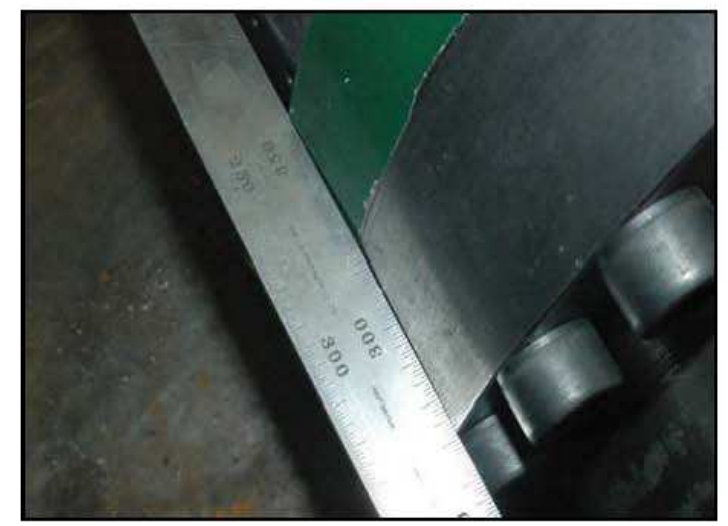

(f)

Figure 24: Photos for the integrated-system Test 4 that illustrate the problems with the EDV closure and bending of the catch-can flange. The photo in (a) shows the explosively driven valve looking through the drift tube port that shows the valve piston partially lodged in the barrel axis. The photo in (b) shows a view looking down through the EDV breech where the piston hanger and back of the piston are visible. The piston was removed easily (see photo in [a])and significant erosion was observed due to propellant gases. Figures (d), (e), and (f) show the shear plates, the back of the flange, and the target chamber and catch-can flange ring, respectively. 


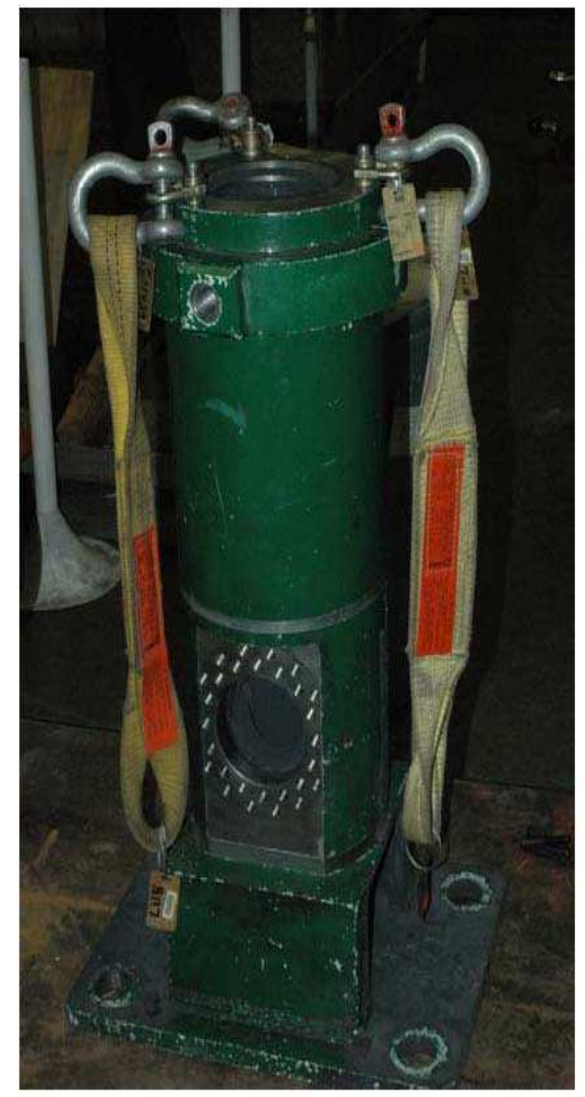

(a)

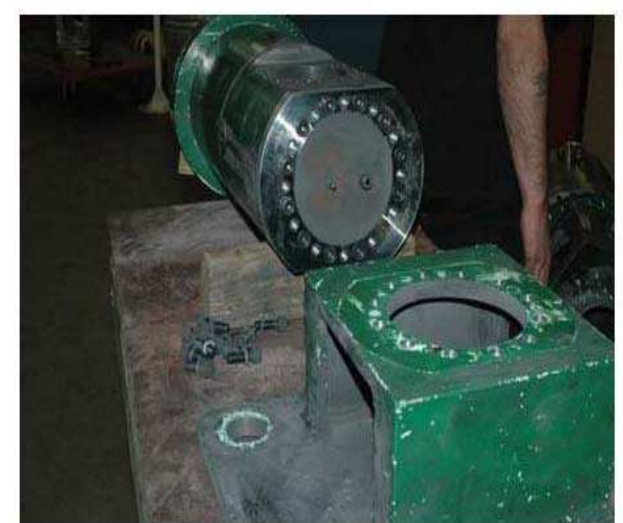

(b)

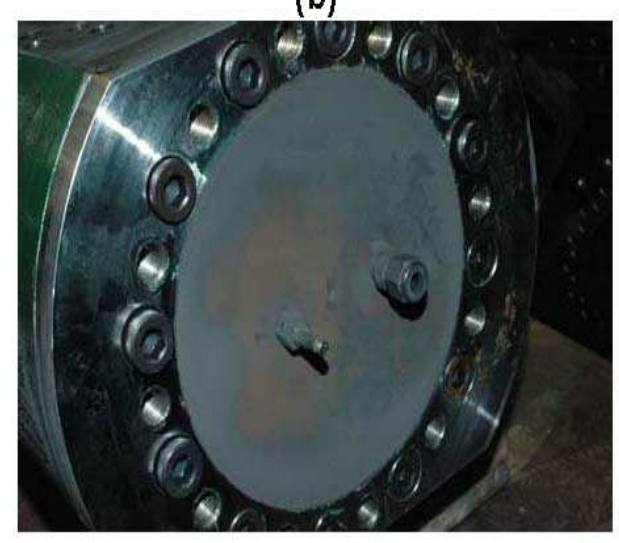

(c)

Figure 25: Photos for the integrated system Test 4 illustrating the disassembly of the EDV following the test. The entire explosive valve body is shown in (a) along with various bottomviews in (b) and (c). 

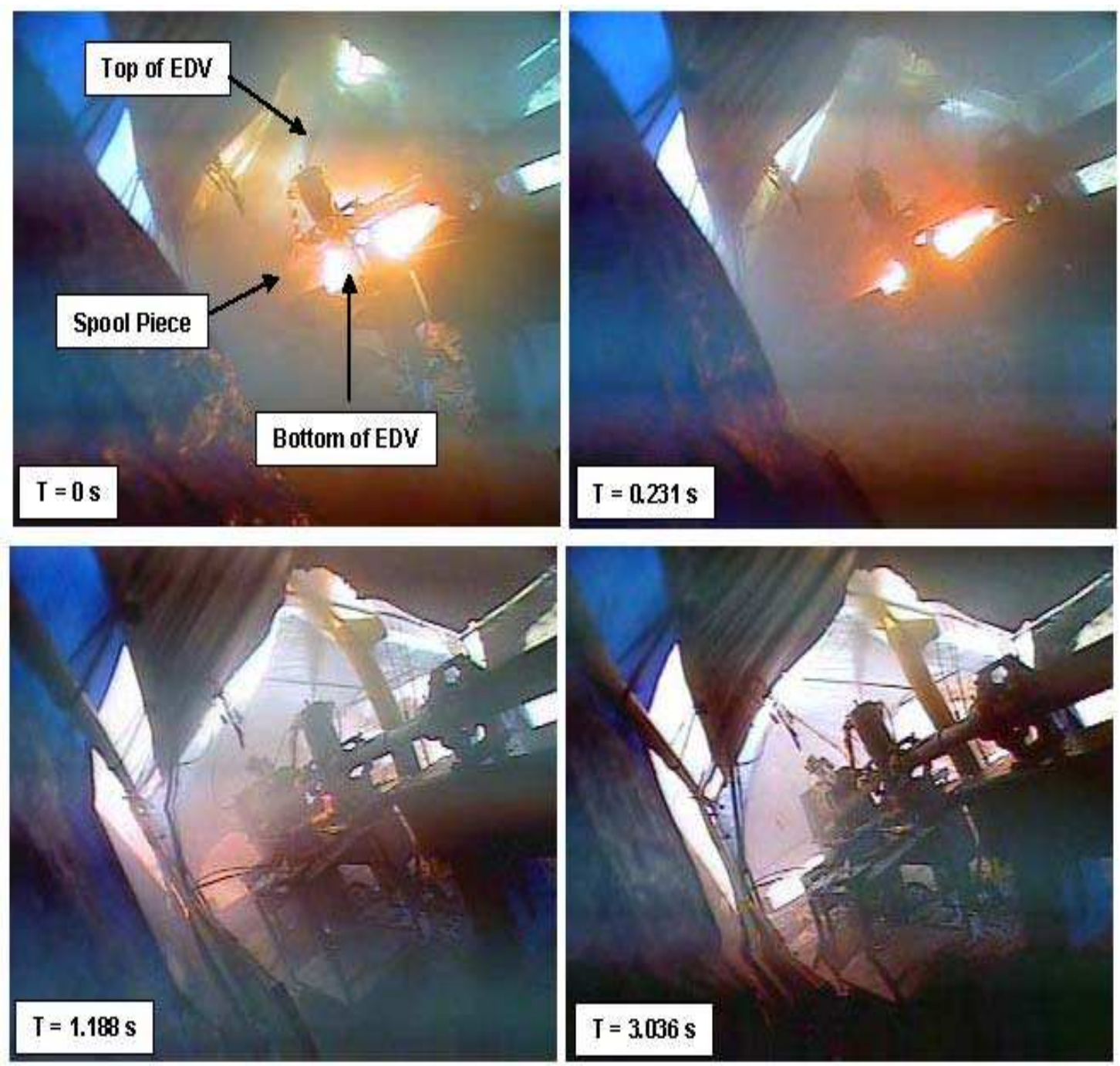

Figure 26: Video frames obtained for LBPG integrated-system Test 4 using a standard video camera. Four frames are shown that span a total of 3 seconds of time during the tests where the top-left frame shows the initial venting occurring from the three areas near the EDV: the vent line on top of the EDV for the EDV breech, the bottom vent line of the EDV, and the vent line on the spool piece that would vent the launcher system. 

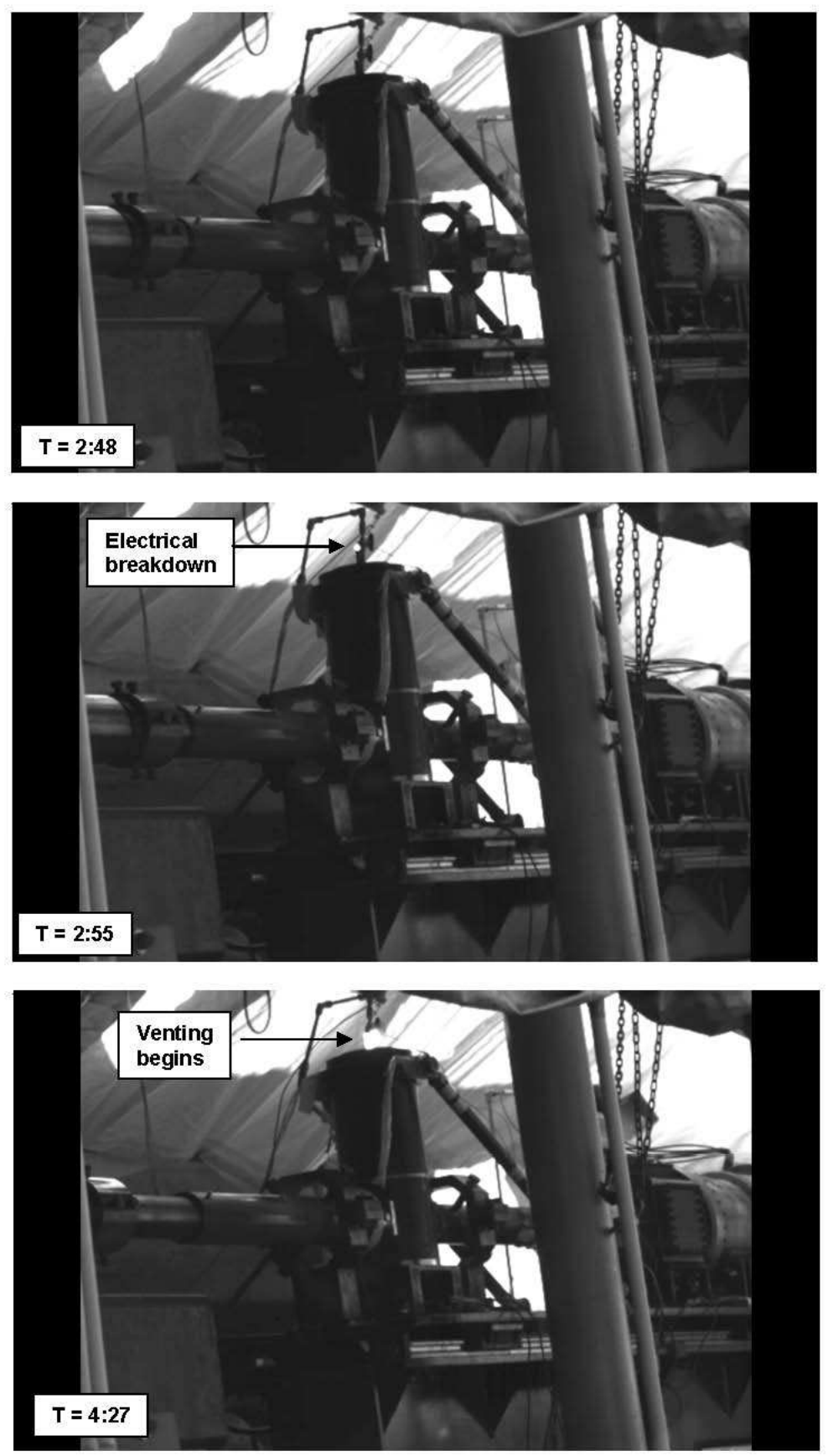

Figure 27: Video frames obtained for the integrated system Test 4 using a high-speed Phantom video camera. The top frame shows the gun just before recoil. The second frame shows the electrical breakdown observed from the high-voltage feedthrough used to initiate the explosive for the explosively driven valve. This frame also shows the beginning of recoil of the launcher barrel. The third frame shows significant barrel recoil along with the initial venting from the top of the EDV. An analysis of the video (frame-by-frame) clearly shows that the vent line was broken during acceleration of the containment system. 

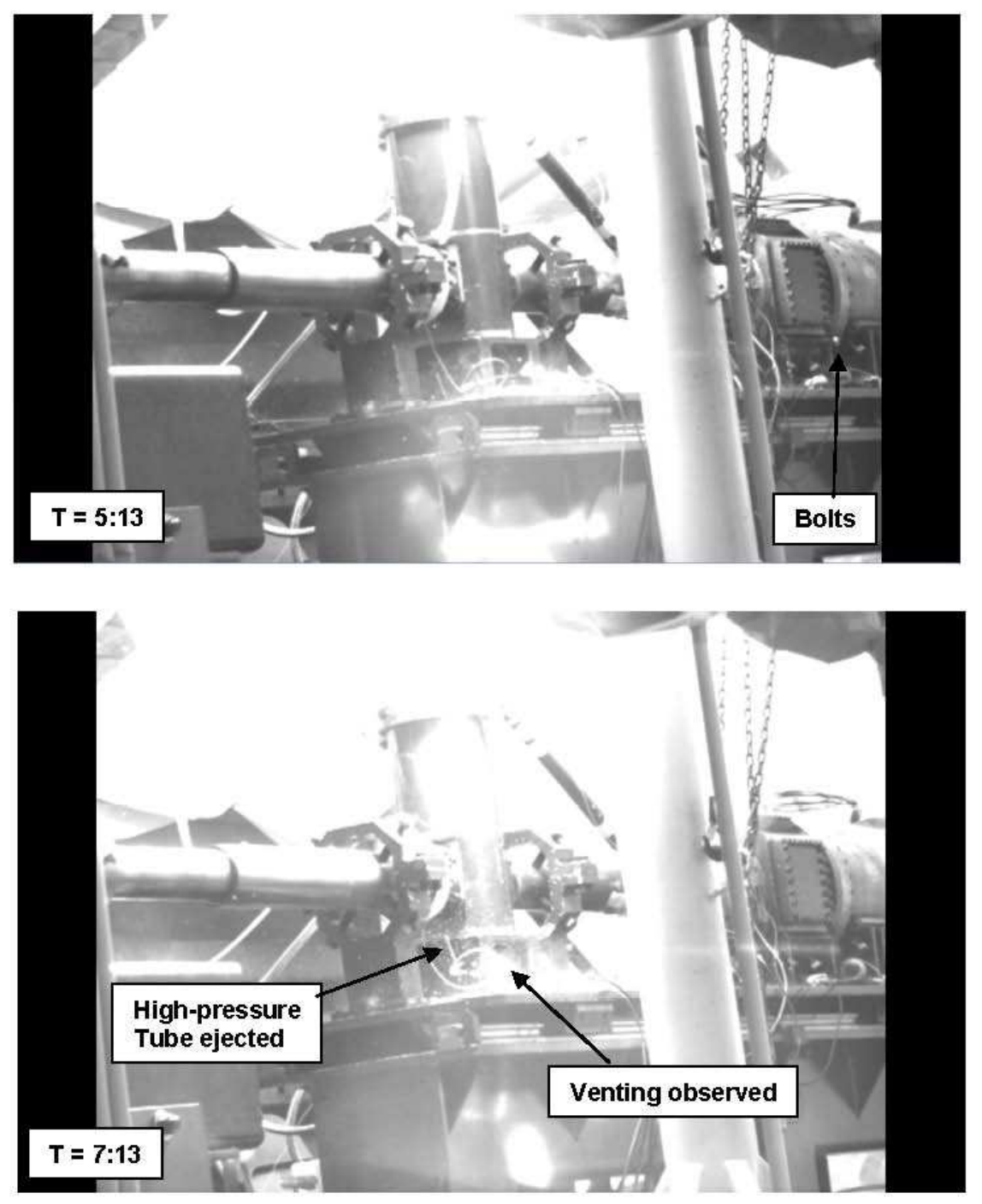

Figure 28: Video frames obtained for integrated-system Test 4 using a high-speed Phantom video camera (continued from the previous figure). The top frame shows the initial venting from the top of the EDV along with a bolt ejected from the target chamber supports. Boltbreaking was frequently observed as a result of motion between the containment assembly and the table during acceleration/deceleration. The bottom flange shows the venting from the bottom of the EDV. Analysis of the video (frame-by-frame) shows that the the bottom vent line was broken during acceleration of the system, and a length of the high-pressure tubing is visible as it is thrown from the table. 


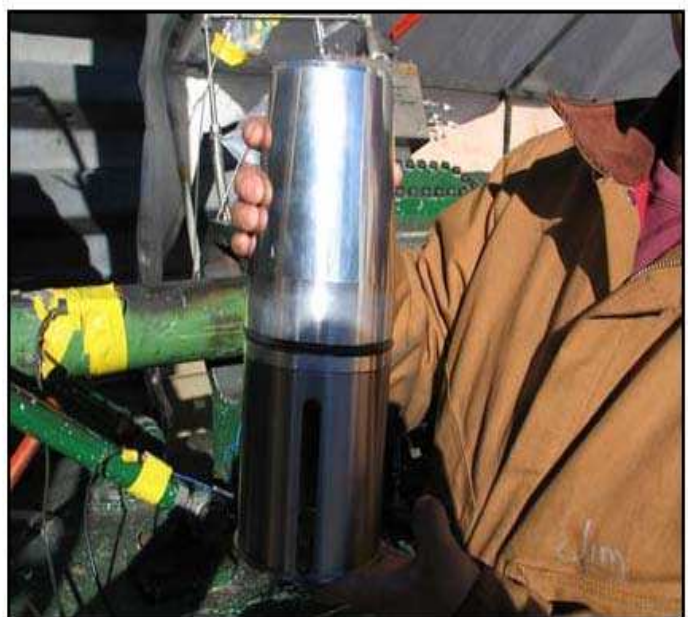

(a)

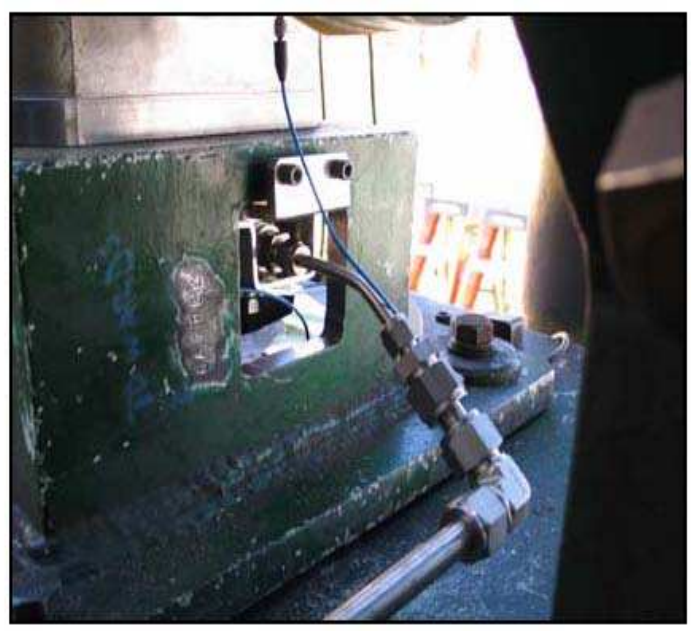

(b)

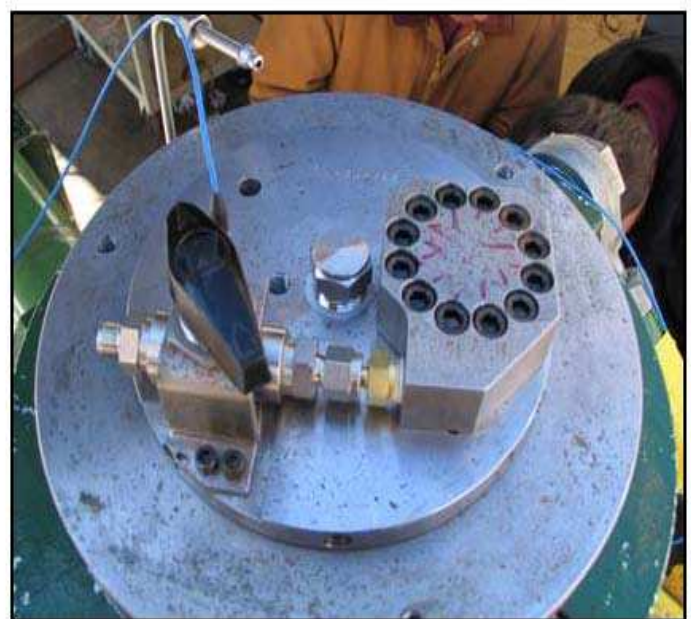

(c)

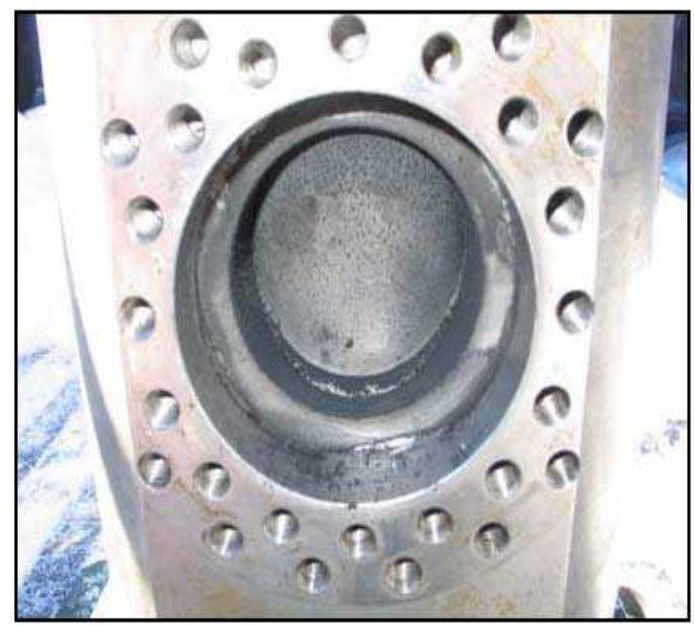

(d)

Figure 29: Photos for the integrated-system Test 5 showing additional modifications and the postshot photos of the EDV. The new EDV piston and hanger configuration is shown in (a). The modifications to the top vent on the EDV include reinforcement of the input connection along with a manual valve to isolate the breech from the vent line. Similar modifications were made to the bottom vent line to prevent breaking during acceleration. The closed EDV is shown in $(\mathrm{d})$. 


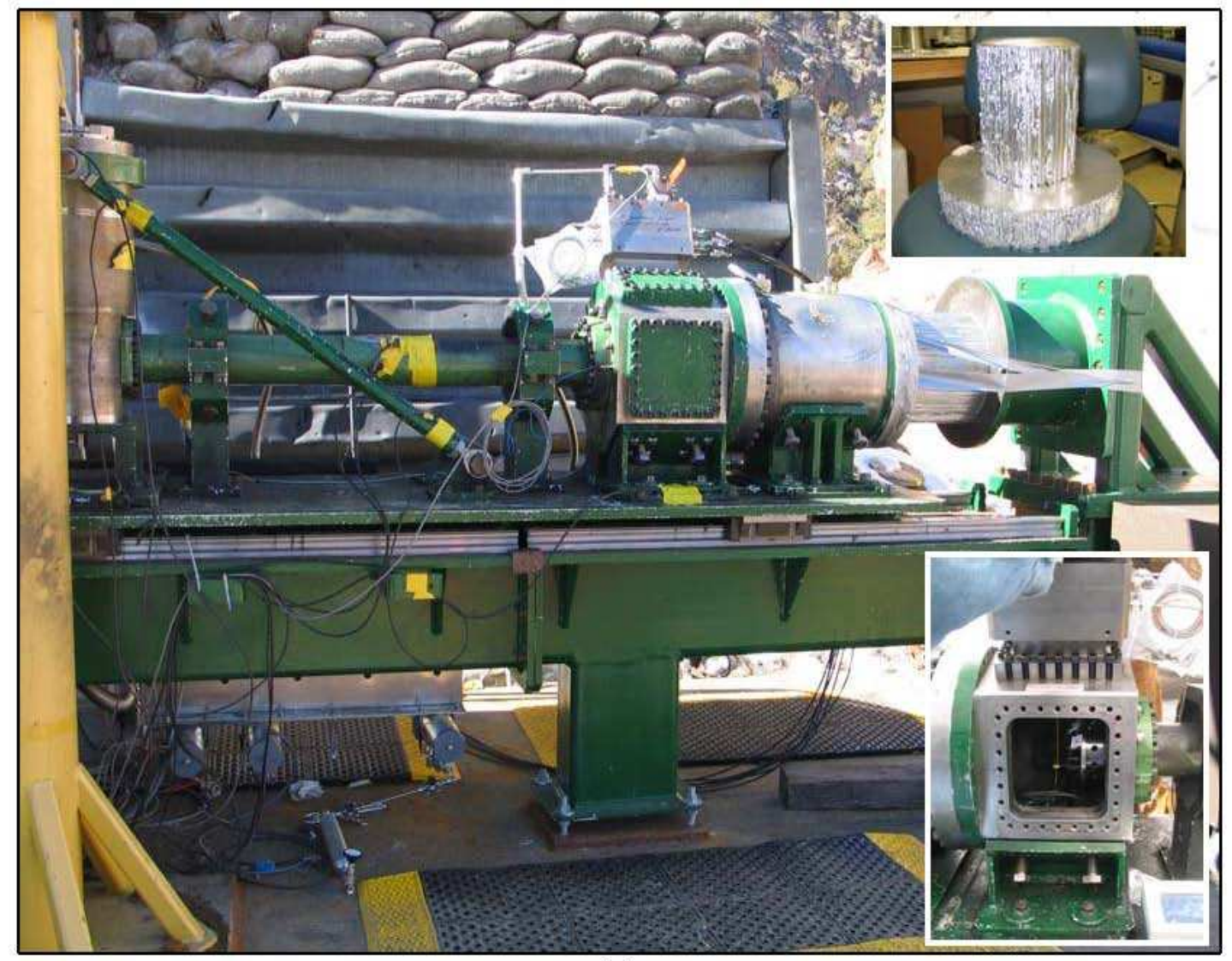

(a)

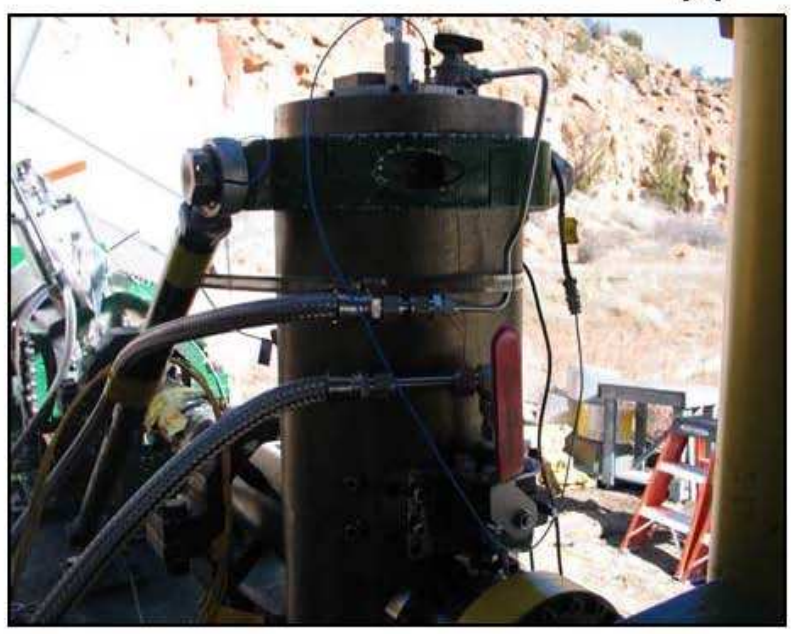

(b)

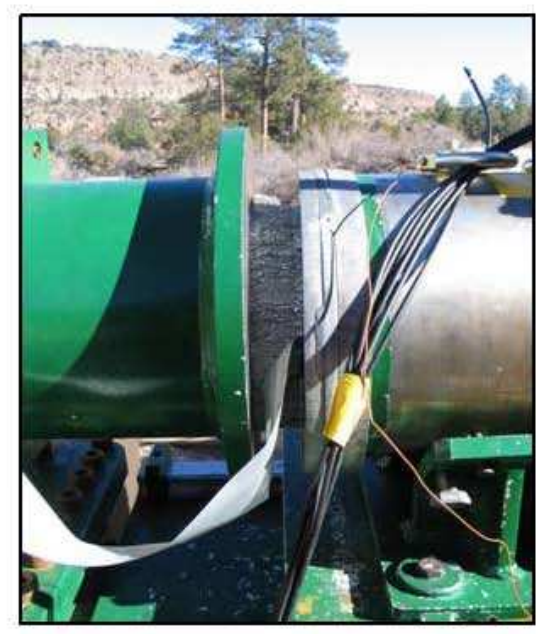

(c)

Figure 30: Photos for the integrated-system Test 5 showing the preshot containment setup along with various modifications. In (a), the containment system is shown that includes the new aluminum crush cylinder that was machined to a smaller diameter to increase the compressibility. The inset photo (top) shows the crush foam postshot where the center did not crush because of the hole in the backstop. The EDV is shown in (b) where the modifications to the vent lines are visible, including the strengthening of the top and bottom EDV vents and the manual ball valve used to isolate the spool-piece vent line from the barrel pressure. The crush foam is shown in (c) postshot. 
flange) as it did in the stand-alone EDV shots[1]. The catch can was disassembled, and the shear plates were inspected with results similar to those observed in Test 3. As shown in Figure 30 , significant compression of the energy absorber (greater than $75 \%$ ) was observed, and the video revealed a less violent deceleration of the system during the experiment. Thus, based on the observations in this test, the following conclusions were made: (1) delayed triggering of the EDV did not affect the outcome of the experiment, indicating that the pressure pulse that affects the EDV piston closure persists and/or possibly indicating an additional effect because of system accerlation/deceleration on the EDV piston, and (2) the EDV reliably closes for breech propellant loads of up to $7 \mathrm{lb}$.

\subsection{Integrated-System Test 6}

Experiment six (shot \#06nts_08_35) used a total of 9 lb of M14 propellant to launch a 1.556$\mathrm{kg}$ magnesium projectile with an aluminum impactor into a containment system closed using the EDV. The ability to seal the containment system was established in the previous test of up to $7 \mathrm{lb}$ of propellant. Thus, the purpose of this test was to extend the working range of the integrated system to $9 \mathrm{lb}$ of propellant using the same EDV configuration as the previous tests where 55 grams of PBX 9501 were used to drive the EDV piston. Before this shot, attempts were made to extend the working range of the EDV to higher HE loads (two discs or greater of 9501), but in all cases the high-voltage feedthrough and vent valves were compromised. The standard velocity target was used with four PZT pins for tilt and one PZT as a standoff trigger. One collimated PDV probe was used to monitor the projectile velocity up to impact. As in the previous experiment, the energy-absorbing cylinder was reduced to a diameter of approximately 9-in., based on WT-7 calculations.

The experiment was performed with a measured projectile velocity of $1.581 \mathrm{~km} / \mathrm{s}$. Fast video along with various strain gauges, accelerometers, and temperature gauges were fielded. An initial pressure spike was observed of approximately 1,000 psi, and the energy-absorbing material was completely compressed, and fast video showed a very gentle deceleration as compared to earlier testing. Immediately postshot, the containment system and gun system appeared to hold pressure, indicating a successful shot, although there was a very small decrease in pressure in the volumes over a 10-15 minute time duration. The gun was inspected before announcing the all-clear, and two leaks were observed: (1) one leak near the manual ball valve on the EDV (spool piece-upstream) and (2) one leak on the EDV breech (vent valve). It was later discovered that the bolts that secured the valve to the EDV body had been mistakenly removed just before the test, and therefore, the movement of the containment system likely caused the valve to fail resulting in a very small leak after the test. Following the initial inspection, it was decided to begin the venting process by first venting the containment system followed by the EDV (top and bottom) and then the barrel. During the first venting step, it became apparent that all volumes were venting simultaneously (through the HEPA filter system) indicating that the EDV did not close. This was confirmed during the final disassembly and inspection process that revealed a worn piston (See Figure 31) that was only partially lodged in the barrel area (similar to Test 4). In addition to the observed leaks on the firing point, examination of the fast-video revealed a momentary venting of gas that originated at the interface between the catch can and the target chamber (see Figure 32). Inspection and discussions revealed that the O-rings at that interface (those between the catch-tank and target chamber) were not changed before the shot (according to WT-7 approval) and that a metal film covered both O-rings likely as a result of molten magnesium from the projectile. The fast video shows the hot gas jet propagating from that interface and through a hole in the target chamber area used for target-catch can 
disassembly. The jet impacted the side target flange and moved both up and down giving the initial impression that the gas also escaped from the side flange. Inspection of the catch can revealed three completely penetrated shear plates and two deformed plates.

Although the EDV closure of the containment system was not successful, this experiment represented a significant milestone in proving that the entire integrated system can function properly as primary containment at higher breech powder loads; the containment system was able to withstand the effects produced by $9 \mathrm{lb}$ of propellant. In addition, the observed venting (though small) and momentary burping reinforces the need for strict oversight and proper procedures in setting up and performing an experiment on such a complex system. Current efforts following this test were focused on examining the data from the past six integratedsystem tests coupled with calculations performed by WT-7 to understand the dynamics within the containment system. In addition, work is now underway to increase the performance range of the EDV to achieve higher velocities to better disrupt the high-pressure gas flow behind the piston. Hybrid tests on a standalone EDV using propellant and explosives are underway to accomplish this[1].

\subsection{Integrated-System Test 7}

Test 7 was performed in June of 2008 with a new operations leader (D. Hof, DE-9) for the launcher, a new lead engineer (R. Valdiviez, WT-7) for containment, and a new gun team to support the operation. The test was denoted the "flow-interrupter test" because the goal was to operate the EDV using a hybrid charge[1] in an attempt to reach higher EDV piston velocities to penetrate the flow within the barrel. Apart from the new EDV configuration, the other experimental parameters were similar to Test 4 where venting from the bottom of the EDV was observed (See Figure 26). Before the test, the possibility of venting from the top of the EDV was discussed from the high-voltage feedthrough and it was pointed out that the EDV had not been tested in the proposed configuration using a hybrid charge. Tests had been performed using a valve body with the tapered stop removed[1]; therefore, it was not known beforehand whether it was possible to stop the faster-moving piston to prevent it from hitting the bottom of the valve. Despite these facts, the new operations leader and lead engineer had confidence that the system was contained allowing the test to be performed during red-flag conditions without the fire department present (normally there is no firing during dry conditions and high winds). Venting occurred from the bottom of the EDV that initiated a fire in the nearby grass resulting in the Ancho Canyon fire that burned approximately 15 acres of wild land. A postshot investigation revealed that hot gases originating from the EDV were the cause of the subsequent fire and pointed to poor communication by the participants as one of the main causes for the incident[16].

\section{DISCUSSION, SUMMARY, AND CONCLUSIONS}

Twenty-four experiments were conducted on the large-bore powder gun to qualify the gun for future experiments to be performed at the U1a complex of the Nevada Test Site. Experiments were performed to measure the projectile velocity, recoil distance, breech strain, and impact tilt for powder loads ranging up to $16 \mathrm{lb}$ of M14 propellant. In some experiments, additional measurements were performed to examine the dynamic melt boundary for shocked cerium metal and to demonstrate the ability of the gun to obtain accurate shock-wave data. Overall, the experiments discussed here were successful. Projectile velocities were obtained up to a maximum 

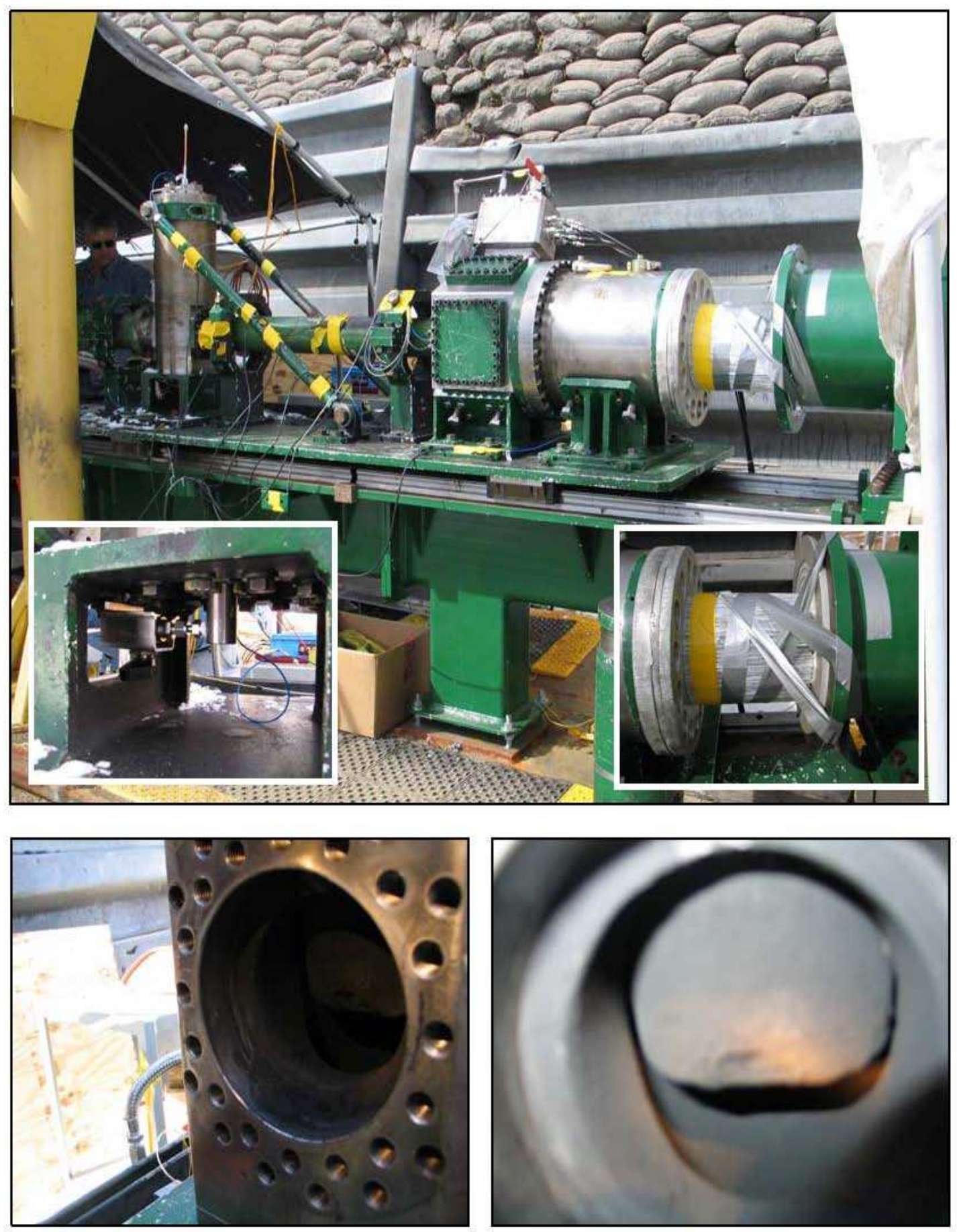

Figure 31: Photos for integrated-system Test 6 showing the preshot configuration and the piston in the EDV postshot. (Top) Shows the containment system before the test along with (insetleft) a photo of the reinforced vent lines under the EDV and (inset-right) the aluminum crush foam. Post-shot photos of the EDV after disassembly (bottom) showing the piston partially lodged into the barrel, but not properly seated. Significant erosion of the piston is visible because of the propellant gas. 

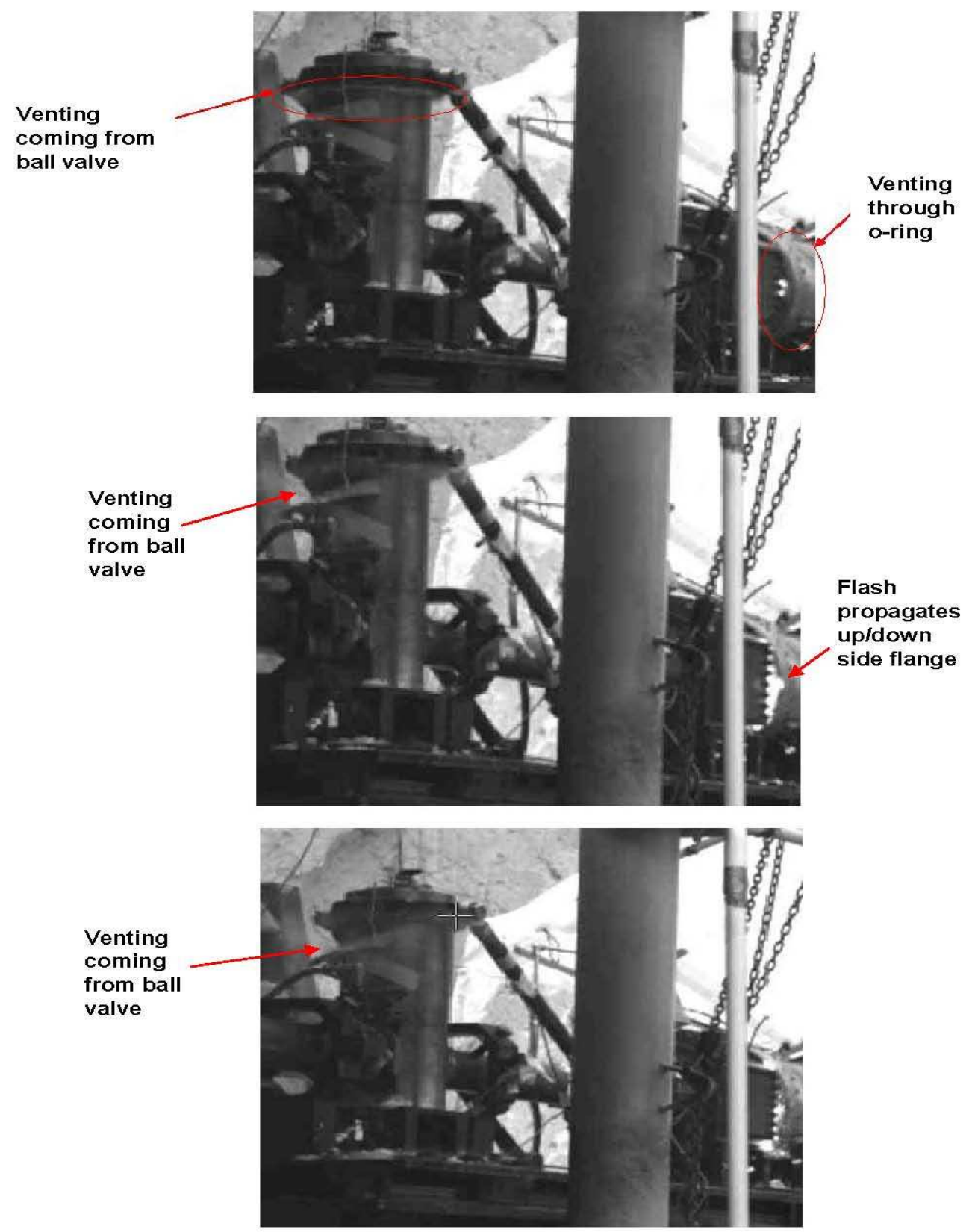

Figure 32: Photos for the integrated-system Test 6 obtained from the fast video that shows venting from a ball valve and at the interface between the target chamber and catch can (approximately $100 \mu \mathrm{s}$ per frame). The photos show venting from the manual ball-valve area (attached to the EDV). This vent was likely damaged during motion of the containment system. Burping of hot gases is observed to come from the target-chamber catch-tank area. Postshot examination revealed metal on the O-ring between the two components, and it was later verified that the O-ring had not been changed. 
value of $2.32 \mathrm{~km} / \mathrm{s}$ with an average tilt of approximately one mrad. The velocity data were used to develop the gun performance curve that relates the projectile velocity to the propellant charge mass and the projectile mass.

Six experiments were performed on the LBPG integrated system to test the performance of the gun coupled to the containment system that used an explosively driven valve to seal the containment system and to prevent contamination to the outside. The test series was based on the initial test plan that outlined five experiments to be performed throughout the operating range of the gun (up to $15-16 \mathrm{lb}$ of propellant) with the first and last experiment performed without the EDV. In the first experiment, a low-propellant charge was used to launch a magnesium projectile into the containment system. The EDV was not used in this test with the goal to examine the pressures in the entire system postshot and to verify that the integrated system could remain helium-leak tight throughout the experiment in the event of EDV failure. During the test, venting was observed from the high-pressure vent lines on the target chamber because of the close proximity of the vent line to the high-pressure and hightemperature impact event. The vent lines were removed from the target chamber and isolated, using manual ball valves before the second experiment. Test 2 was a repeat of the first and was completely successful. Test 3 used the same amount of propellant and projectile mass as Test 2, but used the explosively driven valve to seal the containment system. The experiment was successful in achieving containment, but venting was observed at the spool piece and the bottom of the EDV (both surfaces had face-seal O-rings) that allowed the launcher to vent to the atmosphere. These interfaces were strengthened using double-piston sealing O-rings. Test 4 was similar to Test 3 and used a total of $11.1 \mathrm{lb}$ of propellant ( $75 \%$ breech capacity). The containment system contained the impact event, demonstrating it's robustness, but venting was observed from the high-pressure vent lines on the top and bottom of the EDV and the vent line coming from the spool piece connecting the EDV to the barrel. Analysis of the fast-video data clearly showed that the vent lines were broken during the acceleration of the containment system. These joints were reinforced, and the spool-piece vent line was isolated using a manual ball valve. In addition to the venting, the EDV did not seal the containment and was found only partially lodged in the tapered region of the valve.

These first four experiments established a high degree of confidence in the robustness of the containment system in handling the impact event without loss in structural integrity. However, problems were arising in the EDV performance and it's ability to seal the containment system, and thus, establishing the reusability feature of the large-bore gun. It was hypothesized that the high-pressure, high-velocity propellant was affecting the valve performance because it was observed that the EDV piston in Test 3 was preferentially wedged into the tapered region toward the target chamber. Thus, experiment five was performed as a test experiment (using Test-3 parameters) with the goal of observing the effect of delayed EDV triggering on the valve performance. Impact pins were used to trigger the EDV, providing significant delay time (greater than $1 \mathrm{~ms}$ ) following the impact event. The experiment was successful with no observed venting and a completely contained system. The EDV was disassembled, revealing similar results as those observed in Test 3: a completely seated piston preferentially leaning toward the target chamber. This fact may point to the possibility that the accerelation/deceleration of the entire containment system may also be affecting valve closure. However, further analysis is required to justify this statement. Following this test, the Test 6 was performed using $9 \mathrm{lb}$ of propellant and a delayed EDV trigger to determine whether this trend would extend to the higher propellant loads. The test was performed with the event completely contained in the integrated system with pressure holding for more than 15 minutes before manual venting. During venting, it became apparent that the entire system, gun and containment, was venting 
simultaneously, indicating that the EDV did not properly close. Postshot inspection confirmed this. Thus, it was concluded that the Large-Bore powder gun integrated system could withstand experiments up to $75 \%$ breech capacity (higher propellant tests had yet to be performed), but the EDV was unable to seal the system for propellant loads above $50 \%$ capacity. It was clear that for the LBPG Integrated System to become a useful and qualified system, the issues related to the fast-closure mechanisms must be addressed.

Following this six-experiment series, the project postponed further gun testing (4/2008 to 6/2008) while examining the performance of the EDV. Calculations were performed by WT-7 to assess the valve performance, and it was discovered that the calculations predicted closing problems for breech pressures exceeding $7 \mathrm{lb}$ using only one disc of explosive to drive the EDV piston (all EDV tests used one 55-gram disc of PBX 9501). Thus, while calculations were proceeding, an experimental effort began to learn how to drive the EDV piston to higher velocities[1]. Experiments were performed on a modified EDV (the tapered region was removed to reduce the turnaround time and costs) using a hybrid charge consisting of one disc of PBX 9501 to retain the low-jitter fast closing action of the valve and fast-burning gun propellant (IMR 4350) to increase the magnitude and time duration of the breech pressure in the valve. In addition, a deflector plate was built into the charge design to protect the breech plug and the high-voltage feedthrough from the dynamic event. These experiments were successful with the final experiment using 250 grams of IMR4 350 propellant and 55 grams of PBX 9501 to drive the piston to a velocity of $0.4 \mathrm{~km} / \mathrm{s}$ before exiting the EDV body, demonstrating a significant increase in the EDV performance. Note that a stand-alone test on a complete EDV system was not performed using this hybrid charge.

In May 2008, changes were implemented to allow the engineering design authority (WT-7) to pursue a more rigorous engineering design/analysis approach for the large-bore gun system. This approach would use advanced computer modeling to design and qualify the complete gun system as opposed to the experimental approach and would take advantage of the large body of data already obtained on the large-bore system to provide a final product ready for experiments at the Nevada Test Site. Simultaneously, the physics team (DE-9) began a renewed effort to pursue the physics aspects of the LBPG project that included the use of complex loading to examine the multiphase equation of state for materials - an effort that had been delayed because of the burden of performing the gun-qualification testing. Gun-system testing resumed in June of 2008 with a seventh integrated-system test performed by the new lead engineer (R. Valdiviez, WT-7), which resulted in the Ancho canyon fire. Following this test, the large-bore powder gun operations were suspended pending a complete investigation of the incident[16]. Work is now underway (6/2008 to present) to perform a more complete engineering analysis of the entire integrated system and to develop a path forward for qualification. Testing is scheduled to resume in February of 2009 with a new integrated system that will include a colliding piston EDV to act as a flow interruptor followed by the standard EDV to provide system closure. At the same time, work has begun with KTech Corporation to design and test an explosive pinch-off valve, similar to the valves used on JASPER, to mitigate the risk of the dual-valve concept failure.

In summary, the LBPG project has been a remarkable success with a total of 48 experiments performed to date. Within three years, an EDV had been developed and tested[1], and numerous experiments had been performed on the LBPG (both the prototype gun and the actual launcher) reaching velocities greater than $2.25 \mathrm{~km} / \mathrm{s}$ (maximum $2.32 \mathrm{~km} / \mathrm{s}$ ) and establishing the capability for performing well-defined and highly accurate plate-impact experiments. Furthermore, a prototype containment system was designed, fabricated, and tested. Although the 
tests revealed numerous engineering flaws, these problems were easily corrected, resulting in a robust integrated system capable of containing the intense environment because of the impact event, the high pressures, high temperatures, and high-velocity propellant. EDV closure was successful for powder loads up to approximately $7 \mathrm{lb}$, providing a reliable system for velocities up to $1.3-1.4 \mathrm{~km} / \mathrm{s}$. Effort is now underway to improve or redesign the fast-closure mechanisms to increase the reusability range of the gun from $1.3 \mathrm{~km} / \mathrm{s}$ up to the maximum required velocity in the $2-2.25 \mathrm{~km} / \mathrm{s}$ range. Currently, the LBPG is being moved to an indoor facility at Los Alamos to finish the qualification testing, and to provide a platform for future qualification tests (targets, diagnostics, etc.) and physics experiments. A second LBPG system that incorporates the final design will be fabricated, following the final qualification test series, with an expected delivery date of 10/2009-1/2010 to the Nevada Test site.

\section{ACKNOWLEDGMENTS}

This work was in support of the NTS powder gun project to be conducted at the U1a complex at the Nevada Test Site. The development of the LBPG integrated system was a collaborative effort between WT-7 and DE-9 of Los Alamos National laboratory. Walter Tuzel (WT-7) was the lead engineer, Dan Custer (WT-8) was the designer for the LBPG, and Robert Valdiviez (WT-7) was designated as the lead engineer in March of 2008. Thanks to all those who were involved with this project and provided support including Kathleen Alexander, Robert Hixson, and Drew Martinson. Special thanks are extended to Tim Pierce and Jim Esparza (DE-9) whose dedication and efforts in test preparation and gun setup ensured the success of this portion of the project. Thanks are given to Mike Osborn and Adam Pacheco (WT-7) for leak checking and performing strain measurements. Many thanks are given to Gilbert Sandavol and the people of the NTS shop who directly supported this project by fabricating, assembling, and performing various static tests of the experimental apparatus used in each experiment. Vincent Romero, Doug Devore, Jason Young, Adam Iverson, and others from National Security Technologies (NSTech Los Alamos) are all thanked for their efforts to develop diagnostics feedthroughs and for assistance in fielding some of the diagnostics. David Clark, Jeremy Payton, and Mark Wilke (P-23) are acknowledged for their help with the fast video and trigger circuit diagnostics. Rodger Hall and Brandon Hawk (W-6) provided valuable assistance with the firing system and procedures used for the integrated-system tests. Dennis Shampine (DE-9) is gratefully acknowledged for his advice early in this project and for many discussions regarding the Ancho canyon two-stage gun experiments that successfully used an explosively driven piston valve in the containment system. Thanks to David Robbins (DE-9) and Mable Amador (IRM) for their careful review of this document. Finally, I would like to thank Robert Hixson for his invaluable support, encouragement, and advice during this part of the project.

\section{References}

[1] B.J. Jensen, "Development of an Explosively Driven Valve for the Large-Bore Powder Gun," Los Alamos Laboratory Publication LA-14366 (2008).

[2] W. Tuzel, "The Explosively Driven Valve Qualification," Document SCE-FS-GG-0019 Rev.0 (2006).

[3] W. Tuzel, "Qualifications of the 3.5 in. Explosively Driven Valve for the Gun Experiment," Document SCE-FS-GG-0020 (2006). 
[4] J.D. Harper, "Pipe Closure by Explosives," Los Alamos Laboratory Publication LA-3786 (1966).

[5] W. Tuzel, "Design Specification for the Research Powder Gun to be used for Future Subcritical Experiments at NTS," Document SCE-DS-GG-0044 (2005).

[6] W. Tuzel, "Quality Level Determination for the Primary Containment System to Contain the Plutonium Target for the Powder Gun Experiment," Document SCE-QLD-GG-0034 (2007).

[7] W. Tuzel, "Quality Level Determination for the Large Bore Powder Gun," Document SCEQLD-GG-0022 (2007).

[8] W. Tuzel, "Requirements for Feedthrough Penetrating into the High Pressure Envelope," Document SCE-ICD-GG-0007 (2007).

[9] W. Tuzel, "Test Plan to Verify the Structural Integrity of the Powder Gun," Document SCE-TP-GG-026 (2007).

[10] W. Tuzel, "The Powder Gun Test Report," Document DPE-TRP-GG-0006 (2007).

[11] B.J. Jensen, D.B. Holtkamp, P.A. Rigg, and D.H. Dolan, J. Appl. Phys., 101, 013523 (2006).

[12] R.G. McQueen, J.W. Hopson, and J.N. Fritz, Rev. Sci. Instrum, 53, 2, 245-250 (1981).

[13] J.N. Fritz, in "Shock Compression of Condensed Matter", edited by M.D. Furnish, L.C. Chhabildas, and R.S. Hixson (American Institute of Physics, 1999), pp. 239-244.

[14] W. Tuzel, "The Test Plan to Verify the Structural Integrity of the Powder Gun Primary Containment System Design," Document SCE-TP-GG-0330 (2007).

[15] W. Tuzel, "Qualification of the Integrated Powder Gun Test System," Document DPETP-GG-035 (2008).

[16] Craig Leasure, R. Farris, G. Grauter, and J. Streit, "Report on the Special Review of the Decision Process Leading up to the Large Bore Powder Gun Test at TA-39, Firing Point 6 on June 11, 2008,", Los Alamos National Laboratory (2008). 
This page left blank intentionally. 
This page left blank intentionally. 
This report has been reproduced directly from the best available copy. It is available electronically on the Web (http://www.doe.gov/bridge).

Copies are available for sale to U.S. Department of Energy employees and contractors from:

Office of Scientific and Technical Information

P.O. Box 62

Oak Ridge, TN 37831

(865) 576-8401

Copies are available for sale to the public from: National Technical Information Service

U.S. Department of Commerce

5285 Port Royal Road

Springfield, VA 22161

(800) 553-6847 
- Los Alamos NATIONAL LABORATORY

EST.1943 